INSTITUTO DE PESQUISAS ENERGÉTICAS E NUCLEARES

Autarquia associada à Universidade de São Paulo

\title{
AVALIAÇÃO DA QUALIDADE DE VIDA DOS TRABALHADORES DE SERVIÇOS DE RADIODIAGNÓSTICO
}

\author{
Ivani Martins Fernandes
}

Dissertação apresentada como parte dos requisitos para obtenção do Grau de Mestre em Ciências na Área de Tecnologia Nuclear - Aplicações

Orientadora:

Profa. Dra. Janete Cristina G. G. Carneiro

São Paulo

2011 


\section{DEDICATÓRIA}

Aos meus pais, $\mathcal{M}$ anoel Martins e $\mathcal{A}$ (zira Madalena, por todo carinho e amor dispensados e ensinamentos proporcionados.

Ao meu querido marido, José Fernandes, companheiro de todos os momentos, pelo amor, incentivo e apoío durante a minha caminhada. 


\section{AGRADECIMENTOS}

- Agradeço a Deus, primeiramente, pela minha existência e por sempre guiar e iluminar o meu caminho.

- À minha família - meus pais, que sempre me incentivaram a buscar o conhecimento e o saber nos estudos; meus irmãos: Lucilene, Nilma, Nilson, Gilberto, Geraldo, Valdenice, Sirleide, Antônio e Maxwel, pelo apoio e carinho.

- À minha orientadora, Prof ${ }^{a}$. Dr ${ }^{a}$. Janete Cristina, pela sua competência profissional e paciência em me orientar.

- À Dr Maria da Penha, pela simpatia e contribuição no decorrer do trabalho.

- À Dr ${ }^{\mathrm{a}}$ Clarice F. A. Perez, pelas valiosas contribuições.

- A todos os trabalhadores dos serviços de radiodiagnóstico do hospital onde foi realizada a pesquisa, pela colaboração com o estudo.

- Aos funcionários da Gerência de Radioproteção (GRP) - IPEN, que colaboraram direta e indiretamente para realização deste trabalho, especialmente ao Dr ${ }^{\circ}$. Demerval, por ter acreditado em mim, quando eu o procurei solicitando estágio na instituição.

- Às minhas amigas Amanda Juliene, Paula Nou, Lizandra Pereira, Beatriz Guimarães, pelo apoio e motivação.

- Aos amigos Fábio Suzuki, Eduardo Gerulis, Lucas Rodrigues, Iremar Alves e Rafael Diniz pelo companheirismo.

- À Comissão de Pós-Graduação (CPG) do Instituto de Pesquisas Energéticas e Nucleares - IPEN/CNEN-SP pela oportunidade e incentivo.

- Ao Conselho Nacional de Desenvolvimento Científico e Tecnológico - CNPq, pelo apoio financeiro recebido à realização deste trabalho.

- E a todas as pessoas que direta e indiretamente contribuíram para a concretização desse trabalho. 


\section{SUMÁRIO}

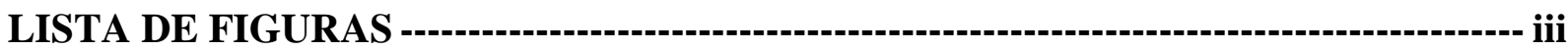

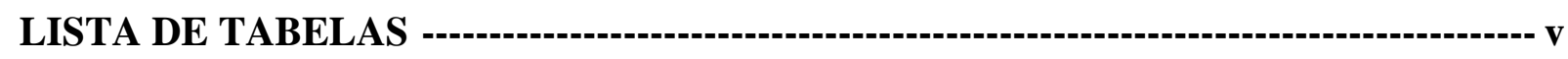

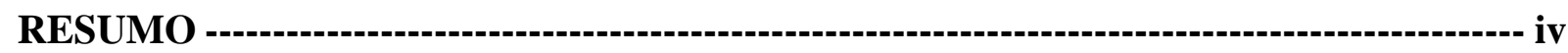

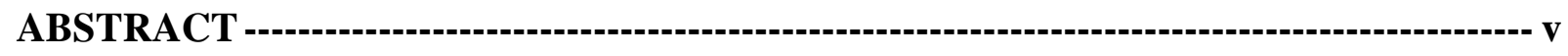

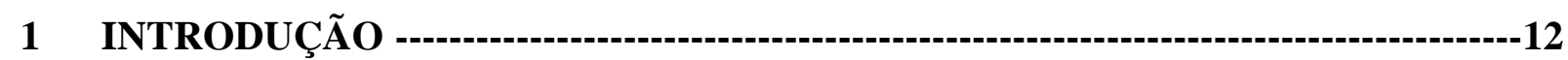

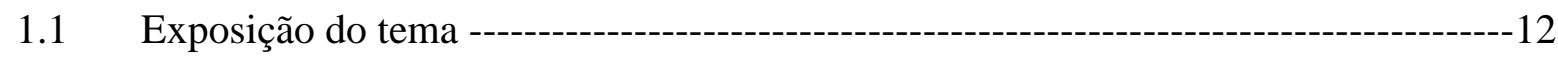

1.2 Sistema de Proteção Radiológica - Exposição Ocupacional decorrente das práticas

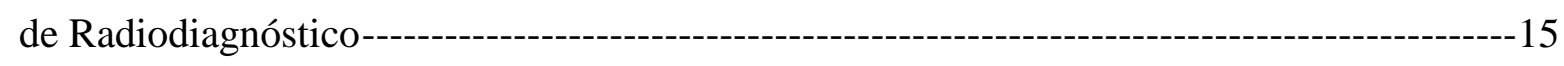

1.3 Finalidades e objetivos do estudo -------------------------------------------------------17

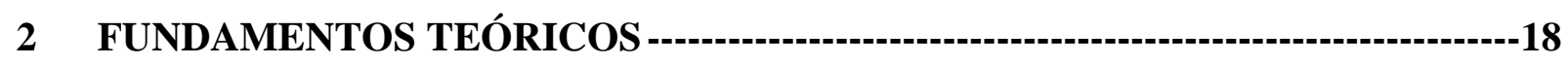

2.1 Contexto histórico e definições da qualidade de vida------------------------------------18

2.2 Instrumentos de avaliação de qualidade de vida ------------------------------------------21

2.3 Propriedades psicométricas de instrumentos de avaliação de QV ----------------------22

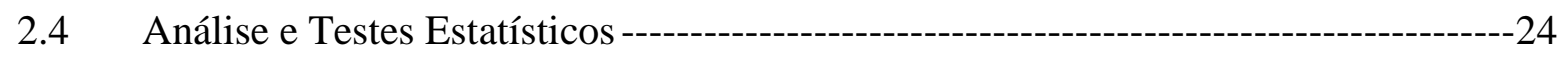

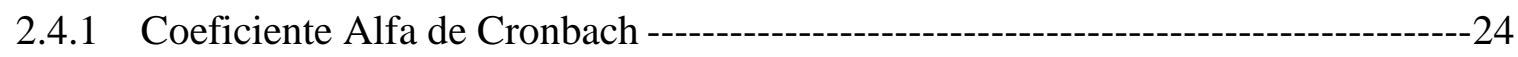

2.4.2 Coeficiente de Correlação de Spearman ----------------------------------------------25

2.4.3 Teste de Correlação ----------------------------------------------------------------------------26

2.4.4 Análise de Regressão Linear----------------------------------------------------------------26

2.4.5 Teste de Mann-Whitney --------------------------------------------------------------------27

2.4.6 Teste de Kruskal-Wallis ----------------------------------------------------------------------29

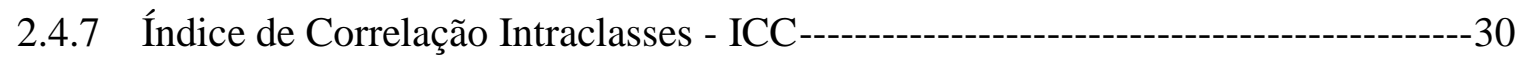

2.4.8 Intervalo de Confiança para a Média -----------------------------------------------------31 
2.4.9 Valor de p-

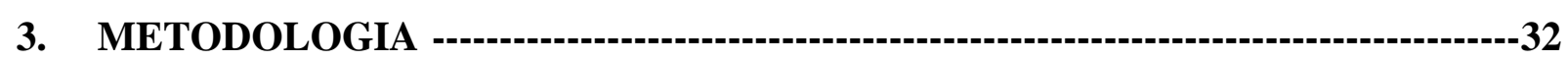

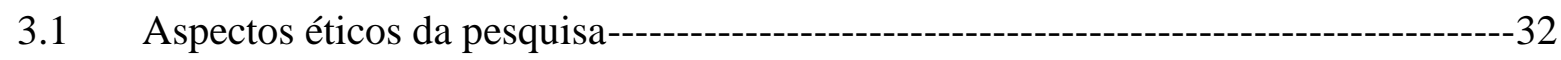

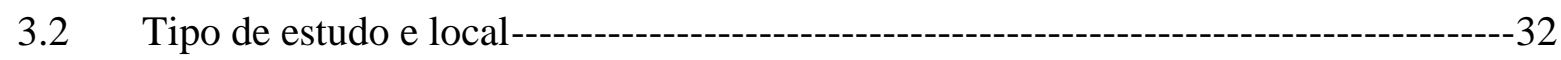

3.3 Critérios de inclusão e exclusão---------------------------------------------------------------33

3.5 Coleta de dados --------------------------------------------------------------------------------33

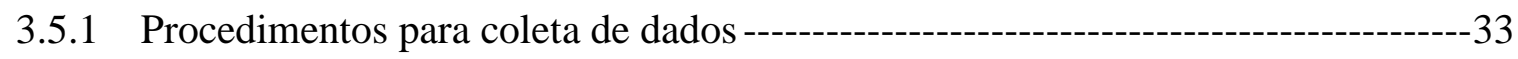

3.5.2 WHOQOL-bref - instrumento de avaliação da QV ------------------------------------35

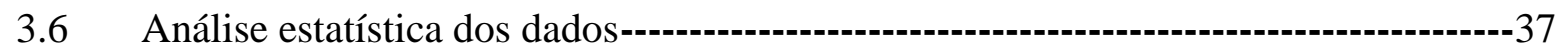

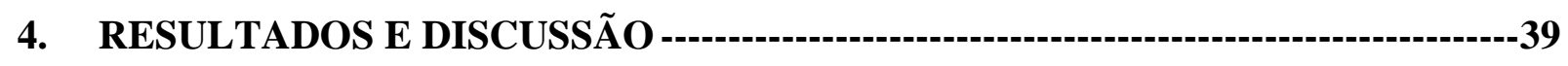

4.1 Resultados da primeira parte do questionário - ficha de informação do participante: variáveis sociodemográficas, condições de trabalho e estilo de vida ----------------------------39

4.2 Resultados da segunda parte do questionário - WHOQOL-bref ------------------------51

4.2.1 Análise descritiva dos domínios do WHOQOL-bref----------------------------------51

4.2.2 Avaliação das propriedades psicométricas do instrumento WHOQOL-bref ------53

4.2.3 Comparação das variáveis qualitativas da primeira parte do questionário (ficha de informação do participante) com os domínios do WHOQOL-bref -------------------------57

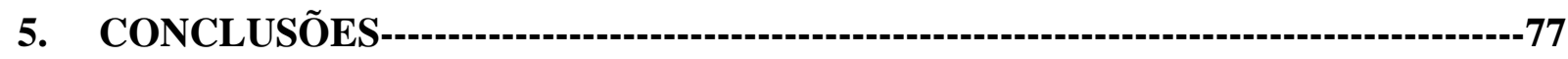

ANEXO I - TERMO DE CONSENTIMENTO LIVRE E ESCLARECIDO -------------79

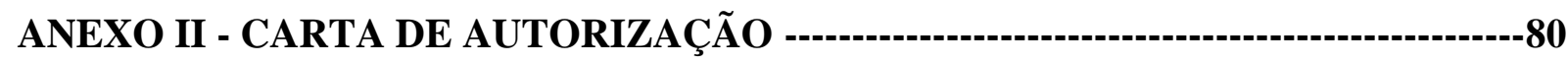

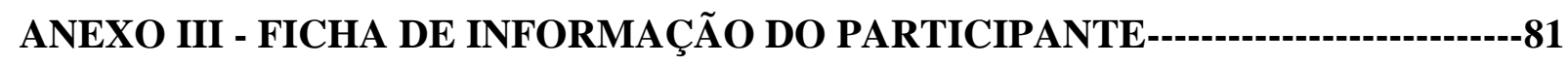

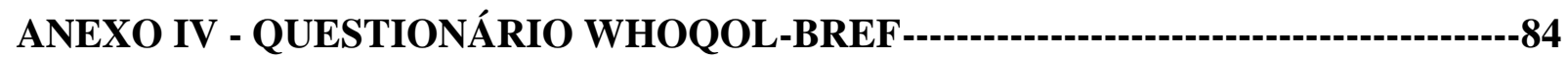

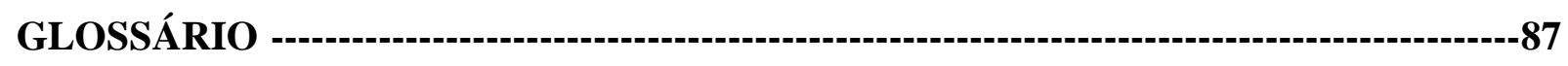




\section{LISTA DE FIGURAS}

Figura 1: Fração de dose efetiva na população para fontes artificiais de radiação. 15

Figura 2: Sintaxe SPSS para o cálculo dos escores do WHOQOL-bref.

Figura 3: Distribuição da amostra por gênero e faixa etária.

Figura 4: Distribuição da amostra por tempo de trabalho na instituição.-

Figura 5: Distribuição da amostra por tempo de trabalho com radiação ionizante.

Figura 6: Distribuição da amostra por categoria profissional. 43

Figura 7: Distribuição da amostra por setor de trabalho.

Figura 8: Distribuição da amostra por satisfação com o trabalho em presença da radiação ionizante.

Figura 9: Distribuição da amostra, por trabalho em turnos (a), diferentes turnos de trabalho (b) e a existência de outro emprego (c).

Figura 10: Distribuição da amostra, em relação às variáveis: treinamento (a), tipos de treinamento (b), EPI's utilizados (c) e monitoramento individual (d). ---------------------------48

Figura 11: Distribuição da amostra por gênero, segundo as variáveis que expressam o estilo de vida dos participantes.

Figura 12: Distribuição das variáveis referentes à condição de saúde atual dos participantes. 50

Figura 13: Média dos escores dos domínios do WHOQOL-bref. 52

Figura 14: Média das facetas de cada domínio do WHOQOL-bref.

Figura 15: Comparação do WHOQOL-bref com o gênero. $-58$

Figura 16: Comparação do WHOQOL-bref com o estado civil. 59

Figura 17: Comparação do WHOQOL-bref com o nível educacional. $-60$

Figura 18: Comparação do WHOQOL-bref com a categoria profissional. 62 
Figura 19: Comparação do WHOQOL-bref com o setor de trabalho.

Figura 20: Comparação do WHOQOL-bref com tempo de trabalho com radiação ionizante. -66 Figura 21: Comparação do WHOQOL-bref com satisfação com o trabalho em presença da

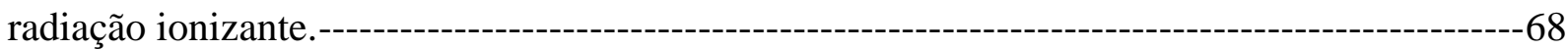

Figura 22: Comparação do WHOQOL-bref com trabalho em turnos. --------------------------69

Figura 23: Comparação do WHOQOL-bref com os diferentes turnos de trabalho. --------------70

Figura 24: Comparação do WHOQOL-bref com a existência ou não de outro emprego. ------71

Figura 25: Comparação do WHOQOL-bref com hábito de fumar. ---------------------------------72

Figura 26: Comparação do WHOQOL-bref com o consumo de bebida alcoólica. --------------73

Figura 27: Comparação do WHOQOL-bref com a prática de atividade física. -------------------74

Figura 28: Comparação do WHOQOL-bref com a condição de saúde atual dos participantes. 


\section{LISTA DE TABELAS}

Tabela 1: Teste de Kruskal-Wallis.

Tabela 2: Domínios e facetas do WHOQOL-bref. $-36$

Tabela 3: Distribuição da amostra, segundo as variáveis sociodemográficas analisadas.

Tabela 4: Distribuição do outro emprego, por local de trabalho. 46

Tabela 5: Exames de saúde realizados no último periódico, em 2010. $-50$

Tabela 6: Análise estatística descritiva dos domínios do WHOQOL-bref. $-52$

Tabela 7: Coeficientes de Correlação de Spearman ( $\rho$ ) entre os domínios do WHOQOL-bref e as variáveis quantitativas - idade e tempo de trabalho na instituição. 55

Tabela 8: Regressão Linear $(\beta)$ e Coeficiente de Correlação de Spearman ( $\rho$ ) entre os diferentes domínios do WHOQOL-bref em relação à QV global. 56

Tabela 9: Regressão Linear ( $\beta$ ) entre os diferentes domínios do WHOQOL-bref e as variáveis sociodemográficas e relacionadas ao trabalho. 56

Tabela 10: Comparação do WHOQOL-bref com o gênero. $-58$

Tabela 11: Comparação do WHOQOL-bref com estado civil. $-59$

Tabela 12: Comparação do WHOQOL-bref com o nível educacional. 60

Tabela 13: Comparação do WHOQOL-bref com a categoria profissional. $-61$

Tabela 14: Comparação do WHOQOL-bref com o setor de trabalho. 63

Tabela 15: Comparação do WHOQOL-bref com o tempo de trabalho (anos) com radiação ionizante. $-65$

Tabela 16: Teste de Mann-Whitney: valores de p. $-65$

Tabela 17: Comparação do WHOQOL-bref com a satisfação com o trabalho em presença da radiação ionizante. 67

Tabela 18: Teste de Mann-Whitney: valores de p. 
Tabela 19: Comparação do WHOQOL-bref com trabalho em turnos.

Tabela 20: Comparação do WHOQOL-bref com os diferentes turnos de trabalho. $-70$

Tabela 21: Comparação do WHOQOL-bref com a existência ou não de outro emprego. ------71

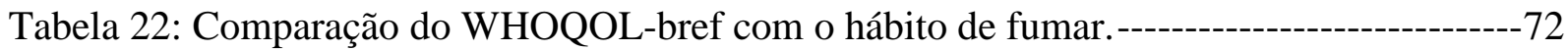

Tabela 23: Comparação do WHOQOL-bref com o consumo de bebida alcoólica. --------------73

Tabela 24: Comparação do WHOQOL-bref com a prática de atividade física. -------------------74

Tabela 25: Comparação do WHOQOL-bref com a condição de saúde dos participantes.------75

Tabela 26: Teste de Mann-Whitney: valores de p. -------------------------------------------------76 


\section{RESUMO}

\section{AVALIAÇÃO DA QUALIDADE DE VIDA DOS TRABALHADORES DE SERVIÇOS DE RADIODIAGNÓSTICO}

Este estudo teve como finalidade principal avaliar a qualidade de vida (QV) dos profissionais de saúde que compõem o serviço de radiodiagnóstico de um hospital da cidade de São Paulo. Além disso, objetivou conhecer o perfil desses profissionais, identificando as variáveis que podem influenciar a QV desses profissionais. Trata-se de um estudo descritivo e exploratório com abordagem quali-quantitativa. Os dados foram coletados usando os questionários: o instrumento abreviado de avaliação de QV - World Health Organization Quality of Life Instrument bref (WHOQOL-bref) da Organização Mundial da Saúde e um questionário sobre as variáveis de interesse: sociodemográficas, condições de trabalho e estilo de vida, ambos questionários auto-aplicáveis. A amostra foi constituída de 118 profissionais nas categorias de: médicos, tecnólogos/técnicos de radiologia, enfermeiros, técnicos e auxiliares de enfermagem, entre outros. A análise dos dados envolveu estatística descritiva, testes não paramétricos e o uso de um modelo de regressão linear. O grau de confiabilidade do instrumento foi avaliado por meio do Coeficiente Alfa de Cronbach $(\alpha)$. O WHOQOL-bref demonstrou ser um instrumento adequado, de aplicação fácil e rápida para a aferição da qualidade de vida; mostrou bom desempenho psicométrico e boa consistência interna $(\alpha=0,884)$. O estudo permitiu conhecer a percepção de qualidade de vida do grupo estudado. 


\section{ABSTRACT \\ QUALITY OF LIFE EVALUATION OF WORKERS FOR DIAGNOSTIC RADIOLOGY SERVICES}

The main objective of this study was to evaluate the quality of life (QOL) of diagnostic radiology services workers at a hospital of São Paulo city. It aimed also to draw the profile of these workers identifying the variables, as its influence on their quality of life. A descriptive exploratory study with qualitative and quantitative approaches was carried out. The data were collected using the questionnaires: the abbreviated instrument for the assessment of the QOL, World Health Organization Quality of Life Instrument bref (WHOQOL-bref) and a questionnaire including the social demographic variables, work conditions and the variables that express the lifestyle of individuals, both questionnaires self-applied. The sample was formed by 118 workers, among them: physicians, technologists/technicians in radiology, nurses, technicians and assistants in nursing, and others health professionals. The data analysis included descriptive statistics, nonparametric tests and the use of a linear regression model. The reliability of the instrument for the studied sample was verified by Cronbach's Alpha Coefficient $(\alpha)$. The WHOQOL-bref proved to be an adequate instrument, with a good level of internal consistency $(\alpha=0.884)$, being easily and quickly administrated for the evaluation of the QOL. The study provided an overview of the perception of quality of life of the studied group. 


\section{INTRODUÇÃOO}

\subsection{Exposição do tema}

Nas últimas décadas, o constructo Qualidade de Vida (QV) passou a ser estudado em diversas áreas do conhecimento humano e, conceitos, metodologias de pesquisa e motivos para medir QV tornaram-se temas de interesse multidisciplinar (médicos, psicólogos, cientistas sociais, entre outros). A mensuração da QV surgiu como uma forma de valorizar as percepções do indivíduo a respeito de vários aspectos sobre sua vida como, por exemplo, aspectos físicos, ocupacionais, psicológicos, sociais e sua relação com o meio ambiente. A QV pode mudar ao longo do tempo, de forma global (satisfação geral do indivíduo com a vida e a percepção geral do bem estar) ou em algumas áreas da vida do sujeito. Mas esta expressão, tão debatida entre os pesquisadores das diversas áreas e que ocupa cada vez mais espaço na sociedade e na política de saúde, não tem uma definição universal. Nas diversas abordagens sobre o tema, são adotados diferentes conceitos, modelos teóricos e instrumentos de mensuração.

Para a Organização Mundial da Saúde (OMS), qualidade de vida é "a percepção do indivíduo sobre a sua posição na vida, no contexto da cultura e dos sistemas de valores nos quais ele vive e em relação a seus objetivos, expectativas, padrões e preocupações" [1]. Baseia-se na própria definição de saúde da OMS (1958), ou seja, na percepção individual de um completo bem estar físico, mental e social, e não simplesmente a ausência de doença ou enfermidade [2].

Neste estudo o enfoque será limitado a conhecer a percepção de QV em uma categoria de profissionais de saúde, no âmbito da Radiologia Diagnóstica.

Um serviço de radiodiagnóstico é a unidade onde se concentram equipamentos que 
realizam atividades concernentes ao uso de raios $\mathrm{X}$ para fins de diagnóstico médico, além disso, são utilizadas substâncias radioativas tanto para fins de diagnose como terapia. Esses serviços são de vital importância na dinâmica de funcionamento de um hospital ou clínica, levando em conta que o desenvolvimento técnico-científico alcançado nesta área permite a eficiência no processo de diagnóstico clínico ou cirúrgico das afecções e, consequentemente, no tratamento a ser administrado [3].

$\mathrm{O}$ uso crescente e diversificado das radiações ionizantes na medicina e em outras áreas de atuação e conhecimento, não pode ser dissociado da preocupação da proteção, segurança e bem estar dos trabalhadores com risco potencial de exposição. Neste sentido, pesquisas tem sido realizadas enfocando a exposição ocupacional às radiações ionizantes, associadas às práticas de proteção radiológica e otimização do processo de trabalho.

Deste modo, levando em conta as características das atividades desenvolvidas e os efeitos que poderão advir de falhas relacionadas com suas instalações é imprescindível que o planejamento de um serviço de radiodiagnóstico seja da responsabilidade de uma equipe multiprofissional. Os aspectos técnicos e científicos referentes ao planejamento devem assegurar medidas que visem à prevenção e proteção contra riscos para toda a equipe de saúde envolvida neste setor [3].

Os profissionais da área de saúde constituem um grupo de pessoas com formação técnica (nível médio) ou superior no campo da saúde. No caso específico deste estudo, será investigada a equipe do serviço de radiodiagnóstico de um hospital universitário da cidade de São Paulo, composta por médicos, tecnólogos e técnicos de radiologia, enfermeiros, técnicos e auxiliares de enfermagem, entre outros profissionais.

O processo de trabalho dos profissionais de saúde é complexo e inclui singularidades não existentes no processo de trabalho de outras categorias profissionais. Pode-se citar como exemplos relevantes para este estudo, a exposição aos riscos ocupacionais, tais como: físicos (risco inerente ao uso das radiações ionizantes), químicos (substâncias químicas), riscos biológicos (sangue e secreções), riscos de acidentes (explosões, acidentes radioativos), riscos 
ergonômicos (estresses e distúrbios osteomusculares), longas jornadas de trabalho em regime de plantão, trabalhos em turnos (diurno e noturno), múltiplos vínculos empregatícios decorrentes dos horários em turnos e dos baixos salários, dentre outros [4].

A carga de trabalho é um fator importante; em geral as exposições ocupacionais são diretamente proporcionais à carga de trabalho [5]. O fato dos profissionais do serviço de radiodiagnóstico trabalharem com radiações ionizantes implicam, ainda, em cuidados mais específicos, nomeadamente o cumprimento rigoroso dos regulamentos e normas de proteção e segurança neste domínio, estabelecidos legalmente pelos organismos internacionais e nacionais, quer para proteger os pacientes quer os próprios profissionais que trabalham com radiações ionizantes [6-11].

O treinamento do profissional, o uso obrigatório de equipamentos de proteção individual, EPI's (dosímetro, aventais de proteção de chumbo, óculos plumbíferos etc.), a inibição da atividade durante o período de gravidez e aleitamento são relevantes, particularmente no controle dos riscos durante a prática de procedimentos intervencionistas (fluoroscopia, cateterismo cardíaco, angiografia) [5, 10-12].

Indiretamente, a má QV em uma das dimensões, por exemplo, física e/ou emocional dos profissionais de saúde, pode comprometer a dinâmica de atendimento, gerando prestação inadequada de serviços, com prejuízo institucional e principalmente, à assistência aos pacientes.

Neste contexto, considerou-se importante avaliar a QV dos trabalhadores do serviço de radiodiagnóstico, uma vez que ela está relacionada a diversos aspectos de sua vida cotidiana, entre eles, as condições de trabalho. 


\subsection{Sistema de Proteção Radiológica - Exposição Ocupacional decorrente das práticas de Radiodiagnóstico}

A maior contribuição na fração de dose efetiva na população é resultante das irradiações médicas (fontes artificiais de radiação ionizante) e dentro desta categoria, a área de radiodiagnóstico é a que apresenta a maior porcentagem, como mostra a Figura 1.

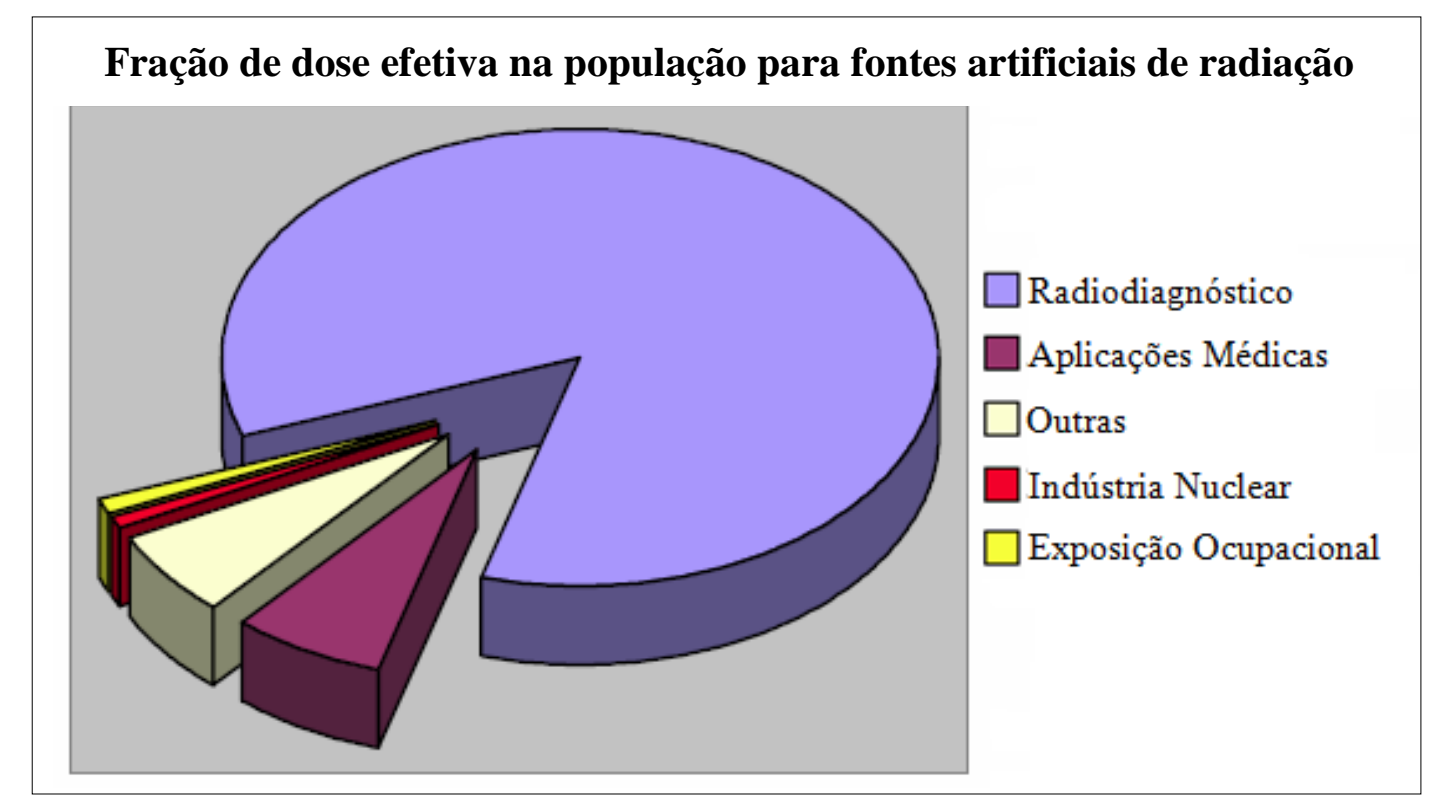

Figura 1: Fração de dose efetiva na população para fontes artificiais de radiação [13].

Em virtude desta constatação, todo esforço deve ser direcionado no sentido de controlar e reduzir estes valores de dose, o que pode ser atingido por meio da aplicação efetiva dos princípios de proteção radiológica.

O sistema de proteção radiológica, segundo a Comissão Internacional de Proteção Radiológica, ICRP - International Commission on Radiological Protection [6, 8], é fundamentado em três princípios básicos, denominados: justificação, otimização e limitação 
de dose, definidos a seguir. Estes princípios são adotados pelos organismos regulatórios nacionais em suas legislações, como requisitos para as práticas (Raios X diagnóstico) que causam exposição e aos indivíduos que recebem as exposições. No nosso país os principais organismos regulatórios são a Comissão Nacional de Energia Nuclear, CNEN [10] e Agência Nacional de Vigilância Sanitária, ANVISA [11].

* O princípio da justificação: nenhuma prática ou fonte associada a essa prática será aceita, a não ser que produza benefícios suficientes para os indivíduos expostos ou para a sociedade, de modo a compensar o detrimento que possa ser causado, tendo-se em conta fatores sociais e econômicos, assim como outros fatores pertinentes.

* O princípio da otimização: em relação às exposições causadas por uma determinada fonte associada a uma prática, salvo no caso das exposições médicas, a proteção radiológica deve ser otimizada de forma que a magnitude das doses individuais, o número de pessoas expostas e a probabilidade de ocorrência de exposições mantenham-se tão baixas quanto possam ser racionalmente alcançáveis (ALARA - As Low as Reasonably Achievable), levando-se em conta fatores econômicos e sociais.

* O princípio da limitação de dose individual: a dose total de qualquer indivíduo provocada por fontes de radiação regulamentadas em situações de exposições planejadas diferentes daquelas decorrentes da exposição médica de pacientes não devem exceder os limites estabelecidos.

As Recomendações da publicação ICRP 103 (2007) envolvem desde o processo anterior que foi baseado num procedimento de proteção que fazia uso das práticas e intervenções (ICRP 60, 1991) para a situação atual que envolve um procedimento baseado nas características das situações de exposição à radiação [6, 8]. O sistema de proteção radiológica é aplicado em princípio a qualquer situação de exposição à radiação. Especificamente, os princípios de justificação e otimização são aplicados universalmente, em todas as situações de exposição, já o princípio de limitação de doses se aplica somente para as doses esperadas, resultantes das exposições planejadas. 


\subsection{Finalidades e objetivos do estudo}

Considerando que o exercício do trabalho é um dos fatores que pode influenciar a QV das pessoas, este estudo tem por finalidades:

Avaliar a QV dos trabalhadores de Serviços de Radiodiagnóstico;

Verificar se existe contribuição dos domínios do WHOQOL-bref (físico, psicológico, social e ambiental) no domínio de QV global;

Identificar as variáveis sociodemográficas, relacionadas ao trabalho e as variáveis que expressam o estilo de vida que podem influenciar a QV desses trabalhadores.

Para se alcançar estas finalidades foram estabelecidos os objetivos a seguir:

* Mostrar a aplicação do teste de campo do WHOQOL-bref em uma amostra de trabalhadores de serviços de radiodiagnóstico;

Conhecer o perfil dos profissionais de saúde que atuam nos Serviços de Radiodiagnóstico de um hospital escola da cidade de São Paulo;

Avaliar as propriedades psicométricas do WHOQOL-bref, por meio de análise estatística;

Identificar nos trabalhadores uma possível associação dos problemas de saúde provocados ou agravados pelo trabalho exercido. 


\section{FUNDAMENTOS TEÓRICOS}

\subsection{Contexto histórico e definições da qualidade de vida}

Qualidade de vida tem sido um tema de investigação crescente em estudos ligados às diversas áreas do conhecimento humano, como sociologia, medicina, enfermagem, psicologia, economia, história social, filosofia, entre outras. De acordo com Bowling, em 1973 constavam apenas cinco referências acerca deste assunto no banco de dados da MEDLINE - Literatura Internacional em Ciências da Saúde, quando o termo "QUALIDADE DE VIDA" era utilizado como palavra-chave e que, cinco anos depois, utilizando-se o mesmo tipo de busca, o número de referências já era igual a 1.252 [14]. A partir da década de 90 ocorreu um expressivo aumento do número de produções científicas a respeito do tema qualidade de vida. Esse aumento demonstra claramente o interesse dos pesquisadores e a eficácia dos estudos sobre este tema em questão.

Em uma pesquisa eletrônica recente na Biblioteca virtual em saúde - BVS, utilizandose o mesmo descritor, "QUALIDADE DE VIDA", foi encontrado um total de 124.827 publicações, para as diferentes fontes de pesquisa desta biblioteca. Dentre as fontes pesquisadas, há registro de 98.707 publicações no banco de dados da MEDLINE; no banco de dados da LILACS - Literatura Latino-Americana e do Caribe em Ciências da Saúde o número de publicações é de 7.908 e do IBECS - Índice Bibliográfico Espanhol de Ciências de Saúde há 1.239 publicações registradas [15].

O termo qualidade de vida foi mencionado pela primeira vez, em 1964, pelo então presidente dos Estados Unidos, Lyndon Johnson, ao declarar que "os objetivos de uma nação não podem ser medidos através do balanço dos bancos. Eles só podem ser medidos através da QV que proporcionam às pessoas" [16]. 
Os conceitos propostos inicialmente sobre o tema priorizavam fatores externos (objetivos) na vida dos indivíduos, ou seja, preocupavam-se com questões materiais como salário, bens adquiridos e sucesso na área profissional. A seguir, foi enfatizado o quanto uma sociedade havia se desenvolvido economicamente, como medida e comparação da QV. Com o passar dos anos, o conceito se ampliou, gradativamente, significando, além do crescimento econômico, o desenvolvimento social, como educação, saúde, lazer, entre outros. Além destes aspectos objetivos, atualmente, percebe-se uma abordagem um pouco diferenciada, apontando uma valorização de fatores subjetivos como satisfação, realização tanto profissional como pessoal, bom relacionamento com a sociedade e acesso a cultura e ao lazer como exemplos reais de bem estar [17].

O termo qualidade de vida abrange muitos significados, que refletem o senso comum, variável de um indivíduo para outro, refletindo expectativas, conhecimentos, experiências, e valores individuais e coletivos, que se reportam a várias épocas e histórias diferentes, sendo, portanto, uma construção social com uma marca cultural. De um modo geral, a qualidade de vida é um construto dinâmico e está relacionada às condições de vida de uma população [18].

Para Gonzales (1998) a satisfação no trabalho é um dos pilares fundamentais na construção do conceito de qualidade de vida, devido o trabalho ocupar grande parte da vida, estabelecer relações e dimensionar diferentes possibilidades que emergem da sua maior ou menor valorização social. A qualidade de vida reflete também, o grau de satisfação encontrado na vida familiar, amorosa, social, ambiental e para a própria estética existencial de indivíduos e coletividades [19].

No final do século XX, mais especificamente na década de 90, a QV passou a integrar de forma mais intensa os discursos informais entre as pessoas e a mídia em geral, bem como, observou-se um grande avanço na quantidade e qualidade de investigações científicas que visavam um maior entendimento sobre a QV e sua relação com questões sociais, culturais e biológicas. Com o avanço das pesquisas e o crescente interesse sobre a temática, em 1995 a Organização Mundial da Saúde (OMS) reuniu especialistas sobre saúde e QV de diversas regiões do mundo (multicêntrico) para formar um grupo de estudos sobre QV - o Grupo 
WHOQOL, World Health Organization Quality of Life Measures - The WHOQOL Group, [1] com a finalidade de aumentar o conhecimento científico da área e de desenvolver instrumentos de avaliação da QV dentro de uma perspectiva transcultural.

A definição proposta pela OMS é a que melhor traduz a abrangência do construto qualidade de vida. O grupo WHOQOL (1995) definiu qualidade de vida como "a percepção do indivíduo sobre a sua posição na vida, no contexto da cultura e dos sistemas de valores nos quais ele vive e em relação a seus objetivos, expectativas, padrões e preocupações" [1]. É considerado um conceito abstrato, subjetivo e multidimensional por envolver vários aspectos da vida humana, tais como: relações sociais, saúde, família, trabalho, meio ambiente, dentre outros. É dinâmico devido a sua característica mutável ao longo do tempo, ou entre as pessoas sob diferentes aspectos culturais, religiosos, éticos e valores pessoais.

$\mathrm{Na}$ área da saúde, duas tendências são identificadas quanto à conceituação do termo qualidade de vida: QV como um conceito mais genérico e QV relacionada à saúde - QVRS. Além dos aspectos associados às enfermidades e intervenções em saúde, a QV apresenta, no primeiro caso, uma acepção mais ampla, aparentemente influenciada por estudos sociológicos, sem fazer referência a disfunções ou agravos, que são os aspectos mais abordados na QVRS [20].

Contudo, mesmo com o grande aumento no número de publicações sobre o assunto, ainda permanecem várias lacunas sobre inúmeros aspectos do constructo QV em relação a sua definição, mensuração e interpretação [21-25]. Entretanto, ainda que não haja um consenso a respeito das definiçõos estabelecidas sobre a temática QV, parece ser aceito, pelas diferentes concepções, a existência de três aspectos fundamentais [25]:

1) Subjetividade, isto é, a perspectiva do indivíduo é o que está em questão. A realidade objetiva só conta na medida em que é percebida pelo indivíduo;

2) Multidimensionalidade - a qualidade de vida é composta por várias dimensões. Este aspecto tem uma consequência métrica importante, a de que não é desejável que um 
instrumento que mensure a $\mathrm{QV}$ venha a ter um único escore, mas sim que a sua medida seja feita por meio de vários escores em vários domínios (p. ex., físico, mental, social, etc.).

3) Presença de dimensões positivas e negativas - para uma "boa qualidade de vida" é necessário que alguns elementos estejam presentes (p. ex.: mobilidade) e outros ausentes (p. ex.: dor).

\subsection{Instrumentos de avaliação de qualidade de vida}

Os primeiros instrumentos destinados a medir a QV apareceram na literatura na década de 70 e, desde então, tem mostrado um desenvolvimento considerável [20]. Atualmente, existem diversos instrumentos de avaliação de qualidade de vida utilizados com diferentes formas de aplicação, extensão e ênfase do conteúdo.

Na publicação Diretório de instrumentos para medir a qualidade de vida e áreas correlatas - Directory of instruments to measure quality of life and correlate areas, (1998), foram identificados 446 instrumentos utilizados para avaliação da $\mathrm{QV}$, num período de sessenta anos, sendo que 322 (mais de 70,0\%) destes apareceram na literatura a partir dos anos 1980. O acentuado crescimento nas duas últimas décadas atesta os esforços voltados para o amadurecimento conceitual e metodológico do uso do termo na linguagem científica [26].

A escolha de um tipo de instrumento depende das características da população a que se destina ou peculiaridades que se queiram analisar.

Os instrumentos que avaliam QV são conhecidos como genéricos (gerais) ou específicos. Os instrumentos genéricos proporcionam uma ampla avaliação de diferentes aspectos referentes à qualidade de vida, podendo ser usados na população geral (quaisquer pessoas) e indicados para estudos populacionais (população geral) ou epidemiológicos, 
planejamento e avaliação geral do sistema de saúde. Exemplos desses instrumentos são: World Health Organization Quality of Life (WHOQOL-100 ou WHOQOL-bref), Índice de Qualidade de Vida de Ferrans e Powers (IQV), Euro QOL (EQ-5D), Schedule for Evaluation of Individual Quality of Life (SEIQOL), Medical Outcomes Study 36-item Short Form Health Survey (SF-36), sendo este último utilizado na avaliação da qualidade de vida relacionado à saúde (QVRS), entre outros.

Os instrumentos específicos avaliam indivíduos com condições ou doenças específicas, com a vantagem dos instrumentos serem mais sensíveis para a população característica e por investigarem aspectos particulares da condição clínica em questão. Como ilustração desses instrumentos, pode-se citar: Quality of Life in Eplepsy (QOLIE-89), Pediatric Asthma Quality of Life Questionnaire (PAQOL), Funcional Assessment of Cancer Therapy-General (FACT-G), entre outros [20, 27, 28].

Os instrumentos de avaliação de QV são questionários compostos por um determinado número de itens ou questões que, agrupados por afinidade, mensura indiretamente um mesmo construto, domínio, dimensão ou escala, refletindo a área do comportamento ou experiência que se pretende medir [27, 29, 30]. Os domínios, em geral, são o físico, o psicológico, relações sociais e meio ambiente, entre outros [31, 32].

A forma de administração dos questionários pode variar de auto-administrável à entrevista direta, por telefone ou por meio de carta e ainda por via eletrônica, privilegiando sempre a perspectiva do avaliado sobre sua $\mathrm{QV}$, obtida preferencialmente, por meio de sua própria resposta.

\subsection{Propriedades psicométricas de instrumentos de avaliação de QV}

A qualidade de um instrumento de avaliação é determinada por variáveis denominadas propriedades psicométricas, dentre as quais se destacam a confiabilidade e a validade [33-35]. 
A confiabilidade refere-se ao grau de coerência ou precisão com que o instrumento mede o atributo que se propõe medir. É a sua capacidade em reproduzir um resultado de forma consistente no tempo e no espaço ou com observadores diferentes. A confiabilidade de um instrumento pode ser verificada por meio da consistência interna entre os itens da escala e da reprodutibilidade ou precisão [30, 33, 34].

A consistência interna é uma medida de correlação entre os componentes individuais de um instrumento, ou seja, cada item deste instrumento é visto como uma medida única de constructo, avaliando aspectos diferentes do mesmo constructo. Ela é determinada com uma única aplicação do instrumento, através de indicadores como o Coeficiente Alfa de Cronbach, com o qual se verifica a homogeneidade dos itens, de modo que possam medir o mesmo construto.

A reprodutibilidade/precisão avalia de forma mais direta se o instrumento produz os mesmos resultados em repetidas aplicações, desde que o respondente mantenha as condições da primeira mensuração. A reprodutibilidade pode ser avaliada através da confiabilidade inter e intra-observador e do teste/reteste.

A validade é definida como a capacidade de um instrumento em realmente aferir aquilo que se propõe a medir. Por exemplo, um instrumento válido para medir a inteligência deve medir a inteligência e não a memória. Esta propriedade deve ser documentada quando se inicia um novo instrumento de pesquisa ou quando se aplica instrumentos estabelecidos para uma nova população. Para tanto, é necessário avaliar a validade do conteúdo, do constructo e do critério do instrumento $[30,33,34,36]$. 


\subsection{Análise e Testes Estatísticos}

\subsubsection{Coeficiente Alfa de Cronbach}

O Coeficiente Alfa de Cronbach ( $\alpha$ ) é um método utilizado para verificar a consistência interna dos dados. Este método tem sido bastante usado para estimar a confiabilidade de instrumentos de medida. $\mathrm{O}$ alfa de Cronbach é obtido a partir da variância dos componentes individuais e da variância da soma dos componentes de cada avaliado, buscando analisar as possíveis relações entre os itens (Cronbach, 1951) [37]. O calculo é feito conforme a equação 1 :

$$
\alpha=\frac{n}{n-1}\left(1-\frac{\sum \sigma_{1}^{2}}{\sigma_{\text {sum }}^{2}}\right)
$$

Onde:

$n=$ corresponde ao número de itens do questionário;

$\sigma_{i}^{2}=$ corresponde à variância dos itens individuais

$\sigma_{\text {sum }}^{2}=$ corresponde à variância total, determinada como a soma de todas as variâncias dos itens do questionário.

Esta estatística tem valor máximo em 1 e quanto maior o seu valor, maior é a consistência interna dos dados. Cronbach (1996) esclarece que valores entre 0,60 e 0,80 são considerados bons para uma pesquisa exploratória, mostrando que os dados são confiáveis e o instrumento tem boa qualidade para interpretação [38]. Para Hair et al., (2005), um valor de pelo menos 0,70 reflete uma fidedignidade aceitável, embora reconheçam que este valor não seja um padrão absoluto [39]. 


\subsubsection{Coeficiente de Correlação de Spearman}

O grau de associação entre duas variáveis é observado a partir da analise de correlação. A correlação de Spearman baseia-se na ordenação de duas variáveis sem qualquer restrição quanto à distribuição de valores, ou seja, mais utilizado para dados não paramétricos. $\mathrm{O}$ primeiro passo é a ordenação de uma variável e o segundo, a transformação dos valores absolutos em valores ordenados [40-42]. A diferença entre os dois postos, $d_{i}$, é calculada e o Coeficiente de Correlação ( $\rho$ ) é determinado, utilizando a equação 2:

$$
\rho=1-\frac{6 \sum_{i=1}^{n} d_{i}^{2}}{n\left(n^{2}-1\right)}
$$

Onde:

$\rho=$ Coeficiente de Correlação de Spearman;

$d_{i}=$ é a diferença entre cada valor $\mathrm{X}$ e cada valor $\mathrm{Y}$ correspondente;

$n=$ número de pares de dados

Essa técnica serve para medir o quanto as variáveis estão interligadas, ou seja, o quanto uma variável está relacionada com a outra. O coeficiente $\rho$ de Spearman varia entre -1 e +1 e quanto mais próximo estiver destes extremos, maior será a associação entre as variáveis. Quando a correlação for positiva significa que à medida que uma variável aumenta seu valor, a outra correlacionada a esta também aumenta, proporcionalmente. Porém, se a correlação for negativa significa que as variáveis variam em sentido contrário (inversamente proporcionais). Os resultados são dados em percentual, facilitando a compreensão.

Quando são feitas diversas correlações ao mesmo tempo os resultados são colocados em uma única tabela, chamada de Matriz de Correlação. Para determinar a qualidade da correlação, é utilizada a escala de classificações abaixo: 


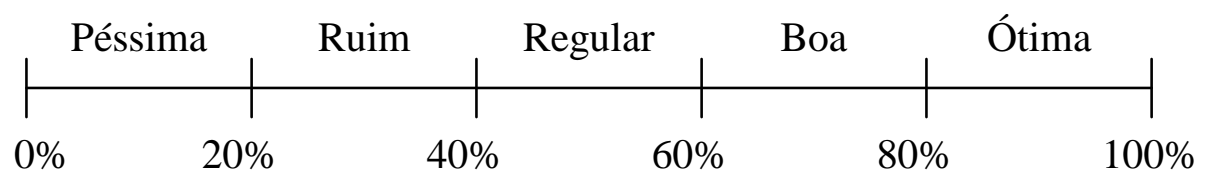

\subsubsection{Teste de Correlação}

O teste para o coeficiente de correlação é aplicado no caso da média e variância, para testar a correlação entre duas variáveis. As hipóteses testadas são:

$$
\left\{\begin{array}{l}
H_{o}: \rho=0 \\
H_{1}: \rho \neq 0
\end{array}\right.
$$

Este teste pode ser realizado através da variável que tem distribuição t de Student com (n-2) graus de liberdade. A partir dos dados da amostra, calcula-se a equação 3:

$$
t_{0}=\rho \sqrt{\frac{n-2}{1-\rho^{2}}}
$$

- Se $t_{0}<-t_{\alpha / 2}$ ou $t_{0}>t_{\alpha / 2}$, rejeita-se a $H_{0}$.

\subsubsection{Análise de Regressão Linear}

A Regressão Linear é uma análise estatística bastante usual e importante, porém usada apenas quando se tem uma análise resposta (dependente) do tipo quantitativo. Esta análise tem por objetivo tentar modelar características de uma determinada população. A modelagem 
serve para tentar predizer uma variável, chamada variável dependente, através de outras variáveis conhecida como independentes ou explicativas. Assim tenta-se ajustar o modelo, conforme a equação 4 :

$$
y_{i}=\alpha+\beta \cdot x_{i}+\varepsilon_{i}
$$

Onde:

- $y_{i}$ : i-ésimo valor predito

- $\alpha$ : valor de intercepto, quando $x_{i}=0$

- $\beta$ : fator multiplicador da variável explicativa

- $x_{i}$ : i-ésima observação da variável explicativa

- $\varepsilon$ : erro, ou seja, parte não explicada pelo modelo. O erro deve ter distribuição normal com média zero e variância constante, ou seja, $\varepsilon_{i} \sim N\left(0, \sigma^{2}\right)$.

Logo, para se obter o modelo, é necessário calcular os valore de $\alpha$ e $\beta$, pois são eles que irão determinar um modelo genérico em base dos dados amostrados.

Para se medir o grau de explicação do modelo, ou seja, o quão bom ele está, existe uma medida chamada de R-quadrado $\left(R^{2}\right)$. O $R^{2}$ é conhecido como coeficiente de determinação e estima a variabilidade (porcentagem) de uma variável explicada pela outra. Esse valor quanto maior, significa uma melhor aderência do modelo, em resumo, quanto maior o $R^{2}$ melhor o modelo. Lembrando que o mesmo varia de $0 \%$ a $100 \%$ [39, 41, 42].

\subsubsection{Teste de Mann-Whitney}

O Teste de Mann-Whitney é um teste não paramétrico (utilizado em baixas amostragens). Esse teste é usado quando se tem amostras independentes e se deseja comparar 
sempre duas a duas as variáveis [40-42]. Assim, ele é composto pela seguinte hipótese:

$$
\left\{\begin{array}{l}
H_{0} \text { : as duas amostras provêem de uma única população } \\
H 1: \text { as duas amostras são de populações diferentes }
\end{array}\right.
$$

Procedimento:

1) Ordenar todas as observações independentemente a qual amostra pertença e atribuir postos;

2) Obter:

$P_{1}$ : soma dos postos das observações pertencentes ao grupo 1

$P_{2}$ : soma dos postos das observações pertencentes ao grupo 2

3) Calcular a equação 5:

$$
T_{0}=\frac{T-\frac{n_{1} n_{2}}{2}}{\sqrt{\frac{n_{1} n_{2}\left(n_{1}+n_{2}+1\right)}{12}}}
$$

Onde:

$n_{1}=$ tamanho da amostra 1

$\mathrm{n}_{2}=$ tamanho da amostra 2

$T=$ soma dos postos

4) Obter o valor de $Z_{\alpha / 2}$ na tabela de distribuição normal [43], tal que:

$$
P\left(Z>Z_{\alpha / 2}\right)=\frac{\alpha}{2} \quad P\left(Z<-Z_{\alpha / 2}\right)=\frac{\alpha}{2}
$$

Se: $T_{0}>Z_{\alpha / 2}$ ou $T_{0}<-Z_{\alpha / 2}$, rejeita-se a $H_{0}$. 


\subsubsection{Teste de Kruskal-Wallis}

O Teste de Kruskal-Wallis é aplicado quando se tem a mesma configuração de dados do Teste de Mann-Whitney, porém aqui a diferença está na comparação de mais de duas variáveis simultaneamente, ou seja, é medido apenas se existe diferença entres os grupos, mas não se conclui em qual grupo está a diferença [40-42]. A hipótese para este teste é a seguinte:

$\left\{\begin{array}{l}H_{0}: \text { as médias de k populações são iguais } \\ H_{1} \text { : pelo menos uma das médias é diferente }\end{array}\right.$

Tabela 1: Teste de Kruskal-Wallis.

\begin{tabular}{cccccc}
\hline & \multicolumn{6}{c}{ Tratamentos } \\
\hline Elemento da Amostra & 1 & 2 & 3 & $\mathrm{k}$ \\
\hline 1 & $x_{11}$ & $x_{21}$ & $x_{31}$ & $\cdots$ & $x_{k 1}$ \\
2 & $x_{12}$ & $x_{22}$ & $x_{32}$ & $\cdots$ & $x_{k 2}$ \\
$\vdots$ & $\vdots$ & $\vdots$ & $\vdots$ & & $\vdots$ \\
$n_{i}$ & $x_{1 n_{1}}$ & $x_{2 n_{2}}$ & $x_{3 n_{3}}$ & $\cdots$ & $x_{k n_{k}}$ \\
\hline
\end{tabular}

Procedimento:

1) Ordenar todas as observações independentemente a qual amostra pertença e atribuir postos (classificação ordinal).

2) Somar os postos das observações de cada amostra.

3) Calcular a equação 6:

$$
T_{0}=\frac{12}{N(N+1)} \sum_{i=1}^{\kappa} \frac{R_{i}^{2}}{n_{i}}-3(N+1)
$$


Onde:

$\mathrm{R}_{\mathrm{i}}=$ soma dos postos da amostra $\mathrm{i}$

$\mathrm{n}_{\mathrm{i}}=$ tamanho da amostra $\mathrm{i}$

$\mathrm{N}=\Sigma \mathrm{n}_{\mathrm{i}}$, número de casos em todas as amostras combinadas

$\mathrm{k}=$ números de grupos/populações/tratamentos

4) Obter o valor de $\chi_{\alpha}^{2}$ com (k-1) graus de liberdade na tabela de distribuição de Qui-Quadrado [43], tal que:

$$
P\left(\chi^{2}>\chi_{\alpha}^{2}\right)=\alpha
$$

Se: $T_{0}>\chi_{\alpha}^{2}$, rejeita-se a $H_{0}$.

\subsection{7 Índice de Correlação Intraclasses - ICC}

O Índice de Correlação Intraclasses, ICC, é usado para mensurar a confiabilidade de uma variável, visto que o Teste de Correlação de Pearson é usado para validar a variável. Os valores de Pearson, Spearman e ICC são normalmente similares para a mesma base de dados [30]. O cálculo de ICC é dado pela equação 7:

$$
r_{i}=\frac{\operatorname{cov}_{x y}}{S_{x} S_{y}}=\frac{\operatorname{cov}_{x y}}{S_{x}^{2}}
$$

Para determinar o quão bom é a correlação utiliza-se a escala de classificações abaixo:

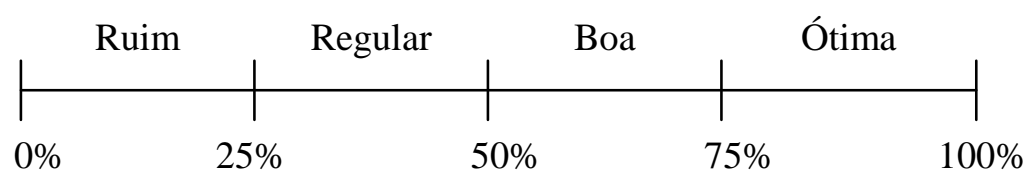




\subsubsection{Intervalo de Confiança para a Média}

O intervalo de confiança para a média é uma técnica utilizada quando se objetiva analisar a média de variação de uma determinada probabilidade de confiança [43]. Essa técnica é descrita pela equação 8 :

$$
P\left(\bar{x}-Z_{\alpha / 2} \frac{\sigma}{\sqrt{n}} \leq \mu \leq \bar{x}+Z_{\alpha / 2} \frac{\sigma}{\sqrt{n}}\right)=1-\alpha
$$

Onde:

$$
\begin{aligned}
& P=\text { probabilidade de confiança } \\
& \bar{x}=\text { média amostral; } \\
& Z_{\alpha / 2}=\text { percentil da distribuição normal; } \\
& \sigma=\text { variância amostral (estatística não viciada da variância populacional); } \\
& \mu=\text { média populacional; } \\
& \alpha=\text { nível de significância. }
\end{aligned}
$$

\subsubsection{Valor de $p$}

O resultado de cada comparação possui uma estatística chamada valor de p. Esta estatística permite concluir sobre o teste realizado. Caso esse valor seja maior que o nível de significância adotado (erro ou $\alpha$ ) conclui-se, portanto, que a $H_{0}$ (hipótese nula) é a hipótese verdadeira, caso contrário se aceita que a $H_{1}$ (hipótese alternativa) é a verdadeira [44]. 


\section{METODOLOGIA}

\subsection{Aspectos éticos da pesquisa}

O presente estudo seguiu os preceitos constantes na Resolução 196/96, do Conselho Nacional de Saúde, que versa sobre as diretrizes e normas regulamentadoras de pesquisas envolvendo seres humanos no Brasil [45]. O projeto foi submetido à apreciação do Comitê de Ética em Pesquisa, CEP, da instituição onde foi realizada a pesquisa, sendo aprovado pelo Protocolo $N^{\circ} 1659 / 09$.

De acordo com a resolução supracitada, para a obtenção dos dados, foi condição imprescindível o consentimento informado do trabalhador, salvaguardando assim os interesses do mesmo e garantindo o respeito pelos direitos humanos e dignidade da pessoa. $\mathrm{O}$ trabalhador foi ainda claramente informado do direito de recusa à participação da pesquisa ou desistir durante a mesma, sem que isso trouxesse qualquer implicação ou consequência para ele. Foi garantido o anonimato, privacidade e confidencialidade da informação coletada [45]. Após o esclarecimento dos objetivos da pesquisa, os trabalhadores leram e assinaram o Termo de Consentimento Livre e Esclarecido, TCLE (ANEXO I), em duas vias. Uma cópia foi entregue ao trabalhador e a outra ficou com a pesquisadora responsável pelo estudo.

\subsection{Tipo de estudo e local}

Realizou-se um estudo descritivo de caráter exploratório, com abordagem quali-quantitativa, no qual buscou analisar e descrever a percepção da QV de trabalhadores do serviço de radiodiagnóstico de um hospital universitário, localizado na cidade de São Paulo. 


\subsection{Critérios de inclusão e exclusão}

Para a constituição da amostra adotou-se os seguintes critérios de inclusão: ambos os gêneros; ser trabalhador atuante do serviço de radiodiagnóstico do hospital analisado; estar presente no local de trabalho nos dias da coleta de dados e aceitar participar voluntariamente da pesquisa.

Foram excluídos da amostra os trabalhadores que estavam usufruindo de férias, os que não estiveram presentes no local de trabalho, no período da coleta de dados e aqueles que não concordaram em tornarem-se sujeitos de pesquisa. Na amostra intencional três trabalhadores não participaram da pesquisa.

\subsection{População e amostra}

A população desse estudo totalizou 121 trabalhadores, entretanto, a amostra foi composta por 118 indivíduos (97,5\% da população) que aceitaram participar da pesquisa e assinaram o TCLE. Entre eles: 21 médicos (as), 59 tecnólogos/técnicos (as), 11 enfermeiros (as), 8 técnicos de enfermagem (as), 11 auxiliares de enfermagem e 8 profissionais de outras categorias (físico, químico, engenheiro, biomédico e equipe de radioproteção).

\subsection{Coleta de dados}

\subsubsection{Procedimentos para coleta de dados}

Para a realização da coleta de dados, primeiramente, encaminhou-se uma carta de 
solicitação de autorização (ANEXO II) aos responsáveis pelos setores do serviço de radiodiagnóstico a ser analisado.

De posse da autorização dos responsáveis, realizou-se a coleta de dados no período de fevereiro a outubro de 2010. Os trabalhadores foram abordados no seu próprio local de trabalho e, após consentirem participar do estudo, cada um respondeu um questionário autoaplicável, dividido em duas partes (1 e 2). A parte 1 - ficha de informação do participante (ANEXO III), elaborada pela pesquisadora, contendo questões referentes às variáveis sociodemográficas, relacionadas às condições de trabalho e variáveis que expressam o estilo de vida dos trabalhadores; e a parte 2, o instrumento genérico de avaliação de QV da OMS, o WHOQOL-bref (ANEXO IV), que é uma versão abreviada do instrumento original (WHOQOL-100) [31, 32].

A busca por um instrumento que fosse capaz de mensurar a QV independente da nacionalidade ou da cultura a qual o indivíduo se insere fez com que o Grupo WHOQOL desenvolvesse inicialmente o WHOQOL-100, assim definido por conter 100 questões, que avaliam seis domínios: físico, psicológico, nível de independência, relações sociais, meio ambiente, e espiritualidade/crenças pessoais. Cada domínio é constituído por facetas (aspectos da vida) que são avaliadas por quatro questões cada uma. Há ainda quatro questões gerais sobre QV e saúde, que são avaliadas em conjunto. Assim, o instrumento é composto por 24 facetas específicas e uma faceta geral (QV e saúde) [31, 32, 46-48].

O Grupo WHOQOL percebendo a necessidade de um instrumento mais curto, que demandasse pouco tempo para seu preenchimento, mas com características psicométricas satisfatórias, desenvolveu uma versão abreviada do WHOQOL-100, o WHOQOL-bref composto por 26 questões. A um nível conceitual, o Grupo WHOQOL determinou que devesse ser mantida a compreensão do instrumento em qualquer versão abreviada do WHOQOL-100, sendo, então, selecionada pelo menos uma questão de cada uma das 24 facetas e duas questões gerais que compõem o instrumento [31,32]. 
Estes instrumentos são disponíveis em 20 idiomas diferentes (WHOQOL GROUP, 1998). As versões em português do WHOQOL-100 e do WHOQOL-bref seguiram a metodologia proposta pela OMS, as quais foram testadas e validadas pelo Centro WHOQOL do Brasil, com sede na Universidade Federal do Rio Grande do Sul, sob a coordenação do professor M. P. A. Fleck do Departamento de Psiquiatria e Medicina Legal [31, 32, 49]. Além destes, o Grupo WHOQOL possui outros instrumentos que não serão tratados neste estudo [50-55].

\subsubsection{WHOQOL-bref - instrumento de avaliação da QV}

O WHOQOL-bref foi testado em várias culturas, tendo sido validado para o Brasil, por meio da versão desenvolvida em português. Este instrumento é composto por 26 questões, referentes às duas últimas semanas vividas pelo respondente, das quais, as duas primeiras avaliam a QV global e, calculadas em conjunto, geram um escore independente: a primeira questão faz referência à QV de modo geral e a segunda à satisfação com a própria saúde. As demais 24 questões são distribuídas em quatro domínios: físico, psicológico, social e ambiental. Os domínios, por sua vez, são constituídos por facetas, distribuídas de forma não sequencial [31, 32, 56-61], como é apresentado na Tabela 1. 
Tabela 2: Domínios e facetas do WHOQOL-bref [60, 61].

\begin{tabular}{|c|c|}
\hline DOMÍNIOS & FACETAS \\
\hline QV Global & $\begin{array}{l}\text { 1. Qualidade de vida de modo geral } \\
\text { 2. Satisfação com a própria saúde }\end{array}$ \\
\hline Domínio I - Físico & $\begin{array}{l}\text { 3. Dor e desconforto } \\
\text { 4. Dependência de medicação ou de tratamentos } \\
\text { 10. Energia e fadiga } \\
\text { 15. Mobilidade } \\
\text { 16. Sono e repouso } \\
\text { 17. Atividades da vida cotidiana } \\
\text { 18. Capacidade de trabalho }\end{array}$ \\
\hline Domínio II - Psicológico & $\begin{array}{l}\text { 5. Sentimentos positivos } \\
\text { 6. Espiritualidade/religião/crenças pessoais } \\
\text { 7. Pensar, aprender, memória e concentração } \\
\text { 11. Imagem corporal e aparência } \\
\text { 19. Autoestima } \\
\text { 26. Sentimentos negativos }\end{array}$ \\
\hline Domínio III - Social & $\begin{array}{l}\text { 20. Relações pessoais } \\
\text { 21. Atividade sexual } \\
\text { 22. Suporte e apoio social }\end{array}$ \\
\hline Domínio IV - Ambiental & $\begin{array}{l}\text { 8. Segurança física e proteção } \\
\text { 9. Ambiente físico (poluição/ruído/trânsito/clima) } \\
\text { 12. Recursos financeiros } \\
\text { 13. Oportunidades de adquirir novas informações e habilidades } \\
\text { 14. Participação em e oportunidades de Recreação/ lazer } \\
\text { 23. Ambiente no lar } \\
\text { 24. Cuidados de saúde: disponibilidade e qualidade } \\
\text { 25. Transporte }\end{array}$ \\
\hline
\end{tabular}

Para a composição das questões do WHOQOL-bref foi selecionada a questão de cada faceta que apresentou maior correlação com o escore médio de todas as facetas do WHOQOL-100. Essas questões foram formuladas para uma escala de resposta do tipo Likert (1-5) [34], com escala de intensidade (nada-extremamente), capacidade (nadacompletamente), freqüência (nunca-sempre) e avaliação (muito insatisfeito-muito satisfeito; muito ruim-muito bom) [32, 60]. Este instrumento não prevê conceitualmente um escore total de QV, considerando a premissa de que a QV é um constructo multidimensional, desta forma, cada domínio é calculado de forma independente. O cálculo dos escores dos domínios é realizado por meio de uma sintaxe (Figura 2), preconizada pelo Grupo WHOQOL, com o software Statistical Package for Social Science (SPSS). O valor mínimo dos escores é zero (pior QV) e o valor máximo é 100 (melhor QV), isto é, quanto mais alto o escore, melhor a QV naquele domínio [59-62]. 


\begin{tabular}{|c|c|}
\hline File Edit View Data & Transform Insert Format Analyze Graphs Utilities Window Help \\
\hline \multicolumn{2}{|c|}{ 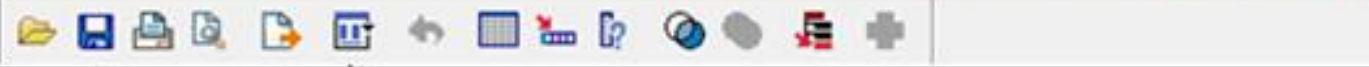 } \\
\hline $\begin{array}{l}\text { Verificar se todos os } 26 \\
\text { itens foram preenchidos } \\
\text { com respostas entre } 1 \text { e } 5\end{array}$ & $\begin{array}{l}\text { RECODE Q1 Q2 Q3 Q4 Q5 Q6 Q7 Q8 Q9 Q10 Q11 Q12 Q13 Q14 Q15 Q16 } \\
\text { Q17 Q81 Q19 Q20 Q21 Q22 Q23 Q24 Q25 Q26 (1=1) }(2=2)(3=3)(4=4)(5=5) \\
\text { (ELSE=SYSMIS). }\end{array}$ \\
\hline $\begin{array}{l}\text { Converter as questões } \\
\text { invertidas }\end{array}$ & RECODE Q3 Q4 Q26 (1=5) (2=4) (3=3) $(4=2)(5=1)$. \\
\hline $\begin{array}{l}\text { Calcular os escores dos } \\
\text { dominios }\end{array}$ & $\begin{array}{l}\text { COMPUTE PHYS=MEAN.6(Q3,Q4,Q10,Q15,Q16,Q17,Q18)*4. } \\
\text { COMPUTE PSYCH=MEAN.5(Q5,Q6,Q7,Q11,Q19,Q26)*4. } \\
\text { COMPUTE SOCIAL=MEAN.2(Q20,Q21,Q22)*4. } \\
\text { COMPUTE ENVIR=MEAN.6(Q8,Q9.Q12,Q13,Q14,Q23,Q24,Q25)*4. }\end{array}$ \\
\hline $\begin{array}{l}\text { Transformar os escores } \\
\text { para uma escala de } 0 \text { a } \\
100\end{array}$ & $\begin{array}{l}\text { COMPUTE PHYS }=(\text { PHYS }-4)^{*}(100 / 16) \\
\text { COMPUTE PSYCH }=(\text { PSYCH-4 } 4)^{*}(100 / 16) \\
\text { COMPUTE SOCLAL }=(\text { SOCLAL-4)* } \\
\text { COMPUTE ENVIR }=(\text { ENVIR-4 } 4)^{*}(100 / 16)\end{array}$ \\
\hline $\begin{array}{l}\text { Excluir os respondentes } \\
\text { cujo numero de itens não } \\
\text { respondidos excedem } \\
20 \% \text { do total de itens }\end{array}$ & $\begin{array}{l}\text { COUNT TOTAL }=\text { Q1 TO Q26 (1 THRU 5). } \\
\text { SELECT IF }(\text { TOTAL }>=21) \\
\text { EXECUTE. }\end{array}$ \\
\hline
\end{tabular}

Figura 2: Sintaxe SPSS para o cálculo dos escores do WHOQOL-bref [59-63].

\subsection{Análise estatística dos dados}

Os dados foram analisados utilizando-se os programas estatísticos: Statistical Package for Social Science (SPSS) versão 16, Excel Office 2007 e Minitab 15 [63, 64]. Inicialmente, foi realizada a estatística descritiva dos dados (medidas de tendência central, de posição e de dispersão), referente à caracterização da amostra e à distribuição dos escores de cada domínio do WHOQOL-bref.

Neste estudo foram aplicados testes e técnicas estatísticas não paramétricas, porque as condições (suposições) para a utilização de testes e técnicas paramétricos, como a normalidade 
(teste de Anderson-Darling) e homocedasticidade (homogeneidade das variâncias, teste de Levene), não foram encontradas (principalmente a normalidade) neste conjunto de dados [39, 40].

As propriedades psicométricas do instrumento WHOQOL-bref, para a amostra de trabalhadores de serviços de radiodiagnóstico, foram verificadas por meio da avaliação de confiabilidade e validade [33-35]. Calculou-se o Coeficiente Alfa de Cronbach ( $\alpha$ ) para verificar a consistência interna do instrumento para amostra estudada. A análise foi realizada para as 26 questões do instrumento, considerando-se o os 118 participantes do estudo. Além disso, calculou-se o ICC para analisar a confiabilidade. A validade do instrumento foi avaliada pelo Coeficiente de Correlação de Spearman e pela Análise de Regressão Linear.

Para analisar a influência das variáveis qualitativas estudadas nos domínios do WHOQOL-bref foram utilizados os testes não paramétricos de Mann-Whitney (para variáveis com duas categorias) e de Kruskal-Wallis (para variáveis divididas em três ou mais categorias).

O nível de significância adotado para este estudo foi de $5 \%(\mathrm{p}<0,05)$, com um nível de confiança estatística de $95 \%$. 


\section{RESULTADOS E DISCUSSÃO}

Os resultados do questionário foram obtidos e organizados em Tabelas e Figuras, procurando atender aos objetivos norteadores desta pesquisa, utilizando as bases conceituais voltadas para o perfil e para a QV dos trabalhadores do serviço de radiodiagnóstico de um hospital universitário de São Paulo.

\subsection{Resultados da primeira parte do questionário - ficha de informação do participante: variáveis sociodemográficas, condições de trabalho e estilo de vida}

$\checkmark \quad$ Variáveis sociodemográficas: idade, gênero, estado civil e nível educacional.

Na Tabela 2 é apresentada a distribuição da amostra (118 indivíduos), segundo as variáveis sociodemográficas analisadas. Observou-se que houve uma distribuição equitativa entre os gêneros (masculino 50,8\% e feminino 49,2\%). A idade dos indivíduos variou de 24 a 72 anos, com média de $(43,7 \pm 10,3)$ anos; a média de idade entre os homens foi de $(41,7 \pm 10,4)$ anos e entre as mulheres de $(45,6 \pm 9,8)$ anos. No que se refere ao estado civil, observou-se que $50,0 \%$ da amostra eram casados, $36,4 \%$ eram solteiros e os divorciados e os viúvos somaram 12,8\%. Analisando as informações sobre nível educacional, evidenciou-se que $60,2 \%$ dos indivíduos eram graduados, 35,6\% tinham ensino médio e 1,7\% declararam ter ensino fundamental.

Conforme a Figura 3, a faixa etária concentrou-se nos intervalos de idade entre 41-50 e 51-60 anos, correspondendo a 59,3\% da amostra. 
Tabela 3: Distribuição da amostra, segundo as variáveis sociodemográficas analisadas.

\begin{tabular}{lc}
\hline VARIÁVEIS & $\mathbf{N = 1 1 8}$ \\
\hline Idade: (média \pm dp) & $(43,7 \pm 10,3)$ \\
Gênero & Frequência $(\%)$ \\
Masculino & $60(50,8)$ \\
Feminino & $58(49,2)$ \\
Estado civil & \\
Casado & $59(50,0)$ \\
Solteiro & $43(36,4)$ \\
Divorciado & $10(8,5)$ \\
Viúvo & $5(4,3)$ \\
Não respondeu & $1(0,8)$ \\
Nível educacional & \\
Graduação & $71(60,2)$ \\
Ensino médio & $42(35,6)$ \\
Ensino fundamental & $2(1,7)$ \\
Não respondeu & $3(2,5)$ \\
\hline
\end{tabular}

N: número total da amostra; dp: desvio padrão.

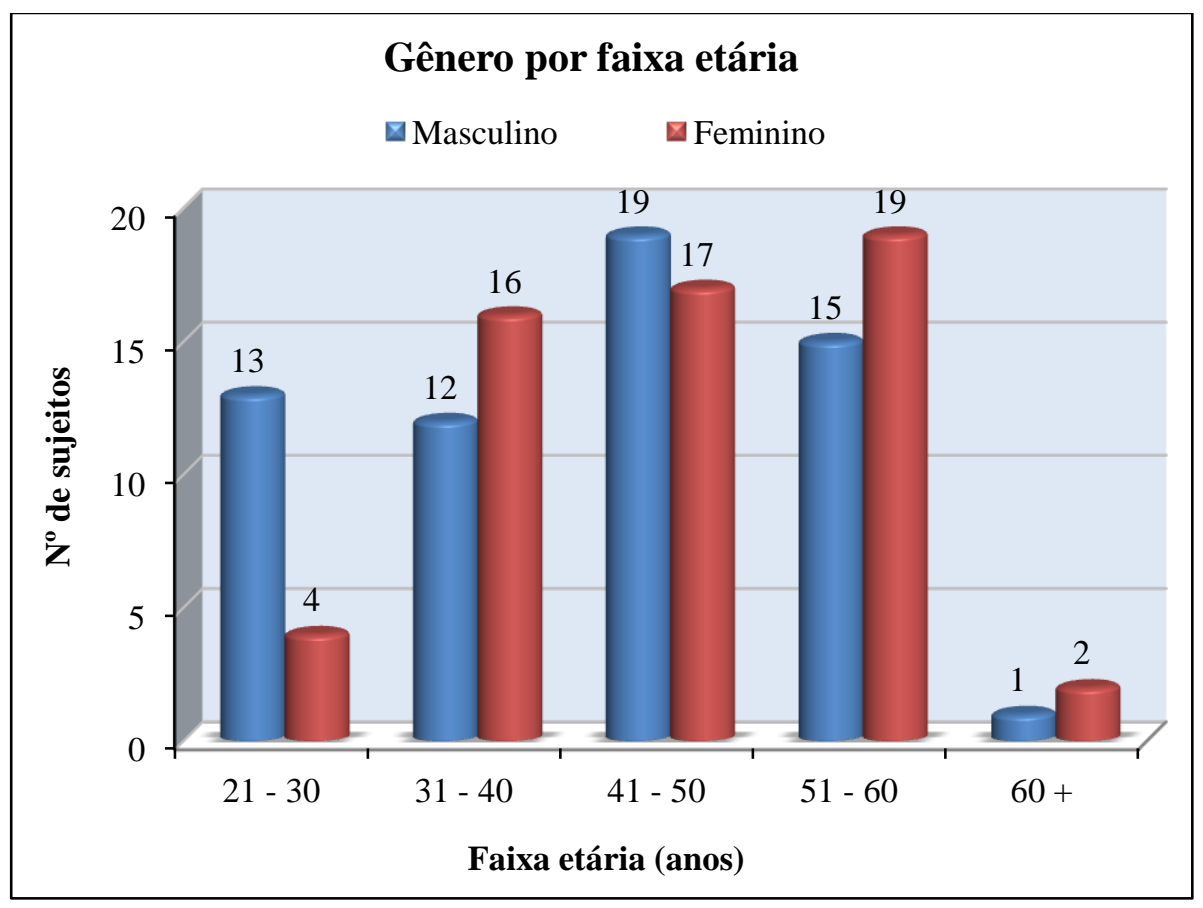

Figura 3: Distribuição da amostra por gênero e faixa etária. 
Variáveis relacionadas às condições de trabalho: tempo de trabalho na instituição, tempo de trabalho com radiação ionizante, categoria profissional, setor de trabalho, satisfação com o trabalho em presença da radiação ionizante, trabalho em turnos, outro emprego, setor de atuação no outro emprego, treinamento, tipo de treinamento, equipamentos de proteção individual (EPI's) utilizados durante os procedimentos e monitoramento individual para exposição às radiações ionizantes.

Na Figura 4 é apresentada a distribuição da amostra, de acordo com o tempo de trabalho na instituição analisada. A longa carreira profissional foi comprovada, $28,8 \%$ dos participantes tinham entre 6-15 anos de tempo de trabalho, 28,0\% entre 16-25 anos e 19,5\% trabalhavam a mais de 25 anos na instituição, totalizando 76,3\% da amostra. Um total de 20,3\% da amostra tinha entre 1-5 anos de trabalho e 3,4\% trabalhavam a menos de um ano na instituição. O tempo médio de trabalho destes profissionais na instituição analisada foi de $(14,6 \pm 10,0)$ anos.

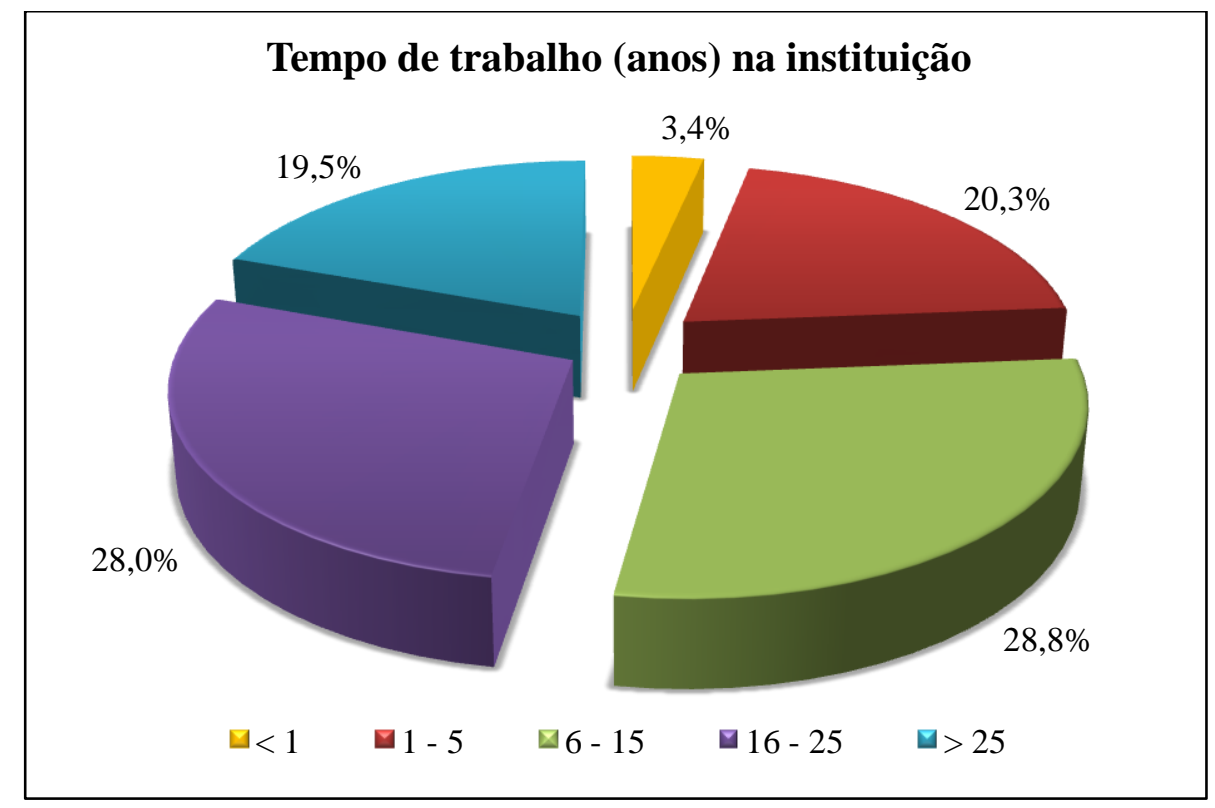

Figura 4: Distribuição da amostra por tempo de trabalho na instituição. 
Na Figura 5 é apresentada a distribuição da amostra, de acordo com o tempo de trabalho com radiação ionizante. Verificou-se que os resultados foram similares aos encontrados na Figura 4. As diferenças encontradas, principalmente nos intervalos de tempo (menor que 1 ano e maior que 25 anos), foram porque alguns dos profissionais, entre eles, médicos, tecnólogos/técnicos de radiologia e técnicos de enfermagem, possuíam experiência anterior com trabalho em presença de radiação ionizante. Além disso, foi constatado que alguns dos profissionais já trabalhavam na instituição exercendo outra atividade e depois começaram a trabalhar com radiação ionizante. O tempo médio de trabalho com radiação ionizante destes profissionais foi de $(12,4 \pm 9,3)$ anos.

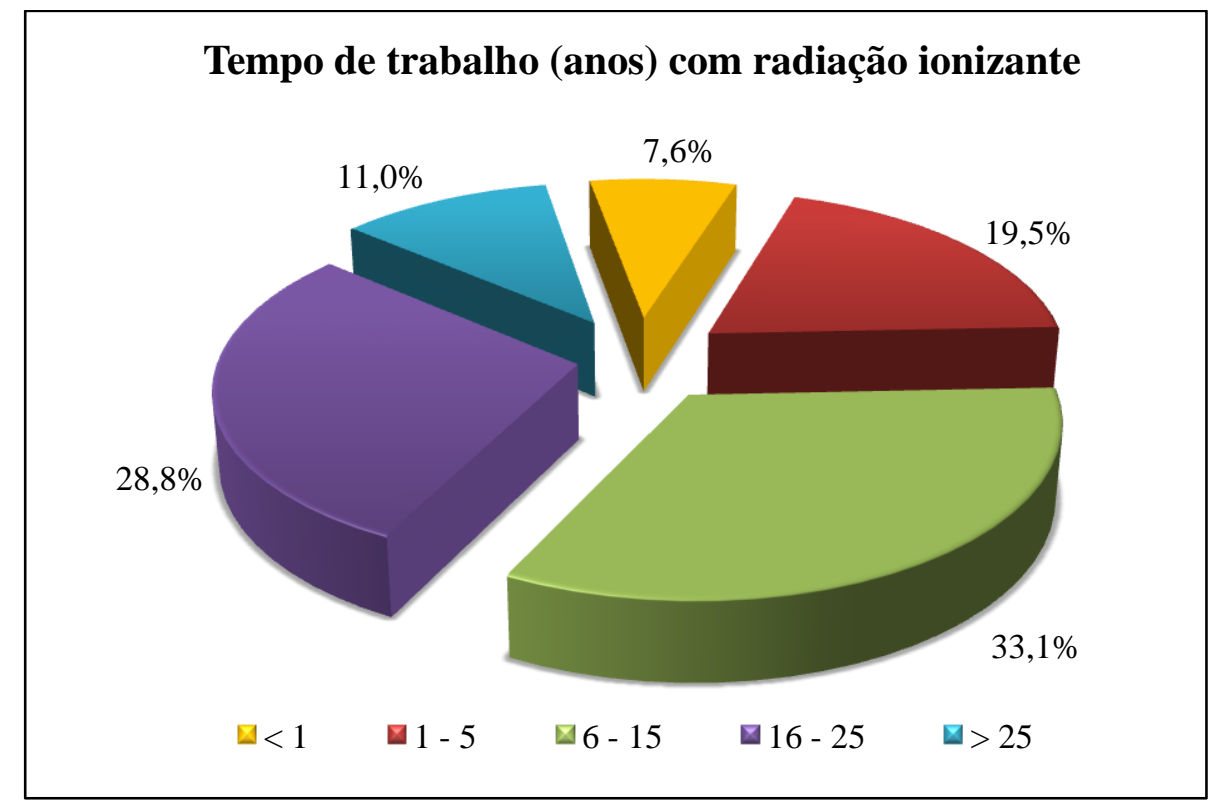

Figura 5: Distribuição da amostra por tempo de trabalho com radiação ionizante. 
Nas Figuras 6 e 7 é apresentada a distribuição da amostra, de acordo com a categoria profissional e o setor de trabalho, respectivamente.

O maior número de profissionais foi observado nas categorias "tecnólogo/técnico de radiologia" (50,0\%) e "médico" (17,8\%), correspondendo a 67,8\% dos indivíduos. As demais categorias (enfermagem, auxiliar e técnico de enfermagem e outros profissionais) somaram $32,2 \%$ da amostra (Figura 6). Ao analisar as categorias profissionais por gênero, observou-se que na categoria "tecnólogo/técnico de radiologia" o gênero masculino foi maioria $(33,1 \%)$, assim como na categoria "médico" $(13,6 \%)$, nas demais categorias o gênero feminino prevaleceu, cerca de $90 \%$ da amostra.

Foi possível verificar que a maioria da força de trabalho do serviço de radiodiagnóstico analisado (Figura 7) concentrou-se nos setores de hemodinâmica (36,4\%), raios X leito $(25,4 \%)$ e tomografia computadorizada $(14,4 \%)$. Os setores de medicina nuclear, raios $\mathrm{X}$ ambulatório, proteção radiológica e mamografia somaram 23,7\% da amostra.

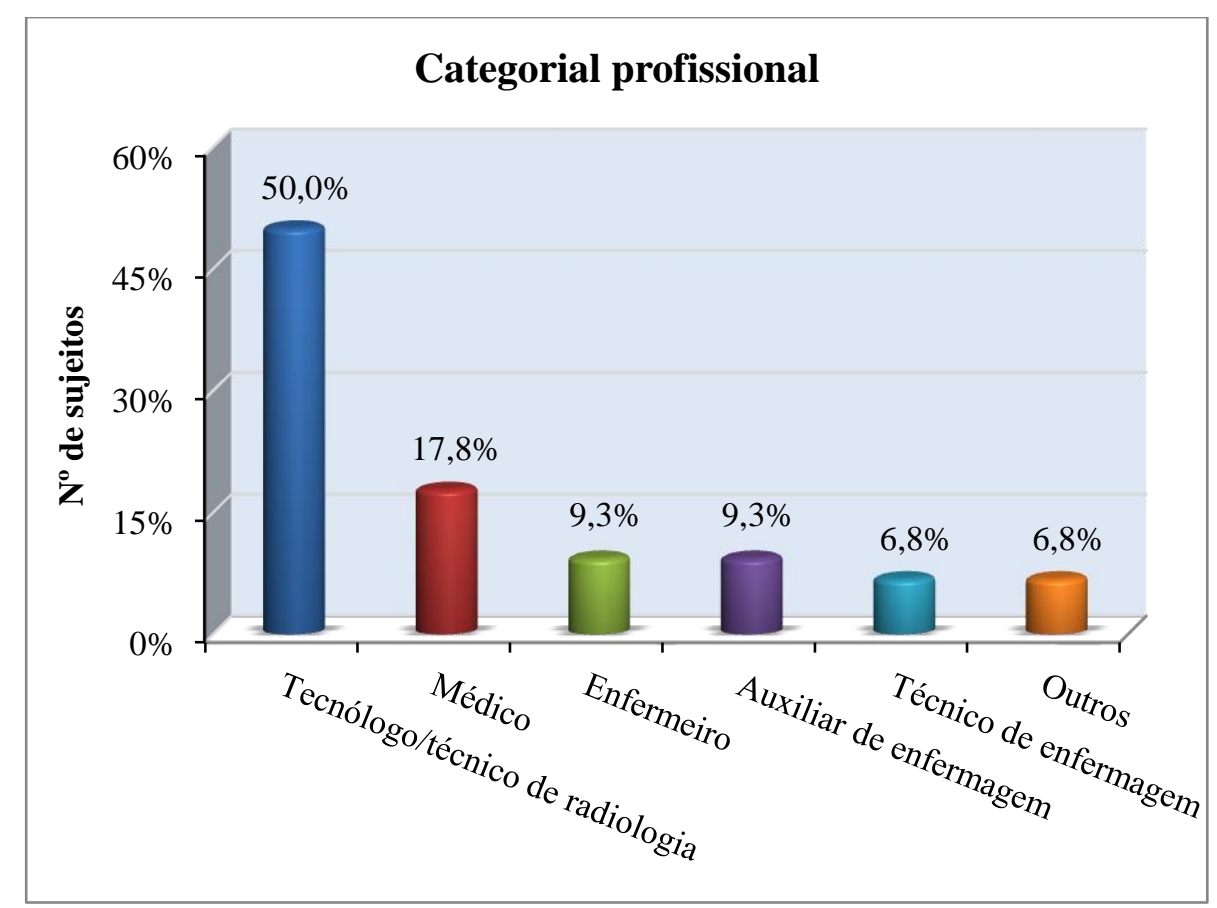

Figura 6: Distribuição da amostra por categoria profissional. 


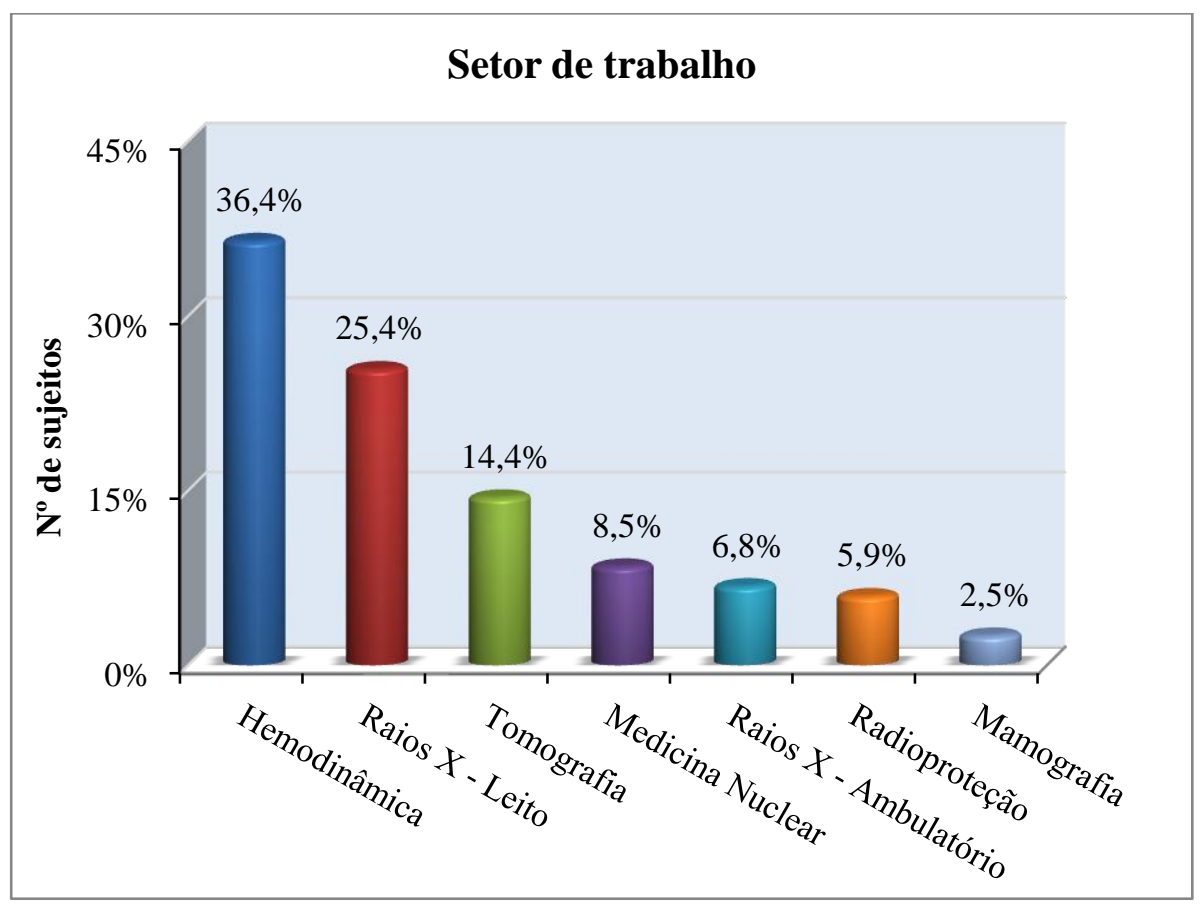

Figura 7: Distribuição da amostra por setor de trabalho.

Na Figura 8 é apresentada a distribuição da amostra, de acordo com a satisfação com o trabalho em presença da radiação ionizante. Observou-se que dos 118 trabalhadores que participaram do estudo, 65,3\% responderam estar "satisfeito" e "muito satisfeito" com o trabalho em presença da radiação ionizante, 4,2\% estavam "insatisfeito" e 8,5\% "muito insatisfeito". Pode-se concluir que os profissionais pesquisados estão na sua maioria satisfeitos com o trabalho. Um indivíduo satisfeito em seu ambiente de trabalho, necessariamente, ele é uma pessoa motivada e irá continuar sua busca para satisfazer suas necessidades. Esta busca por satisfação resulta em um ambiente harmonioso, com equipes integradas e um bom desempenho das atividades laborais, bem como elevará o grau da QV que este indivíduo possui. A satisfação profissional pode resultar na percepção do indivíduo, sobre até que ponto as atividades que ele desenvolve em seu trabalho, atendem a valores considerados, por ele, como importantes [65]. 


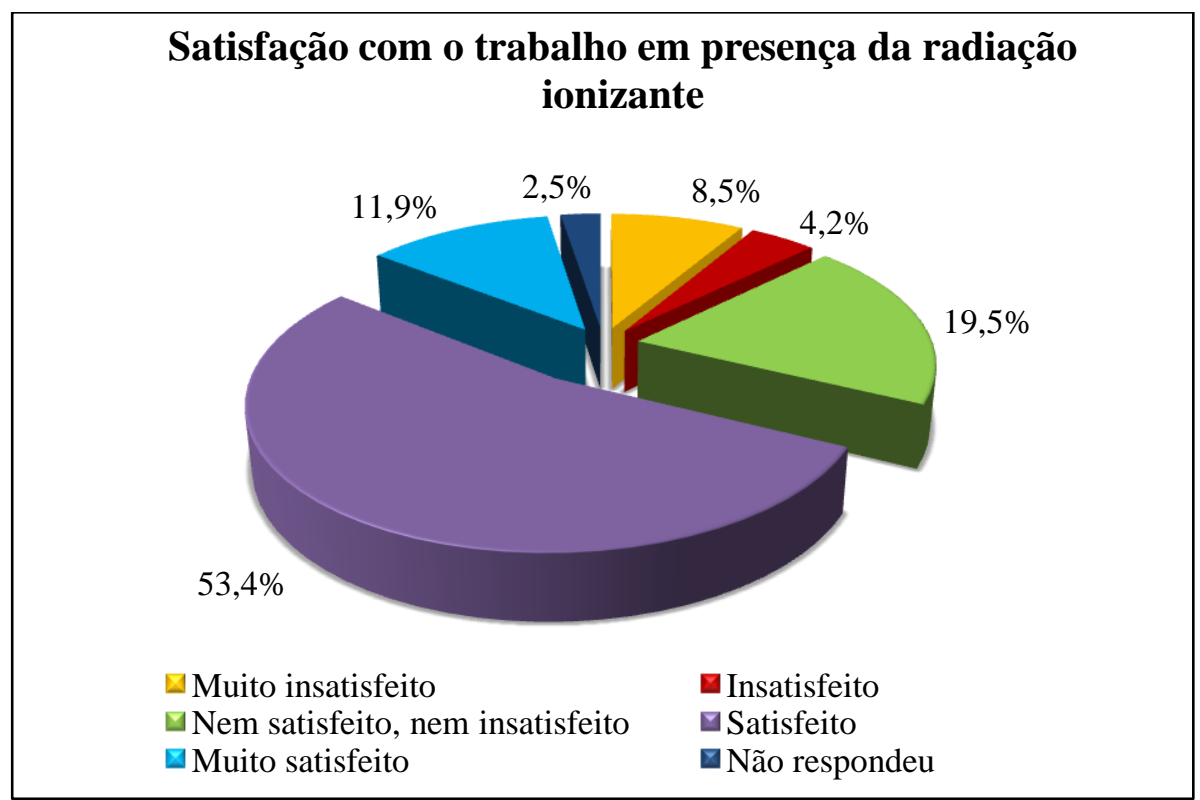

Figura 8: Distribuição da amostra por satisfação com o trabalho em presença da radiação ionizante.

Na Figura 9 é apresentada a distribuição da amostra, segundo o trabalho em turnos (a), os diferentes turnos de trabalho (b) e a existência de outro emprego. Verificou-se na Figura 9(a) que 76,9\% da amostra trabalhavam em turnos, sendo que destes, 22,9\% trabalhavam no turno da noite, $16,1 \%$ no turno da tarde, $14,4 \%$ no turno da manhã, $17,8 \%$ em regime de rodízio, 5,7\% não responderam em qual turno trabalhavam, conforme a Figura 9(b). Quando questionados se possuíam outro emprego, verificou-se na Figura 9(c) que 53,4\% dos participantes responderam dedicar-se profissionalmente a mais de um trabalho. $\mathrm{O}$ tempo médio de trabalho dos profissionais no outro emprego foi de $(10,1 \pm 7,6)$ anos. Foi observado ainda que os trabalhadores dos turnos da manhã e da tarde tem uma tendência a não ter outro emprego, porém os trabalhadores do turno da noite e os que trabalham em regime de rodízio mostraram maior tendência a ter outro emprego. Entre os profissionais que possuíam outro emprego, a maioria $(25,4 \%)$ pertencia à categoria "tecnólogo/técnico de radiologia" e $(14,4 \%)$ à categoria "médico". Este resultado já era esperado, devido a proporção da amostra, como foi apresentado na Figura 6. Além disso, observou-se que 28,0\% dos profissionais responderam exercer a outra atividade profissional em serviços de radiodiagnóstico, como é apresentado na Tabela 3. 
(a) Trabalha em turnos?

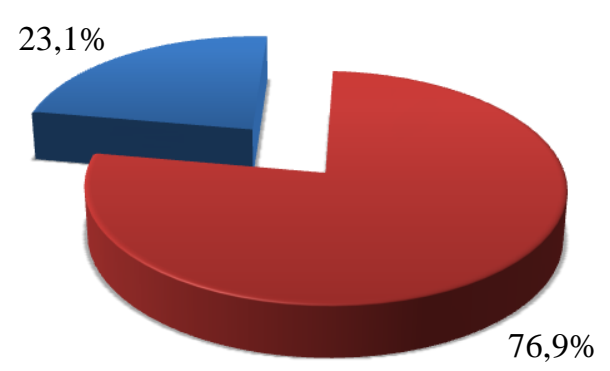

\Não $\square$ Sim (b) Qual o turno de trabalho?

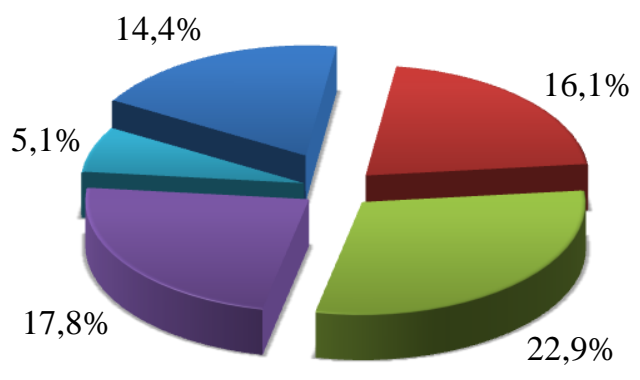

$\begin{array}{ll}\square \text { Mannhã } & \square \text { Tarde } \\ \square \text { Rodízio } & \square \text { Não respondeu }\end{array}$

(c) Possui outro emprego?

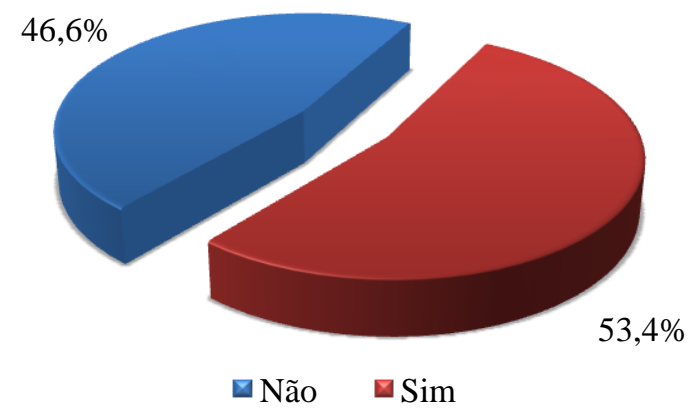

Figura 9: Distribuição da amostra, por trabalho em turnos (a), diferentes turnos de trabalho (b) e a existência de outro emprego (c).

Tabela 4: Distribuição do outro emprego, por local de trabalho.

\begin{tabular}{lcc}
\hline Local de trabalho & $\mathbf{N}$ & $\mathbf{\%}$ \\
\hline Radiodiagnóstico & 33 & $28,0 \%$ \\
Hospital & 8 & $6,8 \%$ \\
UTI & 7 & $5,9 \%$ \\
Clínica & 4 & $3,4 \%$ \\
Consultório & 2 & $1,7 \%$ \\
Pronto socorro & 2 & $1,7 \%$ \\
Berçário & 1 & $0,8 \%$ \\
INSS - Perito & 1 & $0,8 \%$ \\
Não respondeu & 5 & $4,2 \%$ \\
Total & $\mathbf{6 3}$ & $\mathbf{5 3 , 4 \%}$ \\
\hline
\end{tabular}

N: número total da amostra; UTI: Unidade de Terapia Intensiva; INSS: Instituto Nacional do Seguro Social. 
As políticas internas dos serviços de radiodiagnóstico devem atuar não somente com ações de prevenção e de tratamento, mas também com o treinamento e a educação continuada, garantindo assim que os profissionais em radiologia possam desempenhar suas funções, sem pôr em risco sua integridade física e dos pacientes. É de responsabilidade do empregador o fornecimento de equipamentos de proteção individual (EPI's) adequados ao risco de exposição, o treinamento dos trabalhadores quanto à forma correta de utilização e conservação dos mesmos, bem como o monitoramento individual para exposição às radiações ionizantes $[10,11]$.

Na Figura 10 é apresentada a distribuição da amostra, quanto à treinamento (a), tipos de treinamentos (b), uso de EPI's (c) e monitoramento individual para os profissionais expostos às radiações ionizantes (d) no serviço de radiodiagnóstico analisado.

A Figura 10(a) mostrou que $63,6 \%$ dos profissionais responderam que receberam treinamento, sendo que 23,7\% deles receberam treinamento em proteção radiológica, Figura 10(b). Na análise dos dados, verificou-se ainda que dentre os profissionais que receberam treinamento em proteção radiológica $14(11,9 \%)$ pertenciam aos setores de hemodinâmica, $10(8,5 \%)$ medicina nuclear, $3(2,5 \%)$ equipe de radioproteção e $1(0,8 \%)$ ao setor de raios X ambulatorial. Quanto ao uso de EPI's, 114 (96,6\%) dos profissionais responderam que utilizavam dispositivos de proteção e de segurança durante a realização dos procedimentos. A distribuição dos tipos de EPI's utilizados é visualizada na Figura 10(c). No que se refere ao monitoramento individual, para a radiação externa, a Figura 10(d) mostrou que 96,6\% dos sujeitos do estudo utilizavam dosímetro termoluminescente, TL, posicionado sobre o tórax. 


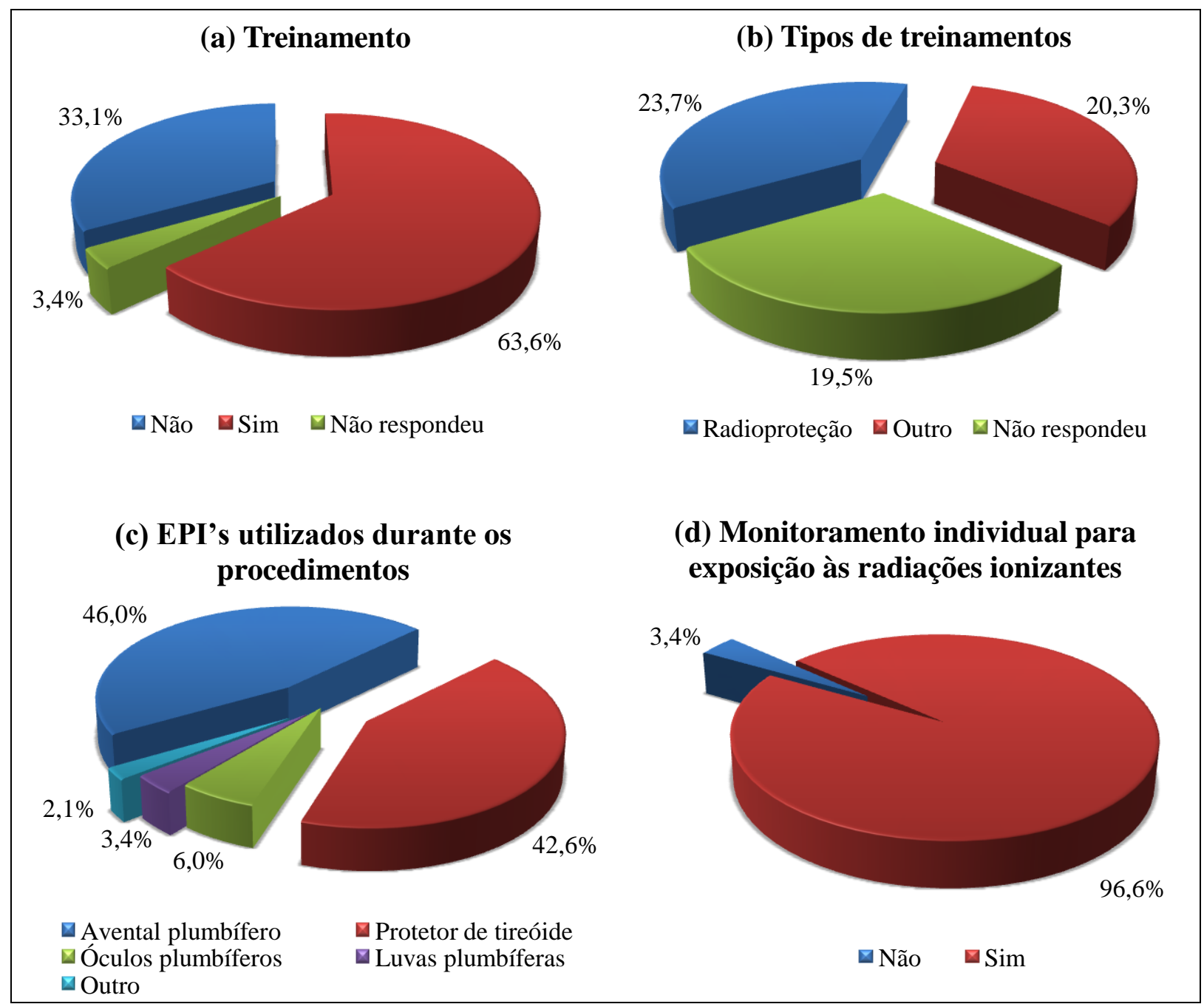

Figura 10: Distribuição da amostra, em relação às variáveis: treinamento (a), tipos de treinamento (b), EPI's utilizados (c) e monitoramento individual (d).

$\checkmark$ Variáveis que expressam o estilo de vida dos participantes: hábito de fumar, consumo de bebida alcoólica e prática de atividade física.

Comprovadamente, a adoção de um estilo de vida saudável com a prática de hábitos saudáveis, proporciona uma melhoria na QV do sujeito. Esta prática, consequentemente, está ligada ao processo de mudança de comportamento, permitindo que os indivíduos tenham possibilidade de ganhar qualitativamente em seu estilo de vida e ampliar a sua expectativa de vida $[24,66]$. 
Na Figura 11 é apresentada a distribuição das variáveis que expressam o estilo de vida dos participantes, de acordo com o gênero masculino e feminino. Os resultados mostraram que $16(13,6 \%)$ da amostra eram fumantes, 64 (54,2\%) consumiam algum tipo de bebida alcoólica e $52(44,1 \%)$ praticavam alguma atividade física regularmente.

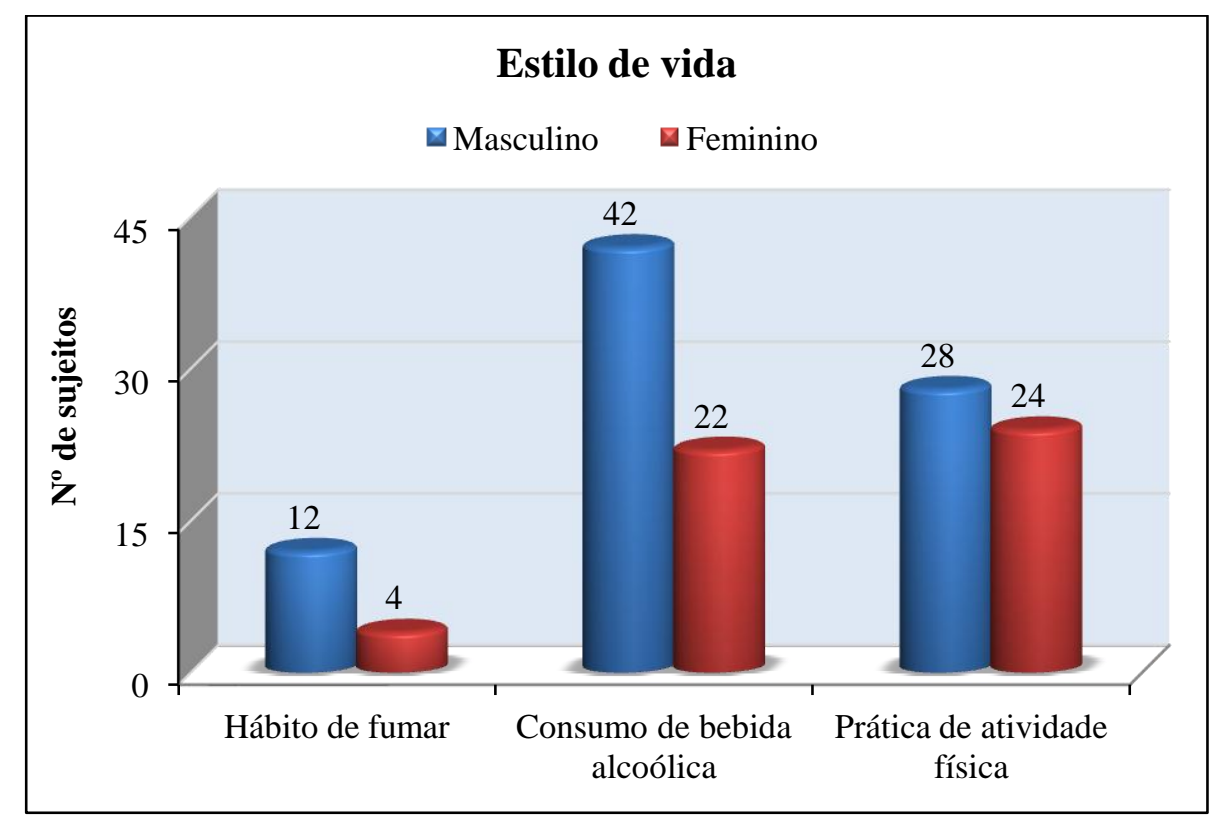

Figura 11: Distribuição da amostra por gênero, segundo as variáveis que expressam o estilo de vida dos participantes.

Na Figura $12(a, b, c)$ é apresentada a distribuição da amostra em relação às variáveis referentes às condições de saúde atual dos participantes. Do total de profissionais que participaram do estudo, 91,5\% responderam que realizam exames periódicos de saúde na instituição onde trabalham, como mostra a Figura 12(a); na questão como está a sua saúde? Figura 12(b), 55,3\% dos participantes consideraram sua condição saúde como "boa" e na questão: tem algum problema de saúde no momento? Figura 12(c), 50,0\% relataram não ter nenhum problema de saúde. Os exames realizados no último periódico também foram relatados, como pode ser visualizado na Tabela 4. 
(a) Realiza exames periódicos de saúde?

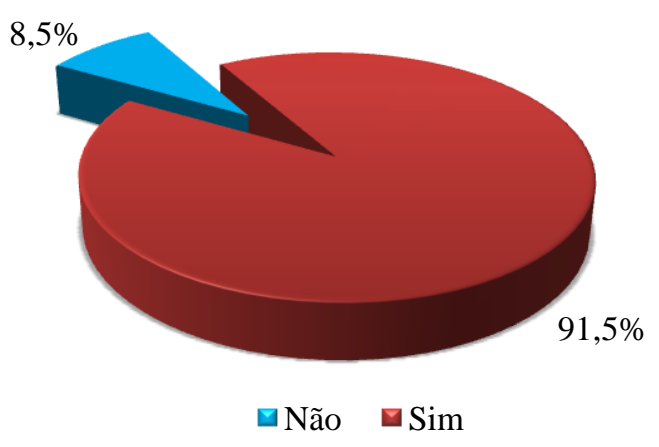

(b) Como está a saúde?

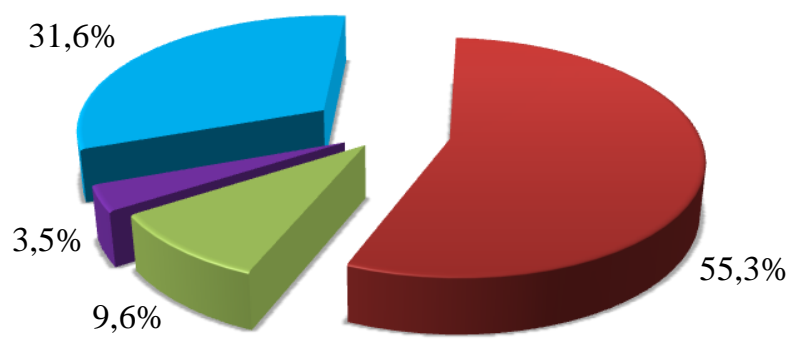

$\square$ Muito Boa $\quad \square$ Boa

$\square$ Nem ruim, nem boa $\square$ Ruim

\section{(c) Tem algum problema de saúde no momento?}

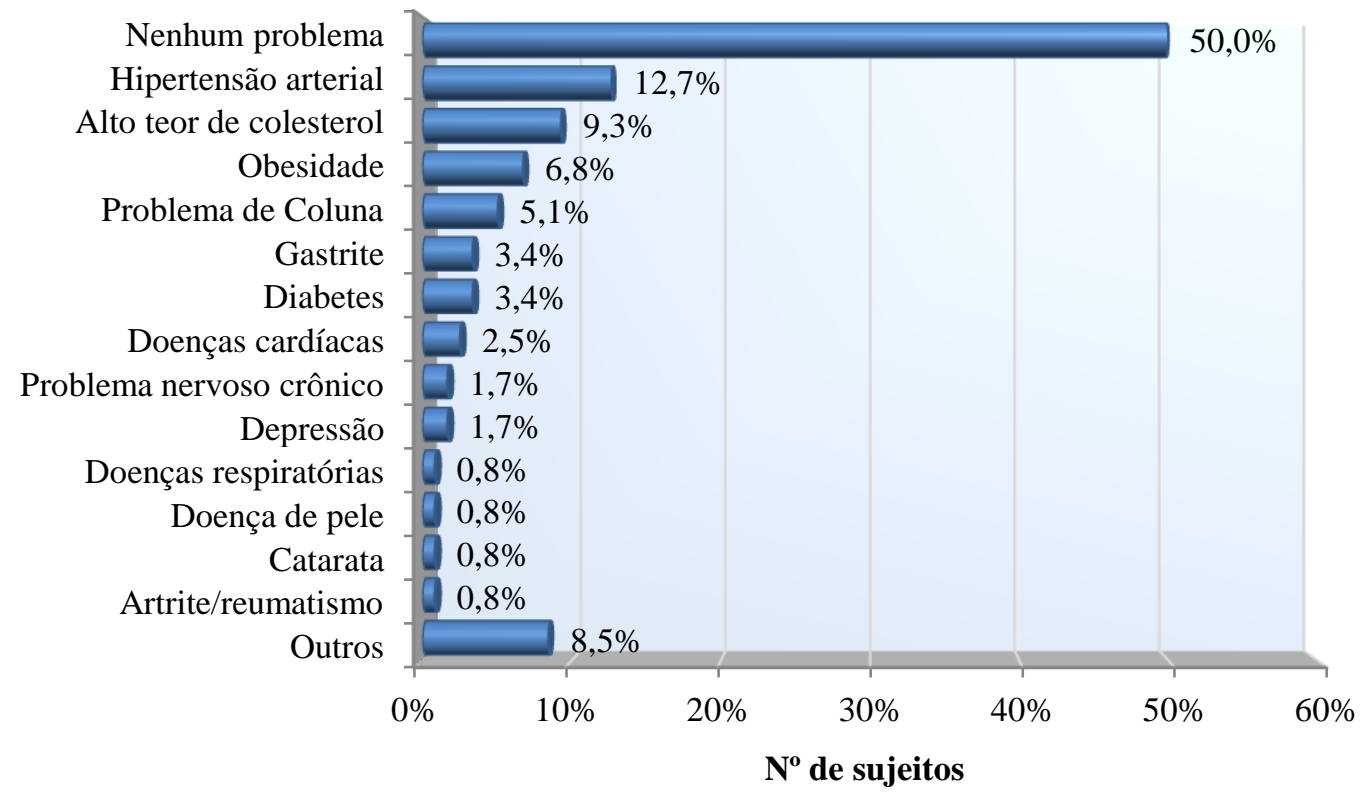

Figura 12: Distribuição das variáveis referentes à condição de saúde atual dos participantes.

Tabela 5: Exames de saúde realizados no último periódico, em 2010.

\begin{tabular}{lcc}
\hline Tipo de exame & $\mathbf{N}$ & $\mathbf{\%}$ \\
\hline Sangue* & 108 & 91,5 \\
Oftalmológico & 21 & 17,8 \\
Mamografia & 17 & 14,4 \\
Eletrocardiograma & 10 & 8,5 \\
Coloscopia e Copocitologia (mulher) & 9 & 7,6 \\
Raios X de tórax & 9 & 7,6 \\
Audiometria & 2 & 1,7 \\
\hline
\end{tabular}

N: número total da amostra; *Colesterol (Total + Frações), Hemograma Completo, Hormônios da Tireóide (T3, T4, TSH), Triglicérides. 


\subsection{Resultados da segunda parte do questionário - WHOQOL-bref}

O questionário WHOQOL-bref foi preenchido por todos os participantes da pesquisa. A média de tempo para o preenchimento do questionário foi de $(11,2 \pm 6,5)$ minutos. A opção em utilizar para este estudo o instrumento WHOQOL-bref foi justamente pelo seu método rápido e prático, fator que contribuiu para a participação efetiva dos profissionais e, também, por se tratar de um instrumento que avalia a QV de um modo geral.

\subsubsection{Análise descritiva dos domínios do WHOQOL-bref}

Na Tabela 5 e na Figura 13 são apresentados os resultados da análise estatística descritiva dos domínios do WHOQOL-bref, representando os escores de QV dos profissionais analisados. Verifica-se que em todos os domínios a variabilidade é baixa, pois o coeficiente de variação (CV) é menor que 50\%, o que demonstra que os dados são homogêneos

(Tabela 5). Todos os domínios apresentaram pontuação máxima, alcançando o escore 100,0 (melhor QV). Os domínios social e QV global obtiveram escore zero (pior QV). No domínio social, o que colaborou para que o mesmo alcançasse este resultado foi o fato dos participantes terem respondido "muito insatisfeito" quanto à vida sexual (9 participantes), relações pessoais (3 participantes) e suporte e apoio social (2 participantes). No domínio QV global (QV de modo geral e satisfação com a saúde), três participantes avaliaram sua QV como "muito ruim" e responderam estar "muito insatisfeito" com a sua saúde.

A média dos escores dos domínios é ilustrada na Figura 13; o domínio ambiental alcançou a menor média $(60,6 \pm 15,6)$ de $\mathrm{QV}$, indicando que os participantes do estudo consideraram ter algumas dificuldades relacionadas à oportunidade de recreação e lazer, ambiente físico (poluição/ruído/transito/clima), recursos financeiros, transporte, cuidado de saúde e oportunidade de adquirir novas informações e habilidades. Os domínios QV global $(69,6 \pm 19,7)$, físico $(76,2 \pm 12,7)$, psicológico $(73,6 \pm 19,3)$ e social $(73,8 \pm 19,3)$ obtiveram 
resultados similares, demonstrando homogeneidade entre esses aspectos na vida dos indivíduos analisados. No domínio físico, apesar de ter apresentado a maior média entre os domínios, observou-se que os participantes manifestaram alguma dificuldade, como indicada na média obtida da faceta: sono e repouso (escore=62,9), mostrado na Figura 14.

Tabela 6: Análise estatística descritiva dos domínios do WHOQOL-bref.

\begin{tabular}{cccccc}
\hline \multirow{2}{*}{ Análise descritiva } & \multicolumn{5}{c}{ Domínios do WHOQOL-bref } \\
\cline { 2 - 6 } & Físico & Psicológico & Social & Ambiental & QV Global \\
\hline Média & $\mathbf{7 6 , 2}$ & $\mathbf{7 3 , 6}$ & $\mathbf{7 3 , 8}$ & $\mathbf{6 0 , 6}$ & $\mathbf{6 9 , 6}$ \\
\hline Mediana & 78,6 & 75,0 & 75,0 & 60,0 & 75,0 \\
\hline DP & 12,7 & 14,9 & 19,3 & 15,6 & 19,7 \\
CV & $17 \%$ & $20 \%$ & $26 \%$ & $26 \%$ & $28 \%$ \\
\hline Q1 & 67,9 & 66,7 & 66,7 & 53,1 & 62,5 \\
\hline Q3 & 85,7 & 83,3 & 89,6 & 68,8 & 75,0 \\
\hline Mínimo & 32,1 & 20,8 & 0,0 & 6,3 & 0,0 \\
\hline Máximo & 100,0 & 100,0 & 100,0 & 100,0 & 100,0 \\
\hline N & 118 & 118 & 118 & 118 & 117 \\
\hline IC & 2,3 & 2,7 & 3,5 & 2,8 & 3,6 \\
\hline
\end{tabular}

DP: desvio padrão; CV: coeficiente de variação; Q1 e Q3: $1^{\circ}$ e $3^{\circ}$ quartil; N: número total da amostra; IC: intervalo de confiança.

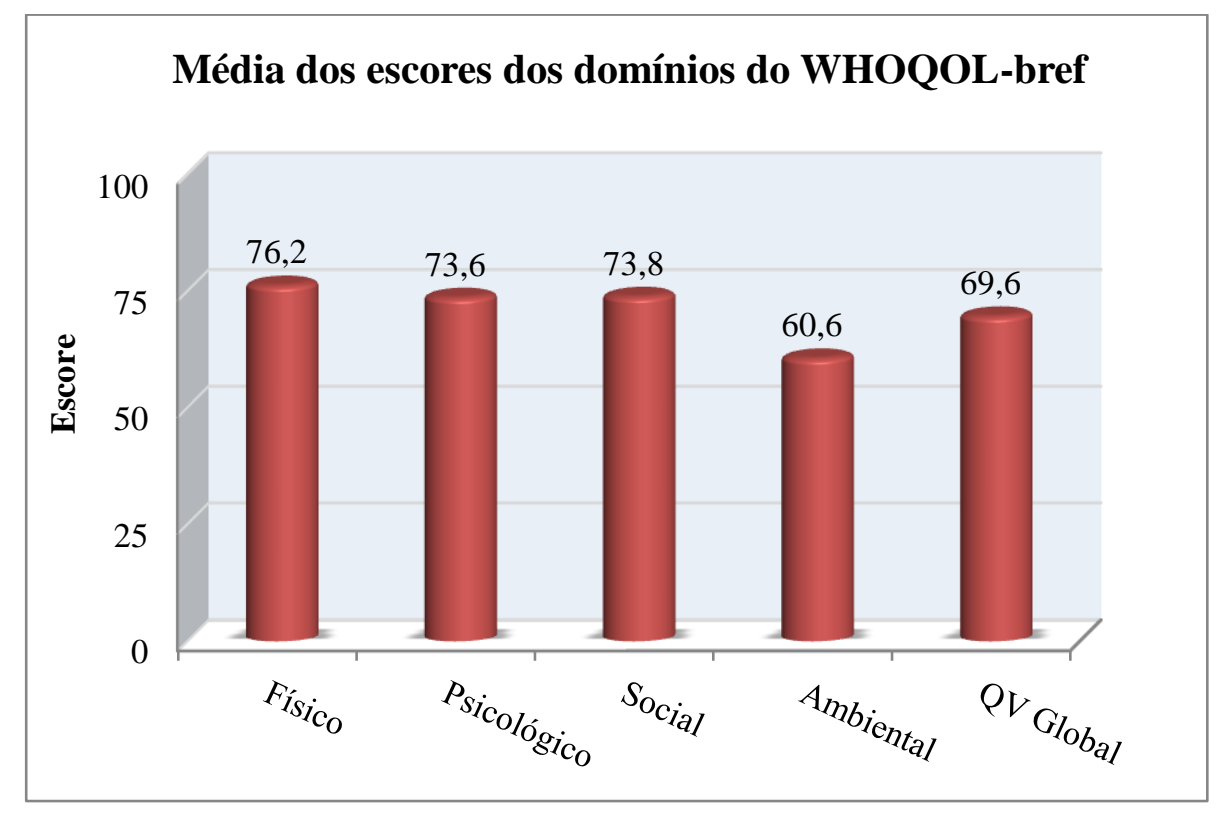

Figura 13: Média dos escores dos domínios do WHOQOL-bref. 


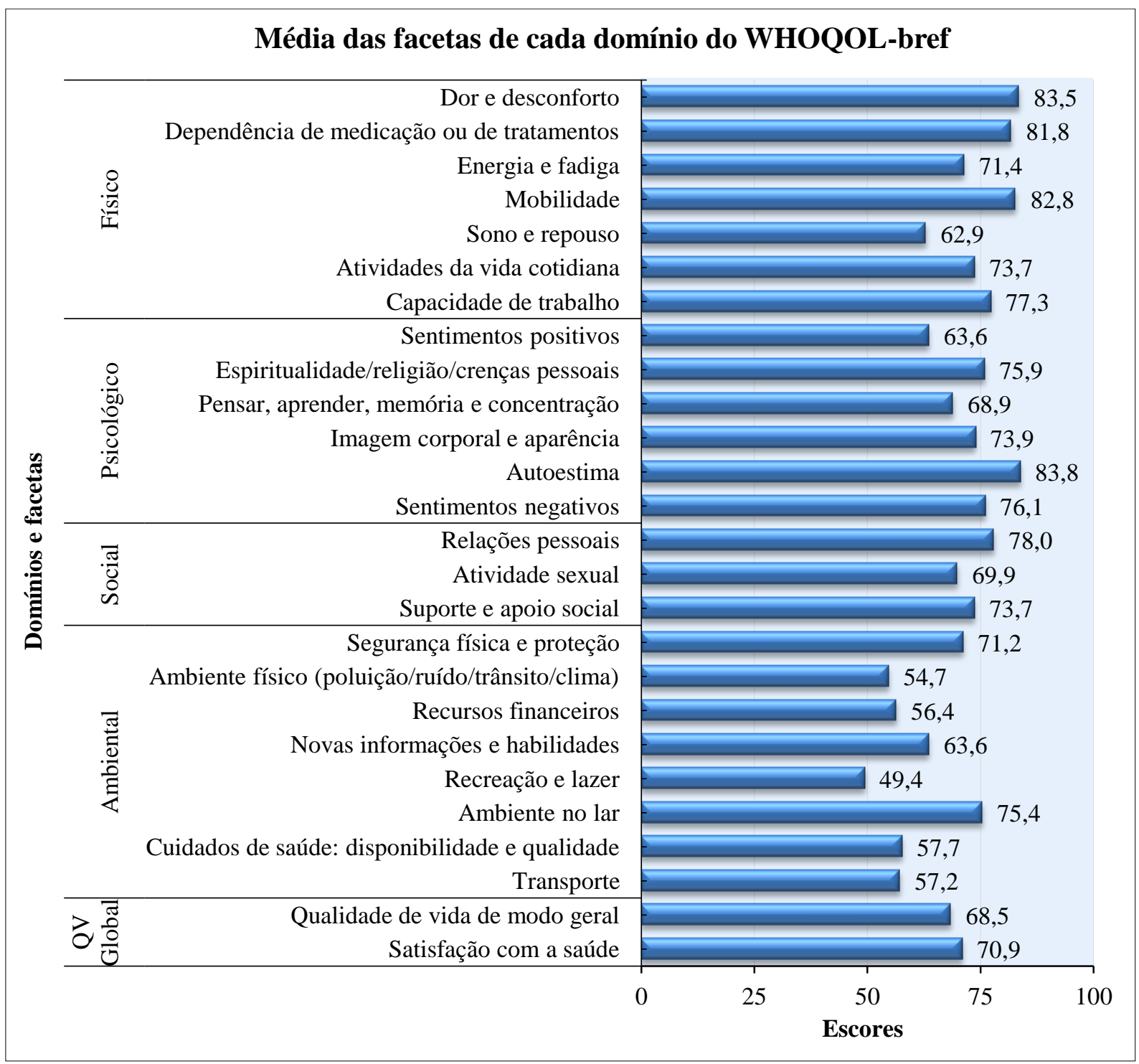

Figura 14: Média das facetas de cada domínio do WHOQOL-bref.

\subsubsection{Avaliação das propriedades psicométricas do instrumento WHOQOL-bref}

A seguir são descritas as propriedades psicométricas básicas do WHOQOL-bref para a amostra estudada. 


\section{$\checkmark$ Confiabilidade}

O instrumento WHOQOL-bref foi avaliado quanto à sua confiabilidade por meio da análise de consistência interna das 26 questões, utilizando-se o Coeficiente Alfa de Cronbach, $\alpha$, e o Índice de Correlação Intraclasses, ICC. O resultado obtido $(\alpha=0,884)$ indica que a consistência interna do instrumento para a amostra estudada foi alta. O resultado do ICC foi considerado estatisticamente significante $(\mathrm{p}<0,001)$ e o valor de $86,0 \%$ pode ser classificado como sendo ótimo, conforme a escala de classificação apresentada anteriormente (item 2.4.7).

\section{$\checkmark$ Validade de critério}

Primeiramente, foi realizada a Correlação de Spearman $(\rho)$ entre os diferentes domínios do WHOQOL-bref em relação à QV global, que pesquisa a percepção do individuo sobre sua QV geral e a satisfação com a sua saúde e as variáveis quantitativas da primeira parte do questionário - idade e tempo de trabalho na instituição. Os resultados foram apresentados em percentual, lembrando que os valores podem ser positivos ou negativos $(-1 \leq \rho \leq 1)$. Para validar as correlações foi utilizado o teste de Correlação.

Na Tabela 6 são apresentados os Coeficientes de Correlação de Spearman ( $\rho$ ) utilizados para medir o grau de relação entre os domínios físico, psicológico, social e ambiental em relação ao domínio QV global; e entre todos os domínios e as variáveis quantitativas: idade e tempo de trabalho na instituição. De acordo com os resultados, não foi apresentada correlação estatisticamente significante $(\mathrm{p}<0,05)$ entre os domínios do WHOQOL-bref e as variáveis, idade e tempo de trabalho, ou seja, estas variáveis não interferiram na QV dos trabalhadores avaliados. Nas correlações interdomínios, verificou-se que todos os domínios correlacionaram significativamente entre si, sendo que as correlações foram predominantemente regulares. O coeficiente de Correlação mais alto foi observado entre o domínio físico e o psicológico, o qual o valor $(\rho=61,2 \%)$ indica que quanto maior o escore físico, maior será o escore psicológico. 
Tabela 7: Coeficientes de Correlação de Spearman ( $\rho$ ) entre os domínios do WHOQOL-bref e as variáveis quantitativas - idade e tempo de trabalho na instituição.

\begin{tabular}{cccccccc}
\hline & & Idade & Tempo de trabalho & Físico & Psicológico & Social & Ambiental \\
\hline Físico & $\rho$ & $-5,9 \%$ & $-11,2 \%$ & & & & \\
\hline \multirow{2}{*}{ Psicológico } & Valor $\mathrm{p}$ & 0,529 & 0,228 & & & & \\
\hline & $\rho$ & $-6,9 \%$ & $-11,3 \%$ & $61,2 \%$ & & & \\
\hline \multirow{2}{*}{ Social } & Valor $\mathrm{p}$ & 0,460 & 0,223 & $\mathbf{0 , 0 0 1}$ & & & \\
\hline & $\rho$ & $-7,5 \%$ & $-9,0 \%$ & $50,6 \%$ & $58,4 \%$ & & \\
\hline Ambiental & Valor p & 0,420 & 0,334 & $\mathbf{0 , 0 0 1}$ & $\mathbf{0 , 0 0 1}$ & & \\
\hline \multirow{2}{*}{ QV Global } & $\rho$ & $-1,0 \%$ & $-5,6 \%$ & $46,1 \%$ & $60,7 \%$ & $42,0 \%$ & \\
& Valor p & 0,918 & 0,545 & $\mathbf{0 , 0 0 1}$ & $\mathbf{0 , 0 0 1}$ & $\mathbf{0 , 0 0 1}$ & \\
\hline & $\rho$ & $-8,5 \%$ & $-8,1 \%$ & $46,3 \%$ & $60,2 \%$ & $50,1 \%$ & $59,5 \%$ \\
\hline & Valor p & 0,363 & 0,388 & $\mathbf{0 , 0 0 1}$ & $\mathbf{0 , 0 0 1}$ & $\mathbf{0 , 0 0 1}$ & $\mathbf{0 , 0 0 1}$ \\
\hline
\end{tabular}

Escala de classificação (r): Muito ruim (0-20), Ruim (20-40), Regular (40-60), Boa (60-80) e Muito boa (80-100). Correlação é significante a um nível de p<0,05 [41, 42].

A validade de critério pretende ainda determinar a adequação de um modelo para a medição do que se pretende medir. Para tanto, procedeu-se a realização de Análise de Regressão Linear ( $\beta$ ), com a qual é possível determinar o peso do modelo dos quatro domínios (variáveis independentes) na variação da percepção da QV global (variável dependente). Os valores de p mostram se os coeficientes foram significativos ou não. Nas duas últimas linhas da tabela é mostrado o $R^{2}$ (R-quadrado) de cada modelo e o valor de $\mathrm{p}$ que avalia a significância deste modelo. Quanto maior for o valor de $R^{2}$, melhor o ajuste do modelo. Lembrando que o $R^{2}$ pode variar de $0 \%$ a $100 \%$ [41, 42].

Na Tabela 7, é apresentada a Análise de Regressão Linear ( $\beta$ ) e o Coeficiente de Correlação de Spearman ( $\rho$ ) entre os diferentes domínios do WHOQOL-bref e a QV global. Observou-se que todos os domínios apresentaram correlações estatisticamente significantes de regular a boa $(\rho=46,3 \%$ a $\rho=60,2 \% ; p<0,001)$ com a QV global. Nota-se que o modelo gerado explicou $11,9 \%$ da variância total $\left(R^{2}\right)$ e que este modelo não foi estatisticamente significante $(\mathrm{p}=0,234)$. 
Tabela 8: Regressão Linear $(\beta)$ e Coeficiente de Correlação de Spearman $(\rho)$ entre os diferentes domínios do WHOQOL-bref em relação à QV global.

\begin{tabular}{ccccc}
\hline Domínios & \multicolumn{4}{c}{ QV Global (variável dependente) } \\
\cline { 2 - 5 } (Variáveis independentes) & $\boldsymbol{\beta}$ & Valor de $\mathbf{p}$ & $\boldsymbol{\rho}$ & Valor de p \\
\hline Físico & 0,15 & 0,284 & $46,3 \%$ & $<\mathbf{0 , 0 0 1}$ \\
\hline Psicológico & 0,48 & $\mathbf{0 , 0 0 3}$ & $60,2 \%$ & $<\mathbf{0 , 0 0 1}$ \\
Social & 0,07 & 0,517 & $50,1 \%$ & $<\mathbf{0 , 0 0 1}$ \\
\hline Ambiental & 0,31 & $\mathbf{0 , 0 1 0}$ & $59,5 \%$ & $<\mathbf{0 , 0 0 1}$ \\
$\boldsymbol{R}^{2}$ & \multicolumn{3}{c}{$11,9 \%$} & \\
\hline P-valor & \multicolumn{3}{c}{0,234} \\
\hline
\end{tabular}

Escala de classificação (r): Muito ruim (0-20), Ruim (20-40), Regular (40-60), Boa (60-80) e Muito boa (80-100). Correlação é significante a um nível de p<0,05 [41, 42].

Na Tabela 8 é apresentado o modelo de Regressão Linear $(\beta)$ entre os diferentes domínios do WHOQOL-bref e as variáveis sociodemográficas e relacionadas ao trabalho.

Tabela 9: Regressão Linear $(\beta)$ entre os diferentes domínios do WHOQOL-bref e as variáveis sociodemográficas e relacionadas ao trabalho.

\begin{tabular}{|c|c|c|c|c|c|c|c|c|c|c|}
\hline \multirow{3}{*}{ Variáveis (independentes) } & \multicolumn{10}{|c|}{ Domínios (variáveis dependentes) } \\
\hline & \multicolumn{2}{|c|}{ Físico } & \multicolumn{2}{|c|}{ Psicológico } & \multicolumn{2}{|c|}{ Social } & \multicolumn{2}{|c|}{ Ambiental } & \multicolumn{2}{|c|}{ QV Global } \\
\hline & $\beta$ & $\mathbf{p}$ & $\beta$ & $\mathbf{p}$ & $\beta$ & $\mathbf{p}$ & $\boldsymbol{\beta}$ & $\mathbf{p}$ & $\boldsymbol{\beta}$ & $\mathbf{p}$ \\
\hline Gênero & 0,48 & 0,868 & $-3,08$ & 0,363 & 2,89 & 0,527 & $-5,54$ & 0,130 & $-2,86$ & 0,536 \\
\hline Idade & 0,08 & 0,675 & 0,11 & 0,602 & 0,31 & 0,282 & 0,04 & 0,867 & $-0,03$ & 0,907 \\
\hline Estado Civil & 2,28 & 0,170 & 2,60 & 0,183 & 4,17 & 0,115 & 1,65 & 0,432 & $-0,13$ & 0,961 \\
\hline Nível educacional & 1,27 & 0,644 & 3,25 & 0,313 & 4,82 & 0,270 & 5,32 & 0,128 & 3,43 & 0,441 \\
\hline Categoria profissional & 1,51 & 0,079 & 2,97 & 0,004 & 2,48 & 0,069 & 2,40 & 0,028 & 2,42 & 0,080 \\
\hline Setor de trabalho & 0,95 & 0,357 & 2,41 & 0,049 & 0,25 & 0,879 & 0,99 & 0,450 & 2,46 & 0,138 \\
\hline Tempo de trabalho c/ RI & $-0,51$ & 0,755 & $-1,05$ & 0,586 & $-2,81$ & 0,285 & $-0,90$ & 0,668 & $-0,83$ & 0,754 \\
\hline Satisfação c/ o trabalho c/ RI & 0,45 & 0,708 & 1,47 & 0,299 & 0,34 & 0,860 & 2,33 & 0,129 & 2,87 & 0,139 \\
\hline Trabalho em turnos & $-6,56$ & 0,048 & $-8,37$ & $\mathbf{0 , 0 3 2}$ & $-2,61$ & 0,617 & $-3,79$ & 0,362 & $-10,18$ & 0,055 \\
\hline Possui outro emprego & 2,73 & 0,310 & 1,17 & 0,711 & $-2,46$ & 0,565 & 1,36 & 0,688 & $-2,19$ & 0,615 \\
\hline$R^{2}$ & \multicolumn{2}{|c|}{$11,9 \%$} & \multicolumn{2}{|c|}{$17,2 \%$} & \multicolumn{2}{|c|}{$8,4 \%$} & \multicolumn{2}{|c|}{$10,7 \%$} & \multicolumn{2}{|c|}{$11,3 \%$} \\
\hline Valor de p & \multicolumn{2}{|c|}{0,234} & \multicolumn{2}{|c|}{0,040} & \multicolumn{2}{|c|}{0,546} & \multicolumn{2}{|c|}{0,326} & \multicolumn{2}{|c|}{0,288} \\
\hline
\end{tabular}

p: Valor de p; $\boldsymbol{\beta}$ : Coeficiente de Regressão Linear; RI: radiação ionizante.

Os resultados da Tabela 8 mostraram que somente o modelo estatístico gerado para o domínio psicológico foi significante $(\mathrm{p}=0,040)$ e, neste modelo, pode-se avaliar que as 
variáveis: setor de trabalho $(\mathrm{p}=0,049)$, categoria profissional $(\mathrm{p}=0,004)$ e trabalho em turnos $(\mathrm{p}=0,032)$ contribuíram para o resultado deste domínio. Os modelos gerados para os demais domínios não apresentaram significância estatística, contudo, verificou-se na análise que o trabalho em turnos influenciou significativamente $(\mathrm{p}=0,048)$ no domínio físico e a categoria profissional influenciou no domínio ambiental $(\mathrm{p}=0,028)$.

\subsubsection{Comparação das variáveis qualitativas da primeira parte do questionário (ficha de informação do participante) com os domínios do WHOQOL-bref}

Todas as variáveis qualitativas foram comparadas com os domínios do WHOQOL-bref, para verificar se existe influência destas variáveis na QV dos profissionais do serviço de radiodiagnóstico analisado. Foram utilizados os testes não paramétricos de Mann Whitney (para variáveis com duas categorias) e de Kruskal-Wallis (para variáveis divididas em três ou mais categorias). A análise descritiva completa dos domínios será apresentada na forma de tabelas com seus respectivos valores de $\mathrm{p}$ (nível de significância adotado $\mathrm{p}<0,05$ ). Os valores próximos do limite de aceitação (até 5 pontos percentuais acima do limite) significa que tendem a ser significantes. Abaixo das tabelas serão ilustradas na forma de Figuras somente as médias dos escores de cada domínio, como pode ser visualizado a seguir.

Variáveis sociodemográficas: gênero, estado civil e nível educacional.

Na Tabela 9 e na Figura 15, é apresentada a comparação do WHOQOL-bref com o gênero, onde observou-se maiores escores de QV para o gênero masculino nos domínios físico, psicológico e social, o que não ocorreu nos domínios ambiental e QV global. Nesta análise, verificou-se que o domínio social apresentou diferença estatisticamente significante $(\mathrm{p}=0,007)$ para o gênero masculino e feminino. $\mathrm{O}$ domínio físico apresentou uma tendência a ser significante $(\mathrm{p}=0,060)$ na comparação com o gênero. 
Tabela 10: Comparação do WHOQOL-bref com o gênero.

\begin{tabular}{ccccccccccc}
\hline & \multicolumn{2}{c}{ Físico } & \multicolumn{2}{c}{ Psicológico } & \multicolumn{2}{c}{ Social } & \multicolumn{2}{c}{ Ambiental } & \multicolumn{2}{c}{ QV Global } \\
\cline { 2 - 12 } & $\mathbf{F}$ & $\mathbf{M}$ & $\mathbf{F}$ & $\mathbf{M}$ & $\mathbf{F}$ & $\mathbf{M}$ & $\mathbf{F}$ & $\mathbf{M}$ & $\mathbf{F}$ & $\mathbf{M}$ \\
\hline Média & $\mathbf{7 4 , 2}$ & $\mathbf{7 8 , 2}$ & $\mathbf{7 2 , 6}$ & $\mathbf{7 4 , 6}$ & $\mathbf{7 0 , 4}$ & $\mathbf{7 7 , 1}$ & $\mathbf{6 1 , 3}$ & $\mathbf{6 0 , 0}$ & $\mathbf{6 9 , 7}$ & $\mathbf{6 9 , 4}$ \\
\hline Mediana & $\mathbf{7 5 , 0}$ & 80,3 & 75,0 & 77,1 & 75,0 & 75,0 & 61,6 & 59,4 & 75,0 & 75,0 \\
\hline DP & 12,0 & 13,1 & 15,1 & 14,7 & 17,9 & 20,2 & 16,6 & 14,7 & 19,5 & 20,1 \\
\hline $\mathbf{Q 1}$ & 67,9 & 70,5 & 62,5 & 70,8 & 58,3 & 75,0 & 50,8 & 53,1 & 62,5 & 62,5 \\
\hline $\mathbf{Q 3}$ & 84,8 & 89,3 & 83,3 & 83,3 & 81,2 & 91,7 & 68,8 & 68,8 & 75,0 & 75,0 \\
\hline $\mathbf{N}$ & 58 & 60 & 58 & 60 & 58 & 60 & 58 & 60 & 57 & 60 \\
\hline IC & 3,1 & 3,3 & 3,9 & 3,7 & 4,6 & 5,1 & 4,3 & 3,7 & 5,1 & 5,1 \\
\hline Valor de p & \multicolumn{2}{c}{0,060} & \multicolumn{2}{c}{0,406} & $\mathbf{0 , 0 0 7}$ & 0,710 & 0,776 \\
\hline
\end{tabular}

F: feminino; M: masculino; DP: desvio padrão; Q1 e Q3: primeiro e terceiro quartil; N: número total da amostra; IC: intervalo de confiança.

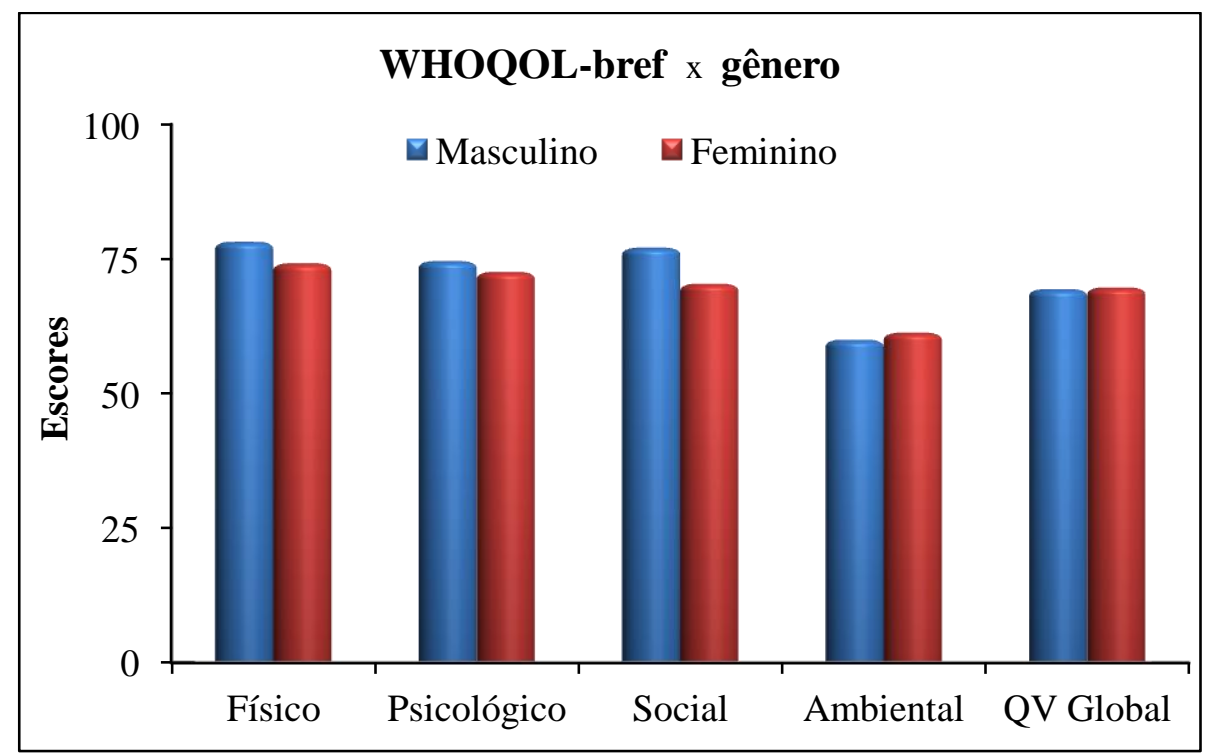

Figura 15: Comparação do WHOQOL-bref com o gênero.

Na Tabela 10 e na Figura 16 é apresentada a comparação do WHOQOL-bref com o estado civil. Foram observados maiores escores de QV para os casados nos domínios físico, psicológico e social, enquanto que nos domínios ambiental e QV global os viúvos obtiveram os maiores escores. Nenhum destes resultados influenciou significativamente $(p<0,05)$ para a QV dos indivíduos analisados nos domínios do WHOQOL-bref, exceto para o domínio social, cujo valor $(\mathrm{p}=0,099)$ tende a ser significante. 
Tabela 11: Comparação do WHOQOL-bref com estado civil.

\begin{tabular}{|c|c|c|c|c|c|c|c|c|c|}
\hline & & Média & Mediana & DP & Q1 & $\mathbf{Q 3}$ & $\mathbf{N}$ & IC & Valor de p \\
\hline \multirow{4}{*}{ Físico } & Casado & 77,2 & 78,6 & 10,7 & 71,4 & 85,7 & 59 & 2,7 & \multirow{4}{*}{0,802} \\
\hline & Divorciado & 75,4 & 75,0 & 17,5 & 61,6 & 88,4 & 10 & 10,9 & \\
\hline & Solteiro & 76,0 & 75,0 & 12,8 & 67,9 & 85,7 & 43 & 3,8 & \\
\hline & Viúvo & 67,1 & 78,6 & 22,5 & 57,1 & 82,1 & 5 & 19,7 & \\
\hline \multirow{4}{*}{ Psicológico } & Casado & 74,9 & 79,2 & 15,8 & 66,7 & 87,5 & 59 & 4,0 & \multirow{4}{*}{0,219} \\
\hline & Divorciado & 64,5 & 66,7 & 18,7 & 57,3 & 78,1 & 10 & 11,6 & \\
\hline & Solteiro & 73,9 & 75,0 & 12,7 & 68,8 & 79,2 & 43 & 3,8 & \\
\hline & Viúvo & 73,3 & 75,0 & 11,3 & 66,7 & 79,2 & 5 & 9,9 & \\
\hline \multirow{4}{*}{ Social } & Casado & 75,0 & 75,0 & 20,5 & 66,7 & 91,7 & 59 & 5,2 & \multirow{4}{*}{0,099} \\
\hline & Divorciado & 67,5 & 75,0 & 23,4 & 58,3 & 75,0 & 10 & 14,5 & \\
\hline & Solteiro & 75,4 & 75,0 & 16,7 & 66,7 & 83,3 & 43 & 5,0 & \\
\hline & Viúvo & 58,3 & 66,7 & 16,7 & 50,0 & 66,7 & 5 & 14,6 & \\
\hline \multirow{4}{*}{ Ambiental } & Casado & 60,8 & 62,5 & 13,9 & 53,1 & 68,8 & 59 & 3,5 & \multirow{4}{*}{0,665} \\
\hline & Divorciado & 50,9 & 57,8 & 26,4 & 31,3 & 67,2 & 10 & 16,3 & \\
\hline & Solteiro & 62,3 & 59,4 & 15,1 & 51,6 & 68,8 & 43 & 4,5 & \\
\hline & Viúvo & 65,3 & 65,6 & 10,3 & 60,7 & 65,6 & 5 & 9,0 & \\
\hline \multirow{4}{*}{ QV Global } & Casado & 68,4 & 75,0 & 20,3 & 62,5 & 75,0 & 59 & 5,2 & \multirow{4}{*}{0,332} \\
\hline & Divorciado & 62,5 & 62,5 & 21,2 & 53,1 & 75,0 & 10 & 13,2 & \\
\hline & Solteiro & 72,0 & 75,0 & 19,1 & 62,5 & 87,5 & 42 & 5,8 & \\
\hline & Viúvo & 75,0 & 75,0 & 17,7 & 75,0 & 75,0 & 5 & 15,5 & \\
\hline
\end{tabular}

DP: desvio padrão; Q1, Q3: primeiro e terceiro quartil; N: número total da amostra; IC: intervalo de confiança.

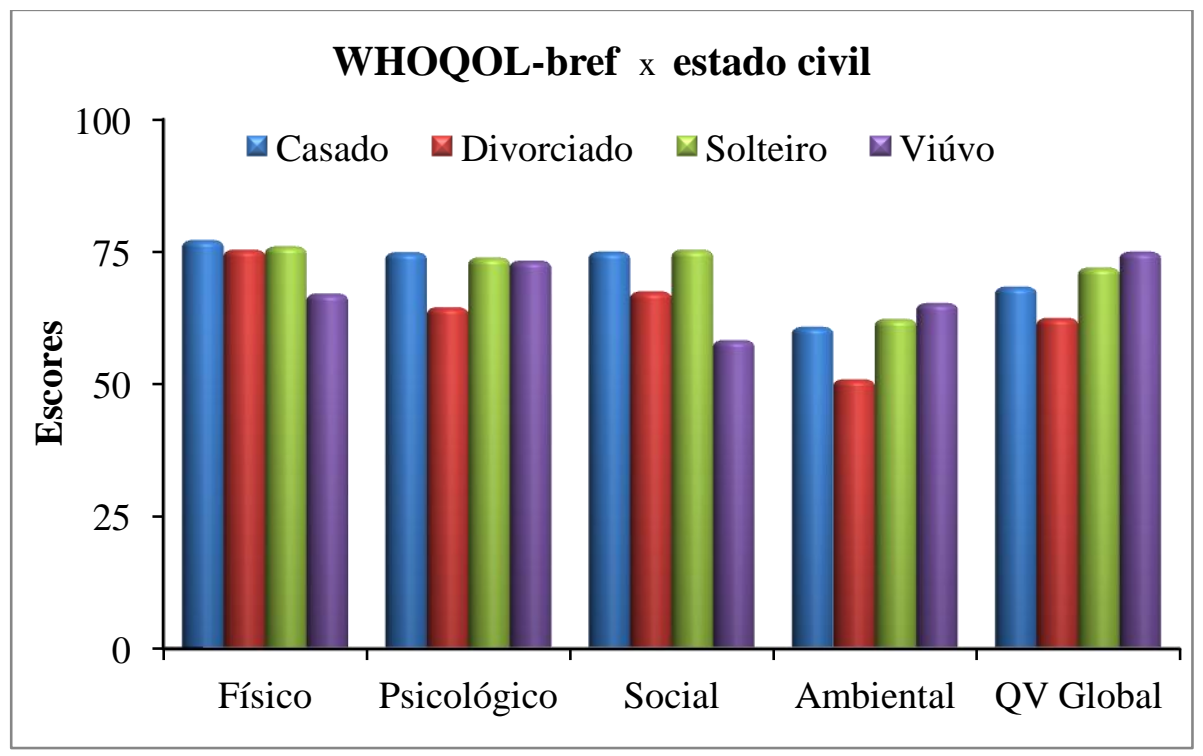

Figura 16: Comparação do WHOQOL-bref com o estado civil.

Na Tabela 11 e na Figura 17 é apresentada a comparação do WHOQOL-bref com o nível educacional. Os valores para graduação e ensino médio foram similares em todos os 
domínios do WHOQOL-bref, não apresentando significância estatística $(\mathrm{p}<0,05)$.

Tabela 12: Comparação do WHOQOL-bref com o nível educacional.

\begin{tabular}{ccccccccccc}
\hline & \multicolumn{2}{c}{ Físico } & \multicolumn{2}{c}{ Psicológico } & \multicolumn{2}{c}{ Social } & \multicolumn{2}{c}{ Ambiental } & \multicolumn{2}{c}{ QV Global } \\
\cline { 2 - 14 } & G & EM & G & EM & G & EM & G & EM & G & EM \\
\hline Média & 76,4 & 76,0 & 73,8 & 74,1 & 74,9 & 72,8 & 61,9 & 58,9 & 69,7 & 69,8 \\
\hline Mediana & 78,6 & 78,6 & 75,0 & 77,1 & 75,0 & 75,0 & 62,5 & 59,4 & 75,0 & 75,0 \\
\hline DP & 12,8 & 13,2 & 16,2 & 12,9 & 21,3 & 16,4 & 15,9 & 15,8 & 22,0 & 16,3 \\
\hline Q1 & 67,9 & 68,8 & 66,7 & 67,7 & 66,7 & 66,7 & 53,1 & 53,1 & 62,5 & 62,5 \\
\hline Q3 & 85,7 & 85,7 & 87,5 & 82,3 & 91,7 & 83,3 & 71,9 & 68,8 & 75,0 & 75,0 \\
\hline N & 71 & 42 & 71 & 42 & 71 & 42 & 71 & 42 & 71 & 41 \\
\hline IC & 3,0 & 4,0 & 3,8 & 3,9 & 5,0 & 4,9 & 3,7 & 4,8 & 5,1 & 5,0 \\
\hline Valor de p & \multicolumn{2}{c}{0,981} & \multicolumn{2}{c}{0,804} & \multicolumn{2}{c}{0,247} & 0,530 & 0,603 \\
\hline
\end{tabular}

G: graduação; EM: ensino médio; DP: desvio padrão; Q1 e Q3: primeiro e terceiro quartil; N: número total da amostra; IC: intervalo de confiança.

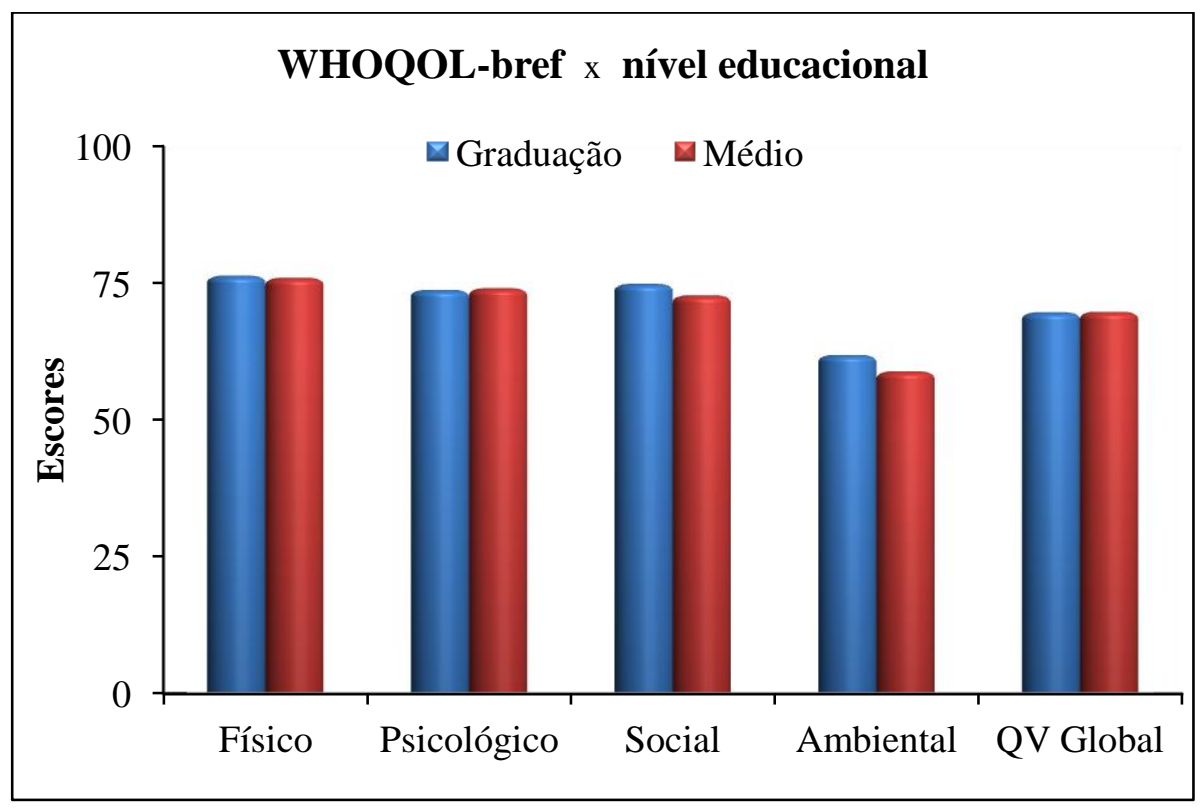

Figura 17: Comparação do WHOQOL-bref com o nível educacional.

$\checkmark$ Variáveis relacionadas às condições de trabalho: tempo de trabalho na instituição, tempo de trabalho com radiação ionizante, categoria profissional, setor de trabalho, satisfação com o trabalho em presença da radiação ionizante, trabalho em turnos, existência ou não de outro emprego. 
Na Tabela 12 e na Figura 18 é apresentada a comparação do WHOQOL-bref com a categoria profissional. Pode ser observado que a categoria "médico" obteve maiores escores de QV nos domínios psicológico (76,8), social $(79,0)$ e QV global $(76,2)$. A categoria "tecnólogo/técnico de radiologia" apresentou maior escore na comparação com o domínio físico e "enfermeiro" com o domínio ambiental $(68,9)$. Não foi apresentada diferença significante $(\mathrm{p}<0,05)$ entre as categorias e os domínios WHOQOL-bref. Somente o domínio ambiental $(\mathrm{p}=0,069)$ apresentou um nível de significância próximo do limite estabelecido.

Tabela 13: Comparação do WHOQOL-bref com a categoria profissional.

\begin{tabular}{|c|c|c|c|c|c|c|c|c|c|}
\hline & & Média & MD & DP & Q1 & Q3 & $\mathbf{N}$ & IC & Valor de p \\
\hline \multirow{6}{*}{ Físico } & Médico & 76,9 & 82,1 & 13,6 & 67,9 & 89,3 & 21 & 5,8 & \multirow{6}{*}{0,313} \\
\hline & Tecnólogo/técnico de Radiologia & 78,0 & 78,6 & 13,1 & 71,4 & 85,7 & 59 & 3,4 & \\
\hline & Enfermeiro & 73,7 & 71,4 & 10,1 & 67,9 & 80,3 & 11 & 6,0 & \\
\hline & Técnico de enfermagem & 70,1 & 73,2 & 11,9 & 62,5 & 79,5 & 8 & 8,3 & \\
\hline & Auxiliar de enfermagem & 75,0 & 75,0 & 12,5 & 66,1 & 80,3 & 11 & 7,4 & \\
\hline & Outros & 72,8 & 73,2 & 10,9 & 67,0 & 80,3 & 8 & 7,6 & \\
\hline \multirow{6}{*}{ Psicológico } & Médico & 76,8 & 79,2 & 11,6 & 70,8 & 83,3 & 21 & 5,0 & \multirow{6}{*}{0,206} \\
\hline & Tecnólogo/técnico Radiologia & 75,8 & 79,2 & 13,3 & 68,8 & 87,5 & 59 & 3,4 & \\
\hline & Enfermeiro & 72,7 & 70,8 & 12,0 & 62,5 & 85,4 & 11 & 7,1 & \\
\hline & Técnico de enfermagem & 64,0 & 68,8 & 15,7 & 55,0 & 76,0 & 8 & 10,9 & \\
\hline & Auxiliar de enfermagem & 68,6 & 70,8 & 18,0 & 62,5 & 81,3 & 11 & 10,7 & \\
\hline & Outros & 66,7 & 68,8 & 25,4 & 57,3 & 85,4 & 8 & 17,6 & \\
\hline \multirow{6}{*}{ Social } & Médico & 79,0 & 75,0 & 15,3 & 75,0 & 91,7 & 21 & 6,5 & \multirow{6}{*}{0,277} \\
\hline & Tecnólogo/técnico Radiologia & 75,8 & 75,0 & 18,6 & 75,0 & 91,7 & 59 & 4,7 & \\
\hline & Enfermeiro & 71,2 & 75,0 & 18,4 & 62,5 & 83,3 & 11 & 10,9 & \\
\hline & Técnico de enfermagem & 68,8 & 70,8 & 10,7 & 64,6 & 75,0 & 8 & 7,4 & \\
\hline & Auxiliar de enfermagem & 65,9 & 66,7 & 23,4 & 58,3 & 79,2 & 11 & 13,8 & \\
\hline & Outros & 64,6 & 70,8 & 31,7 & 54,2 & 85,4 & 8 & 22,0 & \\
\hline \multirow{6}{*}{ Ambiental } & Médico & 64,1 & 62,5 & 16,8 & 53,1 & 78,1 & 21 & 7,2 & \multirow{6}{*}{0,069} \\
\hline & Tecnólogo/técnico Radiologia & 61,0 & 62,5 & 12,8 & 54,7 & 68,8 & 59 & 3,3 & \\
\hline & Enfermeiro & 68,9 & 68,8 & 15,0 & 57,8 & 79,7 & 11 & 8,9 & \\
\hline & Técnico de enfermagem & 53,5 & 56,3 & 22,4 & 46,9 & 66,4 & 8 & 15,5 & \\
\hline & Auxiliar de enfermagem & 49,1 & 50,0 & 14,2 & 40,6 & 54,7 & 11 & 8,4 & \\
\hline & Outros & 59,8 & 64,1 & 20,2 & 53,9 & 68,8 & 8 & 14,0 & \\
\hline \multirow{6}{*}{ QV Global } & Médico & 76,2 & 75,0 & 17,2 & 75,0 & 87,5 & 21 & 7,4 & \multirow{6}{*}{0,146} \\
\hline & Tecnólogo/técnico Radiologia & 69,7 & 75,0 & 18,2 & 62,5 & 75,0 & 59 & 4,6 & \\
\hline & Enfermeiro & 73,9 & 75,0 & 14,2 & 62,5 & 81,3 & 11 & 8,4 & \\
\hline & Técnico de enfermagem & 64,1 & 68,8 & 23,6 & 56,3 & 75,0 & 8 & 16,3 & \\
\hline & Auxiliar de enfermagem & 61,3 & 62,5 & 17,1 & 53,1 & 71,9 & 10 & 10,6 & \\
\hline & Outros & 60,9 & 75,0 & 35,6 & 50,0 & 78,1 & 8 & 24,7 & \\
\hline
\end{tabular}

MD: Mediana; DP: desvio padrão; Q1 e Q3: primeiro e terceiro quartil; N: número total da amostra; IC: intervalo de confiança. 


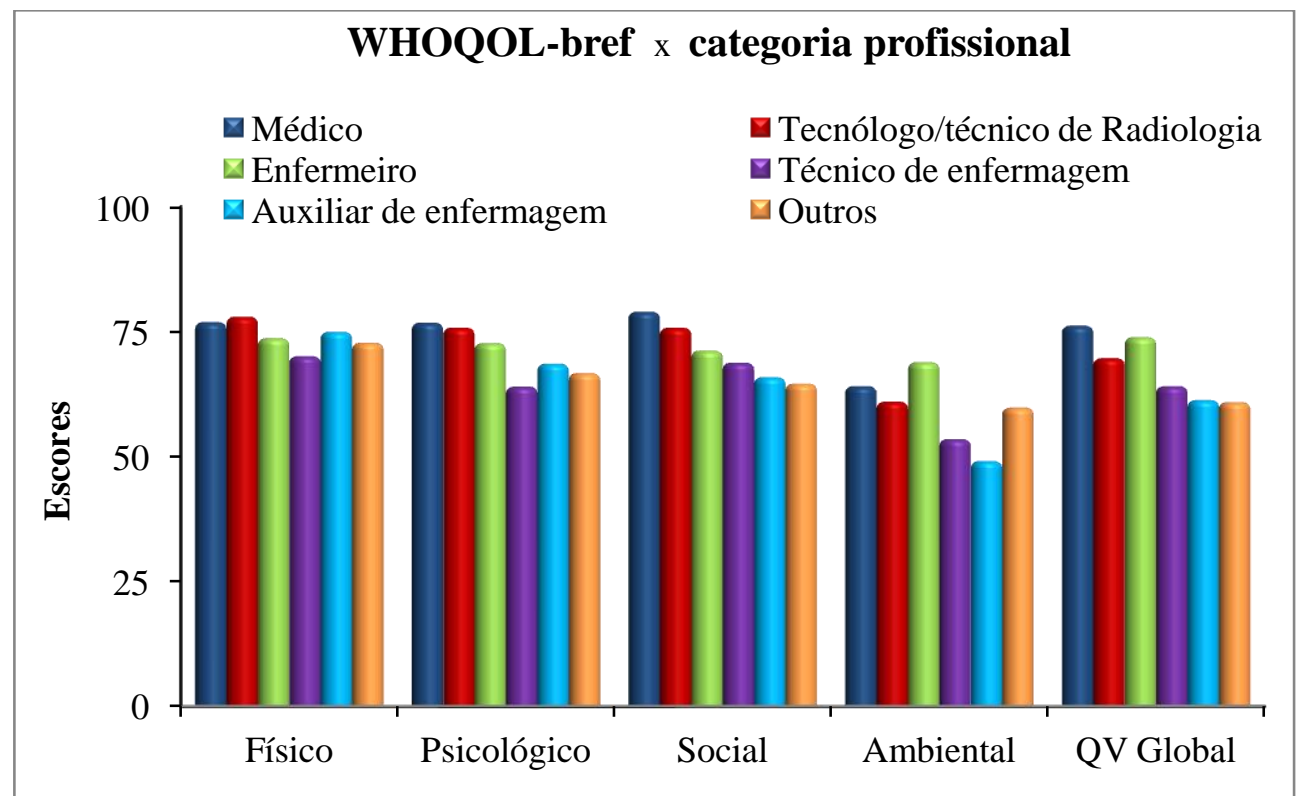

Figura 18: Comparação do WHOQOL-bref com a categoria profissional.

Na Tabela 13 e na Figura 19 é apresentada a comparação do WHOQOL-bref com o setor de trabalho. Nesta análise, o grupo de profissionais do setor de medicina nuclear apresentou escores de QV mais baixos em todos os domínios, não apresentando significância estatística $(\mathrm{p}<0,05)$ para nenhum deles. 
Tabela 14: Comparação do WHOQOL-bref com o setor de trabalho.

\begin{tabular}{|c|c|c|c|c|c|c|c|c|c|}
\hline & & Média & Mediana & DP & Q1 & Q3 & $\mathbf{N}$ & IC & Valor de $p$ \\
\hline \multirow{7}{*}{ Físico } & Hemodinâmica & 77,2 & 78,6 & 10,3 & 71,4 & 83,9 & 43 & 3,1 & \multirow{7}{*}{0,840} \\
\hline & Mamografia & 78,6 & 71,4 & 15,6 & 69,7 & 83,9 & 3 & 17,6 & \\
\hline & Medicina nuclear & 72,9 & 71,4 & 12,3 & 66,1 & 81,2 & 10 & 7,6 & \\
\hline & Radioproteção & 76,5 & 85,7 & 16,5 & 73,2 & 85,7 & 7 & 12,2 & \\
\hline & Raios X (Ambulatório) & 77,7 & 75,0 & 14,0 & 69,7 & 90,2 & 8 & 9,7 & \\
\hline & Raios X (Leito) & 73,8 & 75,0 & 14,5 & 64,3 & 85,7 & 30 & 5,2 & \\
\hline & Tomografia & 78,8 & 78,6 & 13,4 & 67,9 & 89,3 & 17 & 6,4 & \\
\hline \multirow{7}{*}{ Psicológico } & Hemodinâmica & 77,1 & 79,2 & 10,8 & 70,8 & 83,3 & 43 & 3,2 & \multirow{7}{*}{0,106} \\
\hline & Mamografia & 72,2 & 66,7 & 13,4 & 64,6 & 77,1 & 3 & 15,2 & \\
\hline & Medicina nuclear & 61,6 & 68,8 & 19,9 & 49,4 & 74,0 & 10 & 12,3 & \\
\hline & Radioproteção & 74,4 & 87,5 & 26,2 & 68,8 & 89,6 & 7 & 19,4 & \\
\hline & Raios X (Ambulatório) & 79,7 & 79,2 & 9,3 & 78,1 & 82,3 & 8 & 6,4 & \\
\hline & Raios X (Leito) & 70,8 & 72,9 & 14,2 & 66,7 & 79,2 & 30 & 5,1 & \\
\hline & Tomografia & 73,8 & 75,0 & 15,7 & 66,7 & 87,5 & 17 & 7,5 & \\
\hline \multirow{7}{*}{ Social } & Hemodinâmica & 74,2 & 75,0 & 13,3 & 66,7 & 79,2 & 43 & 4,0 & \multirow{7}{*}{0,122} \\
\hline & Mamografia & 77,8 & 75,0 & 4,8 & 75,0 & 79,2 & 3 & 5,4 & \\
\hline & Medicina nuclear & 60,0 & 66,7 & 27,7 & 50,0 & 72,9 & 10 & 17,2 & \\
\hline & Radioproteção & 72,6 & 83,3 & 33,2 & 75,0 & 87,5 & 7 & 24,6 & \\
\hline & Raios X (Ambulatório) & 82,3 & 75,0 & 12,9 & 75,0 & 93,8 & 8 & 9,0 & \\
\hline & Raios X (Leito) & 70,6 & 75,0 & 22,3 & 52,1 & 89,6 & 30 & 8,0 & \\
\hline & Tomografia & 82,4 & 83,3 & 13,8 & 75,0 & 91,7 & 17 & 6,6 & \\
\hline \multirow{7}{*}{ Ambiental } & Hemodinâmica & 61,9 & 59,4 & 16,0 & 53,1 & 68,8 & 43 & 4,8 & \multirow{7}{*}{0,314} \\
\hline & Mamografia & 56,3 & 56,3 & 3,1 & 54,7 & 57,8 & 3 & 3,5 & \\
\hline & Medicina nuclear & 52,5 & 59,4 & 22,9 & 41,4 & 68,0 & 10 & 14,2 & \\
\hline & Radioproteção & 64,7 & 65,6 & 18,5 & 59,4 & 73,4 & 7 & 13,7 & \\
\hline & Raios X (Ambulatório) & 68,4 & 68,8 & 12,4 & 63,3 & 71,1 & 8 & 8,6 & \\
\hline & Raios X (Leito) & 56,9 & 57,8 & 13,5 & 47,7 & 65,6 & 30 & 4,8 & \\
\hline & Tomografia & 64,0 & 65,6 & 13,0 & 53,1 & 71,9 & 17 & 6,2 & \\
\hline \multirow{7}{*}{ QV Global } & Hemodinâmica & 70,9 & 75,0 & 18,0 & 62,5 & 75,0 & 43 & 5,4 & \multirow{7}{*}{0,500} \\
\hline & Mamografia & 58,3 & 62,5 & 19,1 & 50,0 & 68,8 & 3 & 21,6 & \\
\hline & Medicina nuclear & 57,5 & 68,8 & 30,7 & 43,8 & 75,0 & 10 & 19,0 & \\
\hline & Radioproteção & 73,2 & 75,0 & 23,3 & 75,0 & 81,3 & 7 & 17,3 & \\
\hline & Raios X (Ambulatório) & 78,1 & 75,0 & 12,9 & 71,9 & 87,5 & 8 & 9,0 & \\
\hline & Raios X (Leito) & 69,0 & 75,0 & 17,6 & 62,5 & 75,0 & 29 & 6,4 & \\
\hline & Tomografia & 70,6 & 75,0 & 20,2 & 50,0 & 87,5 & 17 & 9,6 & \\
\hline
\end{tabular}

DP: desvio padrão; Q1 e Q3: primeiro e terceiro quartil; N: número total da amostra; IC: intervalo de confiança. 


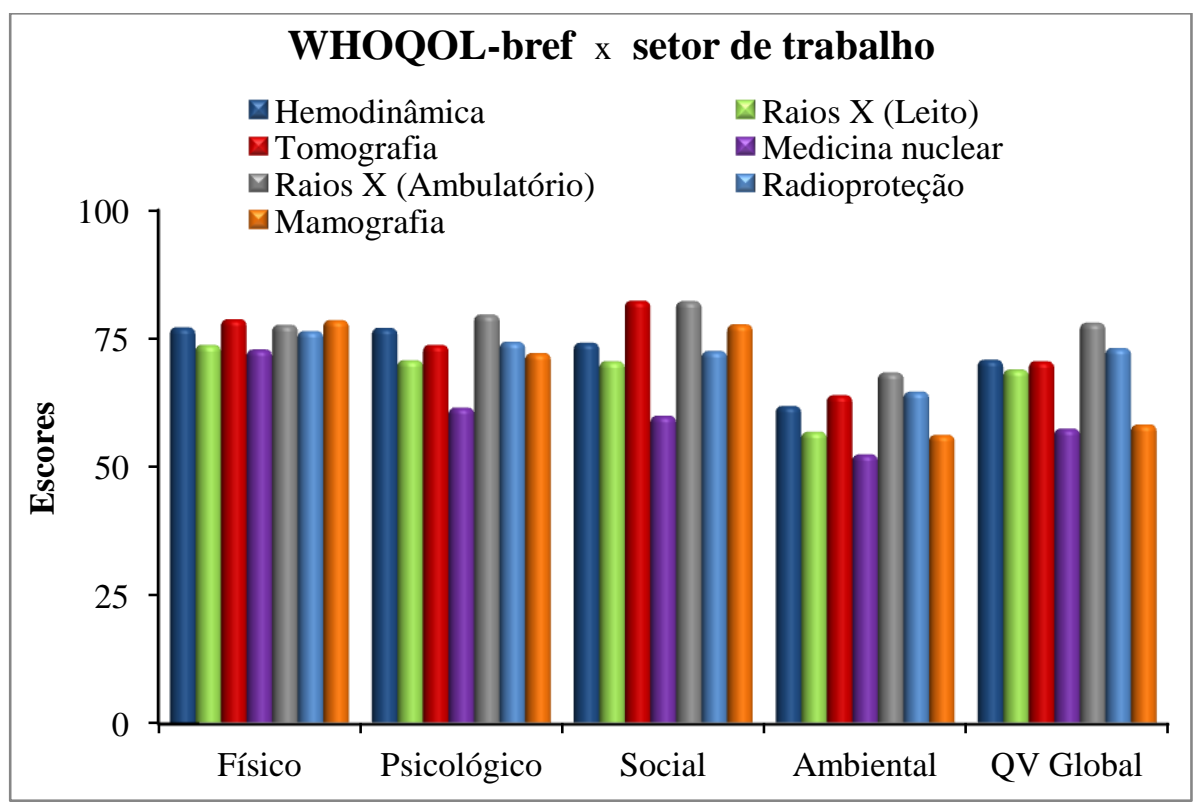

Figura 19: Comparação do WHOQOL-bref com o setor de trabalho.

Na Tabela 14 e na Figura 20 é apresentada a comparação do WHOQOL-bref e o tempo de trabalho com radiação ionizante. A análise mostrou que quanto menor o tempo de trabalho, melhor foi o escore de QV em todos os domínios do WHOQOL-bref. Observou-se ainda que o grupo que tem entre 6-15 anos de trabalho apresentou um escore sempre menor do que os outros grupos, com exceção do domínio ambiental. O domínio psicológico apresentou diferença estatisticamente significante $(\mathrm{p}=0,017)$ para esta variável. Os domínios social $(\mathrm{p}=0,059)$ e ambiental $(\mathrm{p}=0,089)$ mostram uma tendência a ser significantes.

Para determinar quais os níveis de resposta que contribuíram significativamente para esta diferença no domínio psicológico, foram comparados todos os pares de respostas, utilizando-se o teste de Mann-Whitney, conforme é apresentado na Tabela 15. 
Tabela 15: Comparação do WHOQOL-bref com o tempo de trabalho (anos) com radiação ionizante.

\begin{tabular}{|c|c|c|c|c|c|c|c|c|c|}
\hline & & Média & Mediana & DP & Q1 & Q3 & $\mathbf{N}$ & IC & Valor de $p$ \\
\hline \multirow{5}{*}{ Físico } & $<1$ ano & 78,2 & 82,1 & 12,6 & 75,0 & 89,3 & 9 & 8,2 & \multirow{5}{*}{0,442} \\
\hline & $1-5$ anos & 77,5 & 78,6 & 12,7 & 69,7 & 87,5 & 23 & 5,2 & \\
\hline & $6-15$ anos & 73,4 & 75,0 & 13,9 & 67,9 & 83,9 & 39 & 4,4 & \\
\hline & $16-25$ anos & 78,8 & 82,1 & 11,6 & 71,4 & 85,7 & 34 & 3,9 & \\
\hline & $>25$ anos & 74,2 & 75,0 & 11,2 & 71,4 & 82,1 & 13 & 6,1 & \\
\hline \multirow{5}{*}{ Psicológico } & $<1$ ano & 79,6 & 83,3 & 12,8 & 79,2 & 87,5 & 9 & 8,3 & \multirow{5}{*}{0,017} \\
\hline & $1-5$ anos & 73,6 & 75,0 & 15,7 & 66,7 & 83,3 & 23 & 6,4 & \\
\hline & $6-15$ anos & 68,2 & 70,8 & 17,0 & 64,6 & 79,2 & 39 & 5,3 & \\
\hline & $16-25$ anos & 78,5 & 79,2 & 12,0 & 71,9 & 87,5 & 34 & 4,0 & \\
\hline & $>25$ anos & 72,8 & 75,0 & 9,7 & 66,7 & 79,2 & 13 & 5,3 & \\
\hline \multirow{5}{*}{ Social } & $<1$ ano & 86,1 & 91,7 & 11,8 & 75,0 & 91,7 & 9 & 7,7 & \multirow{5}{*}{0,059} \\
\hline & $1-5$ anos & 73,2 & 75,0 & 20,4 & 66,7 & 87,5 & 23 & 8,3 & \\
\hline & $6-15$ anos & 67,5 & 75,0 & 22,7 & 62,5 & 75,0 & 39 & 7,1 & \\
\hline & $16-25$ anos & 76,0 & 75,0 & 16,3 & 66,7 & 83,3 & 34 & 5,5 & \\
\hline & $>25$ anos & 79,5 & 75,0 & 12,1 & 75,0 & 91,7 & 13 & 6,6 & \\
\hline \multirow{5}{*}{ Ambiental } & $<1$ ano & 68,1 & 68,8 & 14,2 & 56,3 & 81,3 & 9 & 9,3 & \multirow{5}{*}{0,089} \\
\hline & $1-5$ anos & 57,9 & 56,3 & 18,2 & 45,3 & 68,8 & 23 & 7,4 & \\
\hline & 6-15 anos & 59,2 & 59,4 & 15,0 & 53,1 & 68,8 & 39 & 4,7 & \\
\hline & $16-25$ anos & 63,7 & 65,6 & 16,0 & 59,4 & 71,9 & 34 & 5,4 & \\
\hline & $>25$ anos & 56,5 & 59,4 & 10,8 & 50,0 & 65,6 & 13 & 5,9 & \\
\hline \multirow{5}{*}{ QV Global } & $<1$ ano & 77,8 & 87,5 & 23,2 & 62,5 & 100,0 & 9 & 15,2 & \multirow{5}{*}{0,120} \\
\hline & $1-5$ anos & 72,3 & 75,0 & 18,4 & 68,8 & 75,0 & 23 & 7,5 & \\
\hline & 6-15 anos & 62,2 & 68,8 & 24,1 & 50,0 & 75,0 & 38 & 7,6 & \\
\hline & $16-25$ anos & 73,5 & 75,0 & 13,0 & 75,0 & 75,0 & 34 & 4,4 & \\
\hline & $>25$ anos & 70,2 & 75,0 & 15,8 & 75,0 & 75,0 & 13 & 8,6 & \\
\hline
\end{tabular}

DP: desvio padrão; Q1 e Q3: primeiro e terceiro quartil; N: número total da amostra; IC: intervalo de confiança.

Na Tabela 15 são apresentados os valores de p das comparações entre os pares de respostas no domínio psicológico (Tabela 14). Verificou-se que o grupo entre "16-25 anos" de trabalho com radiação ionizante apresentou diferença estatisticamente significante $(\mathrm{p}=0,003)$ com o grupo entre "6-15 anos"; o grupo entre "6-15 anos" apresentou diferença significante $(p=0,021)$ com o grupo menor que um ano " $<1$ ano" de trabalho.

Tabela 16: Teste de Mann-Whitney: valores de $\mathrm{p}$.

\begin{tabular}{ccccc}
\hline & $\mathbf{1 - 5}$ anos & $\mathbf{1 6 - 2 5}$ anos & $\mathbf{6 - 1 5}$ anos & $>\mathbf{2 5}$ anos \\
\hline $\mathbf{1 6 - 2 5}$ anos & 0,174 & & & \\
\hline $\mathbf{6 - 1 5}$ anos & 0,194 & $\mathbf{0 , 0 0 3}$ & & \\
\hline$>\mathbf{2 5}$ anos & 0,654 & 0,069 & 0,503 & \\
\hline$<\mathbf{1}$ ano & 0,164 & 0,785 & $\mathbf{0 , 0 2 1}$ & 0,061 \\
\hline
\end{tabular}




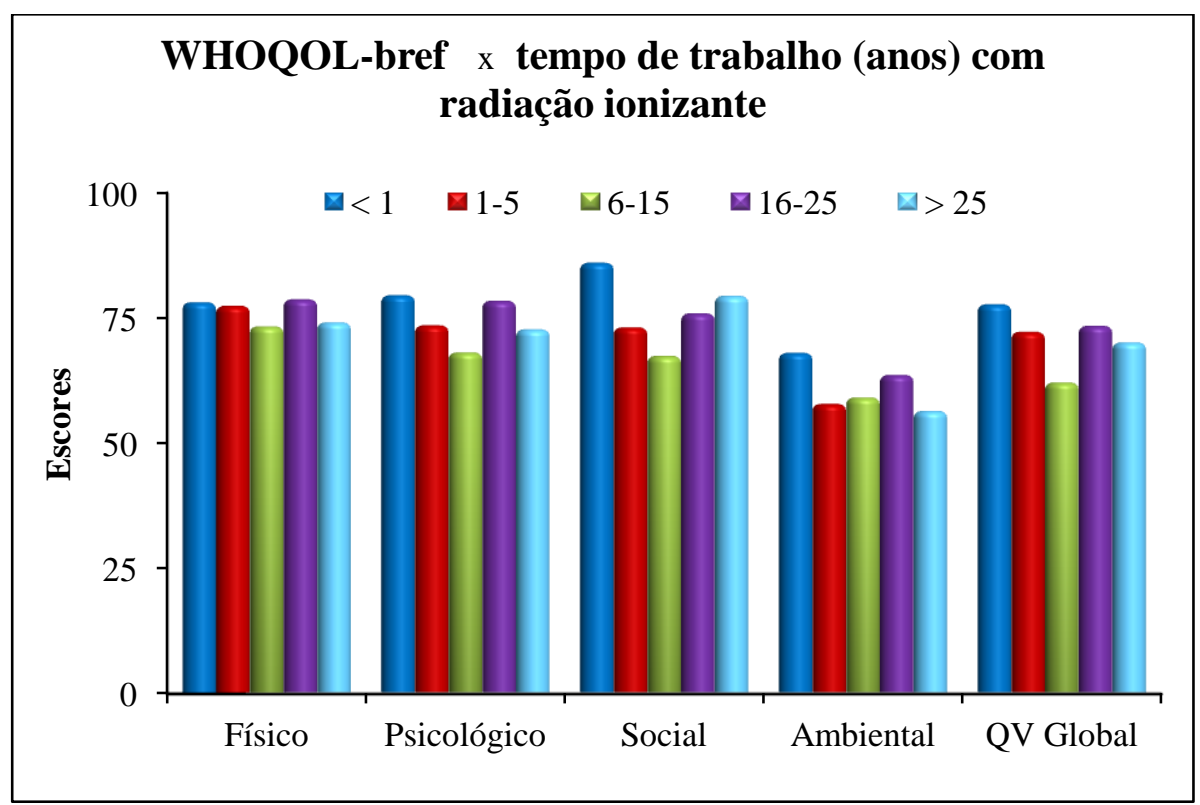

Figura 20: Comparação do WHOQOL-bref com tempo de trabalho com radiação ionizante.

Na Tabela 16 e na Figura 21 é apresentada a comparação do WHOQOL-bref com a satisfação com o trabalho em presença da radiação ionizante. Observou-se que o grupo que respondeu "muito satisfeito" com o trabalho em presença da radiação ionizante alcançou maiores escores de QV nos domínios psicológico, ambiental e QV global. Nos domínios, físico e social o grupo que respondeu "muito insatisfeito" apresentou maiores escores. Verificou-se também que só o domínio físico apresentou valor de p significante ( $\mathrm{p}=0,041)$.

Para determinar entre quais os níveis de resposta ocorreu essa diferença, foram comparados todos os pares de respostas, utilizando-se o teste de Mann-Whitney. Os valores de p obtidos desta comparação são apresentados na Tabela 17. 
Tabela 17: Comparação do WHOQOL-bref com a satisfação com o trabalho em presença da radiação ionizante.

\begin{tabular}{|c|c|c|c|c|c|c|c|c|c|}
\hline & & Média & ME & DP & Q1 & $\mathbf{Q 3}$ & $\mathbf{N}$ & IC & Valor de $p$ \\
\hline \multirow{5}{*}{ Físico } & Muito insatisfeito & 81,4 & 80,3 & 12,2 & 78,6 & 87,5 & 10 & 7,6 & \multirow{5}{*}{0,041} \\
\hline & Insatisfeito & 63,6 & 67,9 & 11,9 & 64,3 & 71,4 & 5 & 10,5 & \\
\hline & Nem satisfeito, nem insatisfeito & 72,5 & 75,0 & 11,5 & 66,1 & 78,6 & 23 & 4,7 & \\
\hline & Satisfeito & 77,1 & 78,6 & 12,4 & 71,4 & 85,7 & 63 & 3,1 & \\
\hline & Muito satisfeito & 79,3 & 82,1 & 13,5 & 67,9 & 88,4 & 14 & 7,0 & \\
\hline \multirow{5}{*}{ Psicológico } & Muito insatisfeito & 76,2 & 72,9 & 7,6 & 70,8 & 82,3 & 10 & 4,7 & \multirow{5}{*}{0,062} \\
\hline & Insatisfeito & 58,3 & 66,7 & 21,5 & 62,5 & 66,7 & 5 & 18,8 & \\
\hline & Nem satisfeito, nem insatisfeito & 70,1 & 75,0 & 15,3 & 62,5 & 79,2 & 23 & 6,2 & \\
\hline & Satisfeito & 73,8 & 75,0 & 15,2 & 66,7 & 87,5 & 63 & 3,8 & \\
\hline & Muito satisfeito & 81,3 & 79,2 & 11,1 & 75,0 & 90,6 & 14 & 5,8 & \\
\hline \multirow{5}{*}{ Social } & Muito insatisfeito & 83,3 & 79,2 & 11,8 & 75,0 & 91,7 & 10 & 7,3 & \multirow{5}{*}{0,166} \\
\hline & Insatisfeito & 56,7 & 66,7 & 33,0 & 58,3 & 75,0 & 5 & 28,9 & \\
\hline & Nem satisfeito, nem insatisfeito & 71,0 & 75,0 & 19,4 & 62,5 & 83,3 & 23 & 7,9 & \\
\hline & Satisfeito & 72,8 & 75,0 & 19,4 & 66,7 & 87,5 & 63 & 4,8 & \\
\hline & Muito satisfeito & 81,0 & 75,0 & 15,1 & 75,0 & 97,9 & 14 & 7,9 & \\
\hline \multirow{5}{*}{ Ambiental } & Muito insatisfeito & 59,2 & 56,3 & 14,4 & 53,9 & 61,7 & 10 & 8,9 & \multirow{5}{*}{0,397} \\
\hline & Insatisfeito & 49,4 & 53,1 & 14,6 & 37,5 & 59,4 & 5 & 12,8 & \\
\hline & Nem satisfeito, nem insatisfeito & 60,1 & 62,5 & 12,6 & 50,0 & 68,8 & 23 & 5,2 & \\
\hline & Satisfeito & 60,7 & 62,5 & 15,8 & 53,1 & 68,8 & 63 & 3,9 & \\
\hline & Muito satisfeito & 66,0 & 67,2 & 20,2 & 51,6 & 79,7 & 14 & 10,6 & \\
\hline \multirow{5}{*}{ QV Global } & Muito insatisfeito & 67,5 & 68,8 & 18,8 & 53,1 & 75,0 & 10 & 11,7 & \multirow{5}{*}{0,210} \\
\hline & Insatisfeito & 47,5 & 50,0 & 28,5 & 25,0 & 75,0 & 5 & 25,0 & \\
\hline & Nem satisfeito, nem insatisfeito & 69,9 & 75,0 & 18,0 & 62,5 & 75,0 & 22 & 7,5 & \\
\hline & Satisfeito & 69,4 & 75,0 & 19,3 & 62,5 & 75,0 & 63 & 4,8 & \\
\hline & Muito satisfeito & 76,8 & 75,0 & 20,1 & 75,0 & 93,8 & 14 & 10,5 & \\
\hline
\end{tabular}

DP: desvio padrão; Q1 e Q3: primeiro e terceiro quartil; N: total da amostra; IC: intervalo de confiança.

Na Tabela 17 são apresentados os valores de p obtidos das comparações entre os pares de respostas no domínio físico, com objetivo de verificar quais as respostas influenciaram no resultado deste domínio (Tabela 16). Verificou-se que o grupo "Insatisfeito" com o trabalho em presença da radiação ionizante apresentou diferença estatisticamente significante $(\mathrm{p}=0,014)$ na comparação com o grupo "muito insatisfeito" e com o grupo "satisfeito" $(p=0,017)$.

Tabela 18: Teste de Mann-Whitney: valores de $p$.

\begin{tabular}{ccccc}
\hline & Insatisfeito & Muito & Muito & Nem satisfeito, \\
\hline Muito insatisfeito & $\mathbf{0 , 0 1 4}$ & & & \\
\hline Muito satisfeito & 0,085 & 0,976 & & \\
\hline Nem satisfeito, nem insatisfeito & 0,117 & 0,051 & 0,127 & \\
\hline Satisfeito & $\mathbf{0 , 0 1 7}$ & 0,388 & 0,559 & 0,091 \\
\hline
\end{tabular}




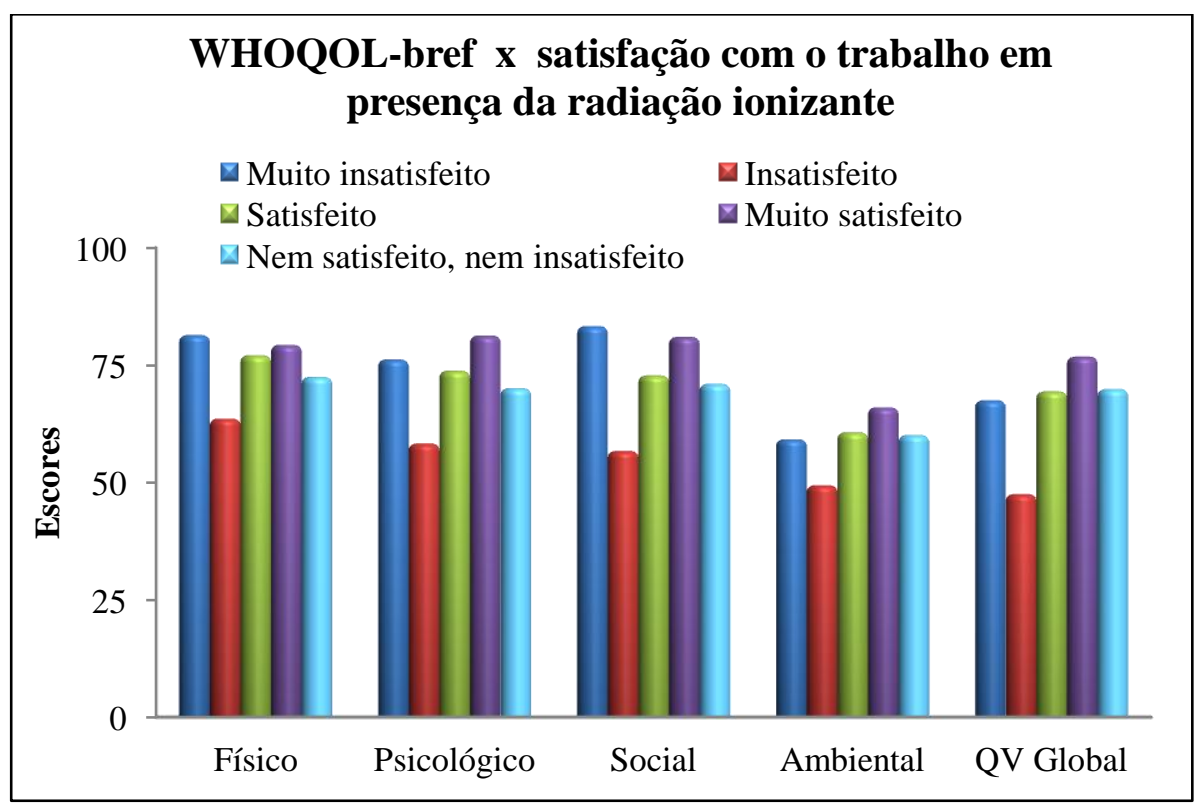

Figura 21: Comparação do WHOQOL-bref com satisfação com o trabalho em presença da radiação ionizante.

Na Tabela 18 e na Figura 22 é apresentada a comparação do WHOQOL-bref com trabalho em turnos.

O trabalho em turnos, assim, como o acúmulo de dois ou mais vínculos empregatícios podem ser considerados possíveis causadores de desordens fisiológicas, psicológicas e desgastes na vida social e familiar, repercutindo sobre o desempenho produtivo e na QV do trabalhador. As perturbações da saúde podem ser observadas através da insônia, irritabilidade, sonolência excessiva, fadiga e mau funcionamento do intestino. As interferências nas relações sócio-familiares são traduzidas pela ausência do ente querido (pai, mãe, filho, amigo, entre outros), principalmente em momentos de datas comemorativas, fins de semana e feriados. As conseqüências destas perturbações são observadas a curto, médio e longo prazo, tanto na QV de vida do trabalhador, como de sua família, na saúde dos trabalhadores, na segurança do trabalhado e consequentemente na capacidade para o trabalho [67].

De acordo com os resultados, observou-se que o grupo que trabalha em turnos apresentou os menores escores de QV em todos os domínios do WHOQOL-bref. No entanto, 
não foi observada significância estatística $(\mathrm{p}<0,05)$ para essa variável em nenhum dos domínios. Somente o domínio psicológico apresentou um nível de significância $(\mathrm{p}=0,064)$ próximo do limite aceitável.

Tabela 19: Comparação do WHOQOL-bref com trabalho em turnos.

\begin{tabular}{ccccccccccc}
\hline & \multicolumn{2}{c}{ Físico } & \multicolumn{2}{c}{ Psicológico } & \multicolumn{2}{c}{ Social } & \multicolumn{2}{c}{ Ambiental } & \multicolumn{2}{c}{ QV Global } \\
\cline { 2 - 11 } & Não & Sim & Não & Sim & Não & Sim & Não & Sim & Não & Sim \\
\hline Média & 79,8 & 75,3 & 76,9 & 72,7 & 75,0 & 73,4 & 63,0 & 59,8 & 74,1 & 68,0 \\
\hline Mediana & 82,1 & 76,8 & 79,2 & 75,0 & 75,0 & 75,0 & 62,5 & 59,4 & 75,0 & 75,0 \\
\hline DP & 11,0 & 13,0 & 16,7 & 14,3 & 22,6 & 18,5 & 15,0 & 15,9 & 18,6 & 19,9 \\
\hline Q1 & 71,4 & 67,9 & 70,8 & 66,7 & 66,7 & 66,7 & 56,3 & 53,1 & 68,8 & 62,5 \\
\hline Q3 & 85,7 & 85,7 & 87,5 & 83,3 & 91,7 & 83,3 & 71,9 & 68,8 & 81,3 & 75,0 \\
\hline N & 27 & 90 & 27 & 90 & 27 & 90 & 27 & 90 & 27 & 89 \\
\hline IC & 4,2 & 2,7 & 6,3 & 3,0 & 8,5 & 3,8 & 5,6 & 3,3 & 7,0 & 4,1 \\
\hline Valor de p & 0,145 & $\mathbf{0 , 0 6 4}$ & 0,436 & 0,256 & 0,153 \\
\hline
\end{tabular}

DP: desvio padrão; Q1 e Q3: primeiro e terceiro quartil; N: número total da amostra; IC: intervalo de confiança.

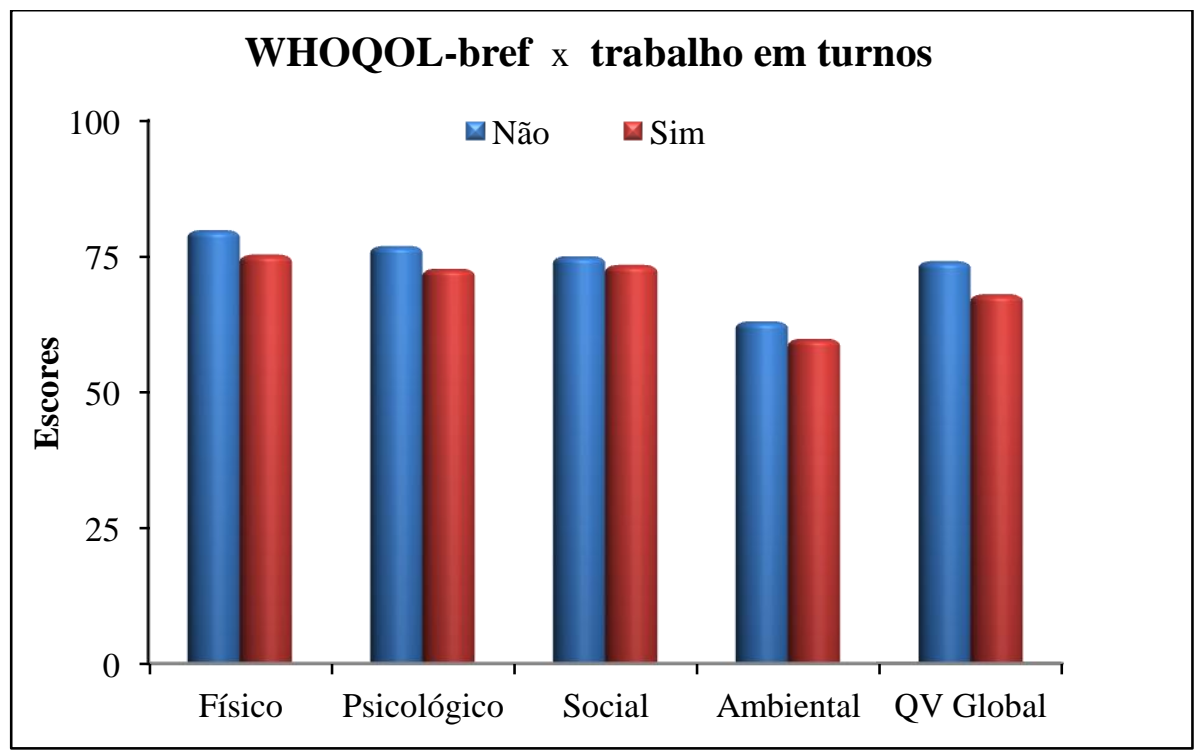

Figura 22: Comparação do WHOQOL-bref com trabalho em turnos.

Na Tabela 19 e na Figura 23 é apresentada a comparação do WHOQOL-bref com os diferentes turnos de trabalho. Observou-se que o grupo que trabalha no turno da manhã apresentou escores sempre menores do que os demais grupos, com exceção do domínio QV 
global, em que este grupo apresentou um escore maior de QV (escore=70,6). Não foi observada significância estatística $(\mathrm{p}<0,05)$ em nenhum dos domínios.

Tabela 20: Comparação do WHOQOL-bref com os diferentes turnos de trabalho.

\begin{tabular}{|c|c|c|c|c|c|c|c|c|c|}
\hline & & Média & Mediana & DP & Q1 & Q3 & $\mathbf{N}$ & IC & Valor de $p$ \\
\hline \multirow{4}{*}{ Físico } & Manhã & 71,6 & 71,4 & 13,7 & 67,9 & 78,6 & 17 & 6,5 & \multirow{4}{*}{0,733} \\
\hline & Tarde & 76,1 & 75,0 & 11,1 & 69,7 & 85,7 & 19 & 5,0 & \\
\hline & Noite & 74,5 & 75,0 & 11,3 & 66,1 & 85,7 & 27 & 4,3 & \\
\hline & Rodízio & 75,8 & 78,6 & 15,5 & 67,9 & 82,1 & 21 & 6,6 & \\
\hline \multirow{4}{*}{ Psicológico } & Manhã & 69,9 & 66,7 & 12,8 & 58,3 & 83,3 & 17 & 6,1 & \multirow{4}{*}{0,649} \\
\hline & Tarde & 73,0 & 75,0 & 13,4 & 68,8 & 83,3 & 19 & 6,0 & \\
\hline & Noite & 73,9 & 75,0 & 14,1 & 68,8 & 81,3 & 27 & 5,3 & \\
\hline & Rodízio & 71,8 & 75,0 & 17,7 & 66,7 & 79,2 & 21 & 7,6 & \\
\hline \multirow{4}{*}{ Social } & Manhã & 67,6 & 75,0 & 20,2 & 58,3 & 75,0 & 17 & 9,6 & \multirow{4}{*}{0,482} \\
\hline & Tarde & 78,1 & 75,0 & 11,9 & 70,8 & 87,5 & 19 & 5,3 & \\
\hline & Noite & 71,9 & 75,0 & 17,9 & 66,7 & 83,3 & 27 & 6,8 & \\
\hline & Rodízio & 73,4 & 75,0 & 23,4 & 66,7 & 91,7 & 21 & 10,0 & \\
\hline \multirow{4}{*}{ Ambiental } & Manhã & 58,3 & 56,3 & 13,3 & 46,9 & 65,6 & 17 & 6,3 & \multirow{4}{*}{0,889} \\
\hline & Tarde & 61,3 & 59,4 & 14,1 & 53,1 & 68,8 & 19 & 6,4 & \\
\hline & Noite & 57,6 & 56,3 & 14,6 & 51,6 & 68,8 & 27 & 5,5 & \\
\hline & Rodízio & 59,7 & 59,4 & 21,5 & 53,1 & 71,9 & 21 & 9,2 & \\
\hline \multirow{4}{*}{ QV Global } & Manhã & 70,6 & 75,0 & 17,1 & 50,0 & 75,0 & 17 & 8,1 & \multirow{4}{*}{0,681} \\
\hline & Tarde & 67,8 & 75,0 & 19,7 & 62,5 & 75,0 & 19 & 8,9 & \\
\hline & Noite & 64,8 & 75,0 & 16,3 & 62,5 & 75,0 & 27 & 6,1 & \\
\hline & Rodízio & 69,4 & 75,0 & 24,5 & 59,4 & 78,1 & 20 & 10,7 & \\
\hline
\end{tabular}

DP: desvio padrão; Q1 e Q3: primeiro e terceiro quartil; N: número total da amostra; IC: intervalo de confiança.

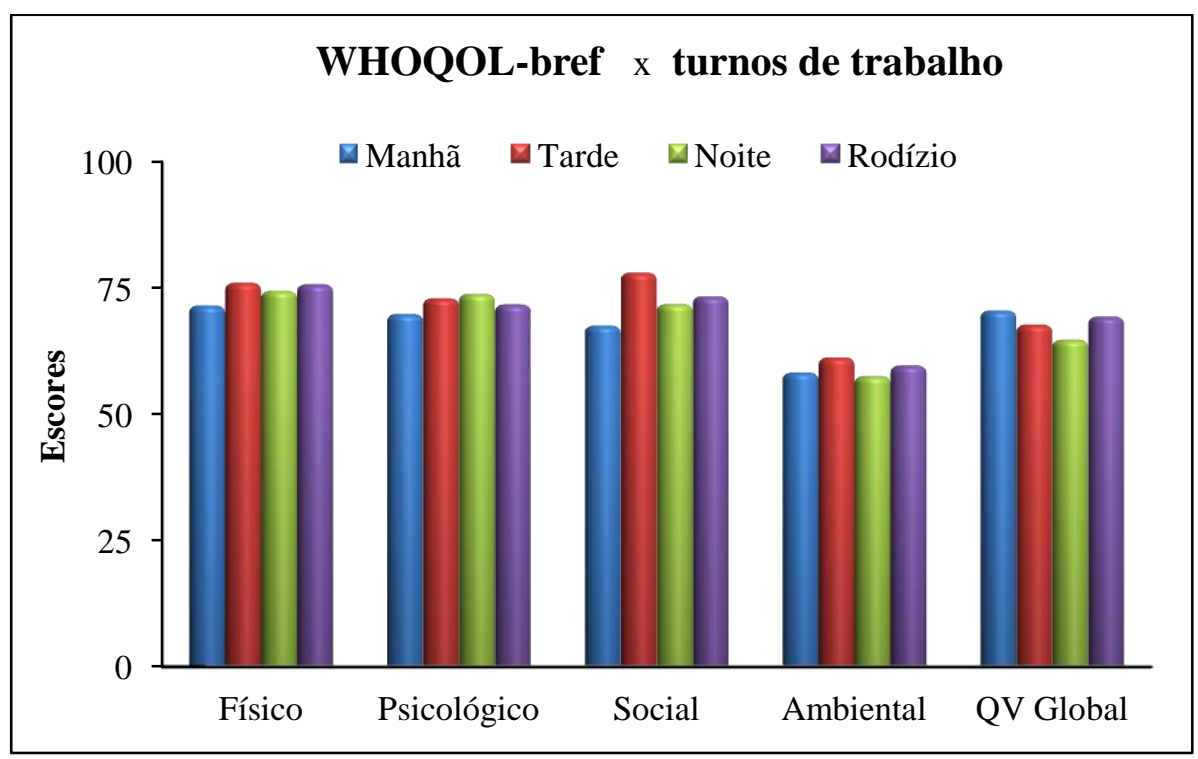

Figura 23: Comparação do WHOQOL-bref com os diferentes turnos de trabalho. 
Na Tabela 20 e na Figura 24 é apresentada a comparação do WHOQOL-bref com a existência ou não de outro emprego. Observou-se que o grupo que respondeu "sim" apresentou escores sempre maiores do que o grupo que respondeu "não", com exceção do domínio QV global, o grupo que não tem outro emprego apresentou um escore maior. Não foi observada significância estatística $(\mathrm{p}<0,05)$ em nenhum dos domínios.

Tabela 21: Comparação do WHOQOL-bref com a existência ou não de outro emprego.

\begin{tabular}{ccccccccccc}
\hline & \multicolumn{2}{c}{ Físico } & \multicolumn{2}{c}{ Psicológico } & \multicolumn{2}{c}{ Social } & \multicolumn{2}{c}{ Ambiental } & \multicolumn{2}{c}{ QV Global } \\
\cline { 2 - 11 } & Não & Sim & Não & Sim & Não & Sim & Não & Sim & Não & Sim \\
\hline Média & 74,8 & 77,7 & 73,1 & 74,0 & 73,3 & 74,2 & 60,0 & 61,4 & 71,3 & 68,3 \\
\hline Mediana & 75,0 & 78,6 & 75,0 & 79,2 & 75,0 & 75,0 & 59,4 & 62,5 & 75,0 & 75,0 \\
\hline DP & 13,2 & 12,0 & 14,2 & 15,6 & 18,8 & 20,1 & 15,9 & 15,5 & 17,3 & 21,7 \\
\hline Q1 & 67,9 & 71,4 & 66,7 & 66,7 & 66,7 & 66,7 & 53,1 & 53,1 & 62,5 & 62,5 \\
\hline Q3 & 85,7 & 85,7 & 83,3 & 87,5 & 89,6 & 87,5 & 68,8 & 70,3 & 75,0 & 75,0 \\
\hline N & 54 & 63 & 54 & 63 & 54 & 63 & 54 & 63 & 54 & 62 \\
\hline IC & 3,5 & 3,0 & 3,8 & 3,9 & 5,0 & 5,0 & 4,3 & 3,8 & 4,6 & 5,4 \\
\hline Valor de p & \multicolumn{2}{c}{0,224} & \multicolumn{2}{c}{0,569} & \multicolumn{2}{c}{0,616} & 0,751 & 0,580 \\
\hline
\end{tabular}

DP: desvio padrão; Q1 e Q3: primeiro e terceiro quartil; N: número total da amostra; IC: intervalo de confiança.

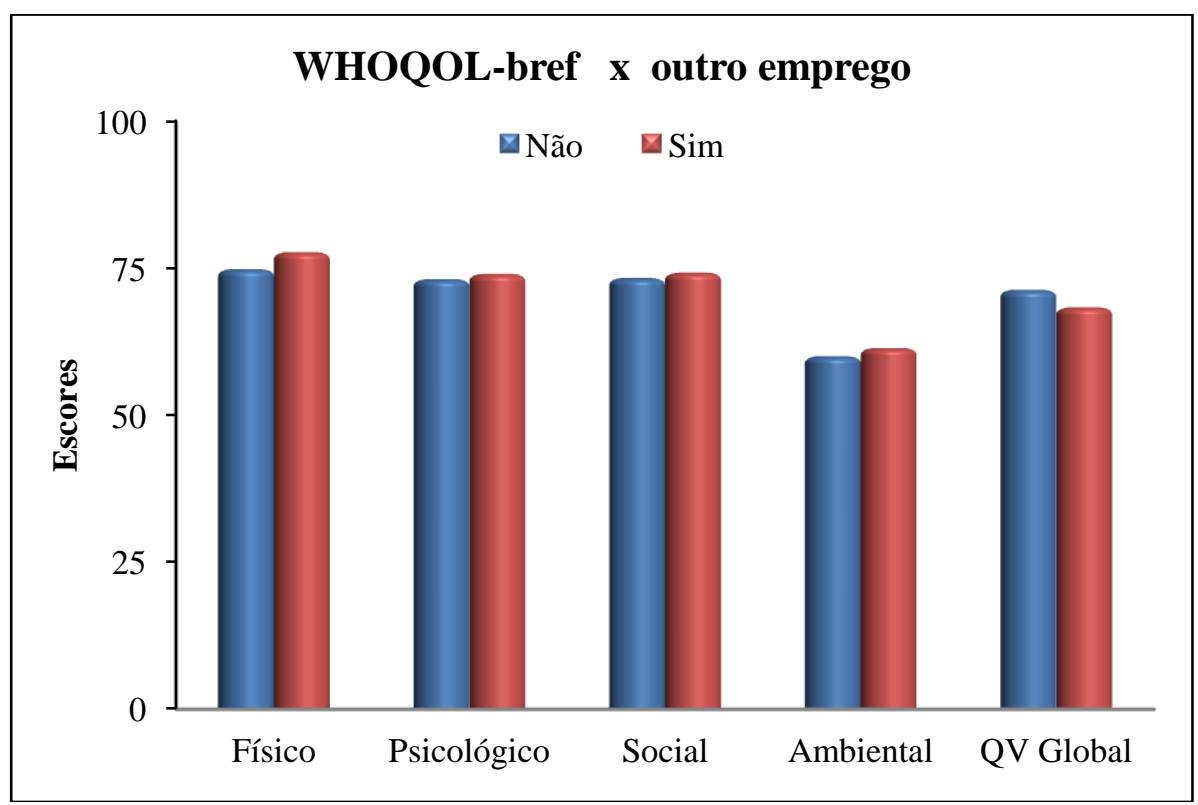

Figura 24: Comparação do WHOQOL-bref com a existência ou não de outro emprego. 
Variáveis que expressam o estilo de vida dos participantes: hábito de fumar, consumo de bebida alcoólica e prática de atividade física

Na Tabela 21 e na Figura 25 é apresentada a comparação do WHOQOL-bref com o hábito de fumar. Observou-se que o grupo de "fumantes" apresentou escores maiores do que os "não fumantes" nos domínios físico $(78,1)$, social $(76,6)$ e ambiental $(61,7)$. Nos domínios psicológico e QV global os escores foram similares para os dois grupos. Não foi observada significância estatística $(\mathrm{p}<0,05)$ para nenhum dos domínios.

Tabela 22: Comparação do WHOQOL-bref com o hábito de fumar.

\begin{tabular}{ccccccccccc}
\hline & \multicolumn{2}{c}{ Físico } & \multicolumn{2}{c}{ Psicológico } & \multicolumn{2}{c}{ Social } & \multicolumn{2}{c}{ Ambiental } & \multicolumn{2}{c}{ QV Global } \\
\cline { 2 - 11 } & Não & Sim & Não & Sim & Não & Sim & Não & Sim & Não & Sim \\
\hline Média & 75,9 & 78,1 & 73,5 & 73,4 & 73,4 & 76,6 & 60,3 & 61,7 & 69,5 & 69,5 \\
\hline Mediana & 78,6 & 80,3 & 75,0 & 77,1 & 75,0 & 79,2 & 59,4 & 67,2 & 75,0 & 75,0 \\
\hline DP & 12,3 & 15,2 & 14,3 & 18,8 & 19,0 & 22,2 & 15,1 & 19,3 & 18,8 & 25,8 \\
\hline Q1 & 67,9 & 70,5 & 66,7 & 65,6 & 66,7 & 70,8 & 53,1 & 52,3 & 62,5 & 62,5 \\
\hline Q3 & 85,7 & 89,3 & 83,3 & 87,5 & 83,3 & 91,7 & 68,8 & 72,7 & 75,0 & 75,0 \\
\hline N & 101 & 16 & 101 & 16 & 101 & 16 & 101 & 16 & 100 & 16 \\
\hline IC & 2,4 & 7,5 & 2,8 & 9,2 & 3,7 & 10,9 & 3,0 & 9,5 & 3,7 & 12,6 \\
\hline Valor de p & 0,493 & \multicolumn{2}{c}{0,690} & \multicolumn{2}{c}{0,325} & & 0,413 & 0,832 \\
\hline
\end{tabular}

DP: desvio padrão; Q1 e Q3: primeiro e terceiro quartil; N: número total da amostra; IC: intervalo de confiança.

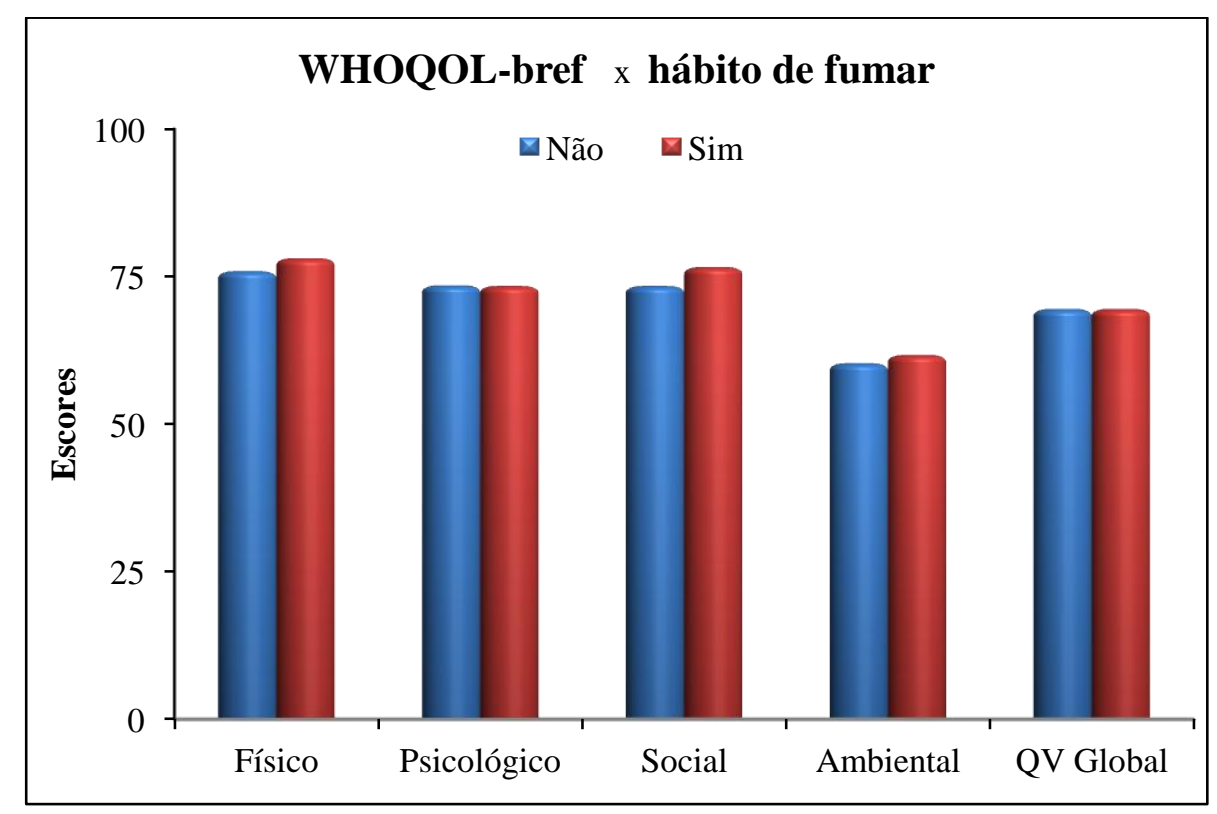

Figura 25: Comparação do WHOQOL-bref com hábito de fumar. 
Na Tabela 22 e na Figura 26 é apresentada a comparação do WHOQOL-bref com o consumo de bebida alcoólica. Observou-se que no domínio físico o grupo que respondeu "sim" apresentou um escore maior $(77,8)$, enquanto que no domínio ambiental o grupo que respondeu "não" apresentou maior escore $(62,6)$. Nenhum dos domínios apresentou diferença estatisticamente significante $(\mathrm{p}<0,05)$.

Tabela 23: Comparação do WHOQOL-bref com o consumo de bebida alcoólica.

\begin{tabular}{ccccccccccc}
\hline & \multicolumn{2}{c}{ Físico } & \multicolumn{2}{c}{ Psicológico } & \multicolumn{2}{c}{ Social } & \multicolumn{2}{c}{ Ambiental } & \multicolumn{2}{c}{ QV Global } \\
\cline { 2 - 11 } & Não & Sim & Não & Sim & Não & Sim & Não & Sim & Não & Sim \\
\hline Média & 74,5 & 77,8 & 73,9 & 73,5 & 74,2 & 73,4 & 62,6 & 59,0 & 69,3 & 69,6 \\
\hline Mediana & 75,0 & 78,6 & 75,0 & 77,1 & 75,0 & 75,0 & 62,5 & 59,4 & 75,0 & 75,0 \\
\hline DP & 13,3 & 12,1 & 13,4 & 16,1 & 16,1 & 21,9 & 15,5 & 15,8 & 18,4 & 21,0 \\
\hline Q1 & 64,3 & 71,4 & 66,7 & 66,7 & 66,7 & 66,7 & 53,1 & 52,3 & 62,5 & 62,5 \\
\hline Q3 & 85,7 & 85,7 & 83,3 & 83,3 & 83,3 & 91,7 & 68,8 & 68,8 & 75,0 & 75,0 \\
\hline N & 53 & 64 & 53 & 64 & 53 & 64 & 53 & 64 & 53 & 63 \\
\hline IC & 3,6 & 3,0 & 3,6 & 3,9 & 4,3 & 5,4 & 4,2 & 3,9 & 5,0 & 5,2 \\
\hline Valor de p & 0,170 & 0,811 & \multicolumn{2}{c}{0,675} & 0,267 & 0,876 \\
\hline
\end{tabular}

DP: desvio padrão; Q1 e Q3: primeiro e terceiro quartil; N: número total da amostra; IC: intervalo de confiança.

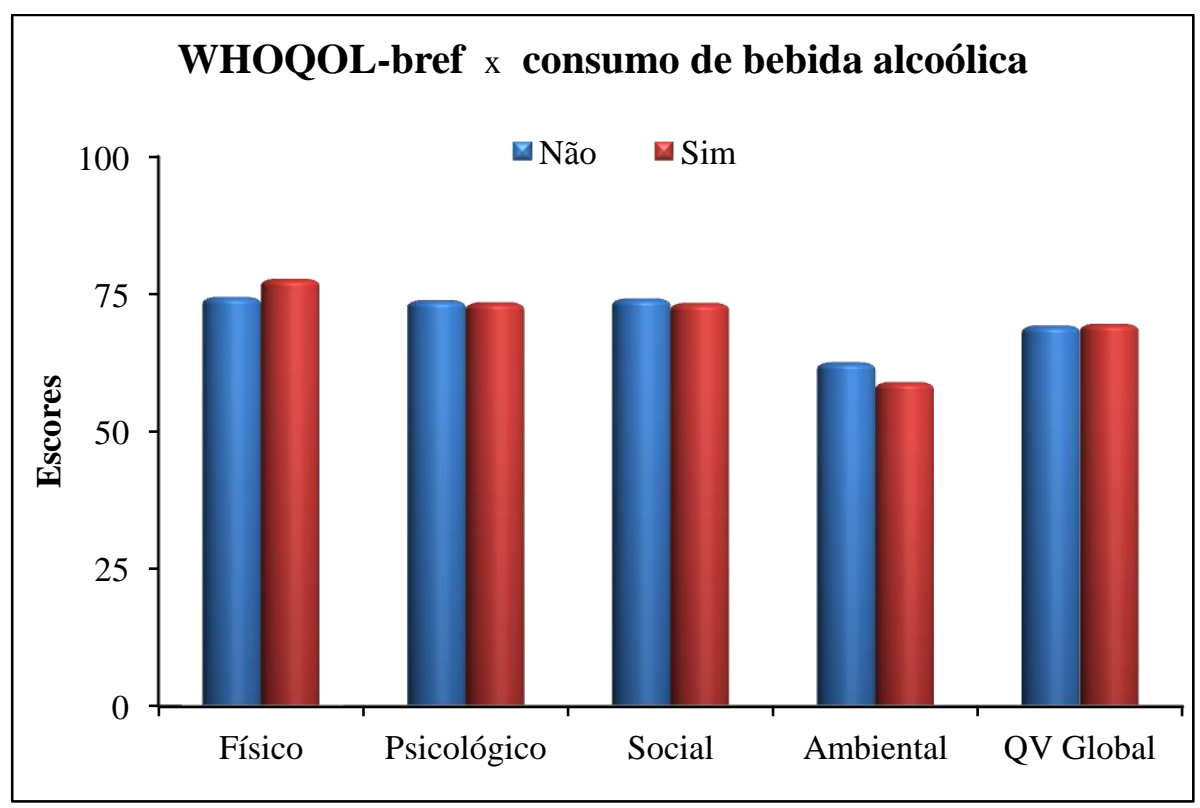

Figura 26: Comparação do WHOQOL-bref com o consumo de bebida alcoólica. 
Na Tabela 23 e na Figura 27 é apresentada a comparação do WHOQOL-bref com a prática de atividade física. A atividade física é considerada um dos principais comportamentos positivos para a promoção da QV e melhoria da saúde do ser humano. Assim, sua prática habitual além de promover a saúde, influencia na reabilitação de determinadas patologias associadas à morbidade e mortalidade [66]. De acordo com os resultados, o grupo que respondeu "sim" apresentou maiores escores de QV em todos os domínios. Nenhum dos domínios apresentou diferença estatisticamente significante $(\mathrm{p}<0,05)$.

Tabela 24: Comparação do WHOQOL-bref com a prática de atividade física.

\begin{tabular}{ccccccccccc}
\hline & \multicolumn{2}{c}{ Físico } & \multicolumn{2}{c}{ Psicológico } & \multicolumn{2}{c}{ Social } & \multicolumn{2}{c}{ Ambiental } & \multicolumn{2}{c}{ QV Global } \\
\cline { 2 - 11 } & Não & Sim & Não & Sim & Não & Sim & Não & Sim & Não & Sim \\
\hline Média & 76,0 & 76,8 & 72,3 & 75,6 & 71,2 & 77,4 & 59,5 & 62,9 & 68,2 & 71,8 \\
\hline Mediana & 78,6 & 78,6 & 75,0 & 75,0 & 75,0 & 75,0 & 59,4 & 62,5 & 75,0 & 75,0 \\
\hline DP & 13,9 & 11,1 & 17,4 & 10,4 & 21,5 & 15,9 & 15,6 & 13,9 & 20,4 & 18,7 \\
\hline Q1 & 67,9 & 70,5 & 66,7 & 66,7 & 66,7 & 75,0 & 49,2 & 53,1 & 62,5 & 68,8 \\
\hline Q3 & 85,7 & 85,7 & 83,3 & 84,4 & 83,3 & 91,7 & 68,8 & 68,8 & 75,0 & 81,3 \\
\hline N & 64 & 52 & 64 & 52 & 64 & 52 & 64 & 52 & 64 & 52 \\
\hline IC & 3,4 & 3,0 & 4,3 & 2,8 & 5,3 & 4,3 & 3,8 & 3,8 & 5,0 & 5,1 \\
\hline Valor de p & \multicolumn{2}{c}{0,880} & \multicolumn{3}{c}{0,723} & 0,168 & \multicolumn{2}{c}{0,248} & 0,178 \\
\hline DP: desvio padrão; Q1 e Q3: primeiro e terceiro quartil; N: número total da amostra; IC: intervalo de confiança.
\end{tabular}

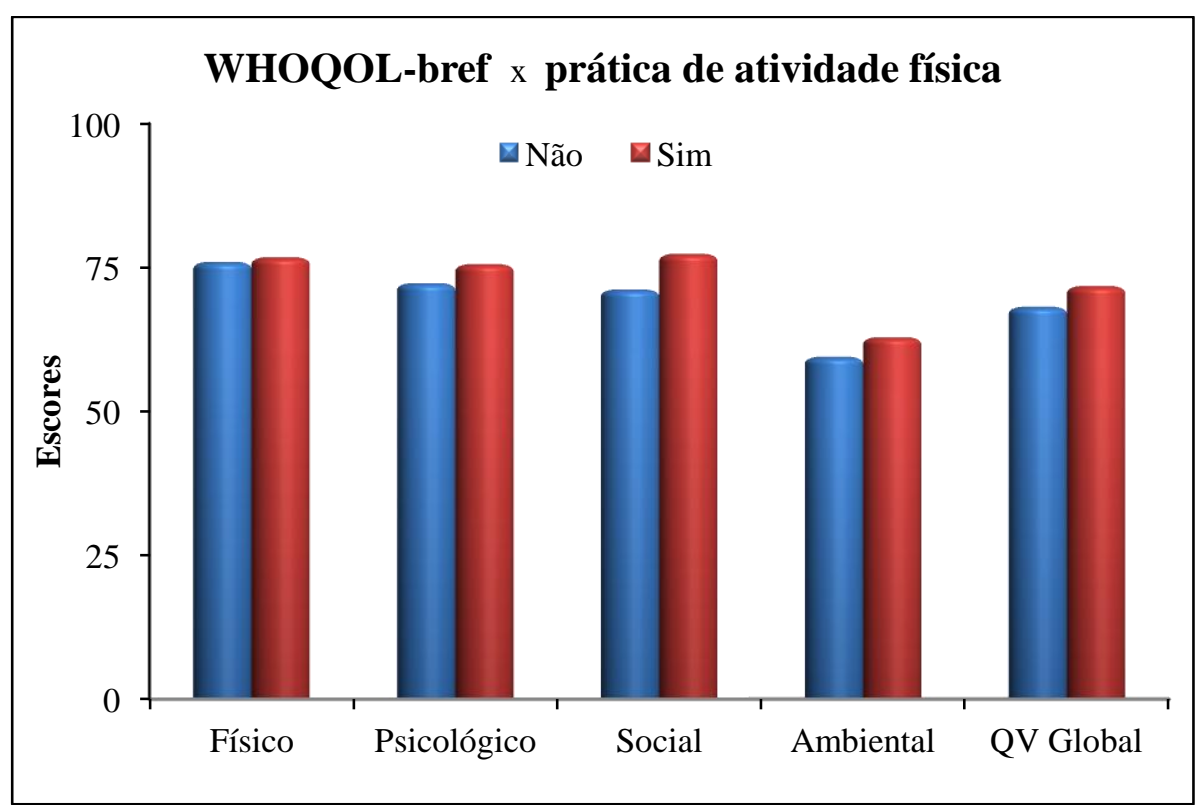

Figura 27: Comparação do WHOQOL-bref com a prática de atividade física. 
Na Tabela 24 e na Figura 28 é apresentada a comparação do WHOQOL-bref com a condição de saúde atual dos participantes. O grupo que considerou sua saúde atual (últimas duas semanas) "muito boa" obteve escores mais altos em todos os domínios. Verificou-se, ainda, que existem diferenças estatísticas nos domínios físico $(\mathrm{p}=0,018)$, psicológico $(\mathrm{p}=0,019)$, social $(\mathrm{p}=0,026)$ e QV global $(\mathrm{p}=0,008)$.

Para determinar entre quais as opções de resposta ocorreram essas diferenças, comparou-se todas as respostas entre si, utilizando-se o teste de Mann-Whitney. Os valores de p desta comparação são apresentados na Tabela 25.

Tabela 25: Comparação do WHOQOL-bref com a condição de saúde dos participantes.

\begin{tabular}{|c|c|c|c|c|c|c|c|c|c|}
\hline & & Média & Mediana & DP & Q1 & Q3 & $\mathbf{N}$ & IC & Valor de p \\
\hline \multirow{4}{*}{ Físico } & Muito Boa & 80,7 & 82,1 & 9,2 & 78,6 & 85,7 & 36 & 3,0 & \multirow{4}{*}{0,018} \\
\hline & Boa & 75,1 & 75,0 & 12,2 & 67,9 & 85,7 & 63 & 3,0 & \\
\hline & Nem ruim, nem boa & 75,0 & 75,0 & 14,7 & 62,5 & 82,1 & 11 & 8,7 & \\
\hline & Ruim & 54,5 & 50,0 & 22,5 & 45,5 & 58,9 & 4 & 22,0 & \\
\hline \multirow{4}{*}{ Psicológico } & Muito Boa & 79,5 & 79,2 & 9,3 & 74,0 & 87,5 & 36 & 3,0 & \multirow{4}{*}{0,019} \\
\hline & Boa & 71,7 & 75,0 & 15,7 & 66,7 & 83,3 & 63 & 3,9 & \\
\hline & Nem ruim, nem boa & 68,5 & 70,8 & 17,2 & 58,3 & 75,0 & 11 & 10,2 & \\
\hline & Ruim & 60,4 & 56,3 & 24,2 & 43,7 & 72,9 & 4 & 23,7 & \\
\hline \multirow{4}{*}{ Social } & Muito Boa & 80,6 & 75,0 & 13,7 & 75,0 & 91,7 & 36 & 4,5 & \multirow{4}{*}{0,026} \\
\hline & Boa & 72,4 & 75,0 & 20,8 & 66,7 & 83,3 & 63 & 5,1 & \\
\hline & Nem ruim, nem boa & 63,6 & 66,7 & 23,9 & 54,2 & 75,0 & 11 & 14,2 & \\
\hline & Ruim & 60,4 & 58,3 & 18,5 & 47,9 & 70,8 & 4 & 18,1 & \\
\hline \multirow{4}{*}{ Ambiental } & Muito Boa & 64,9 & 62,5 & 14,3 & 55,5 & 75,8 & 36 & 4,7 & \multirow{4}{*}{0,319} \\
\hline & Boa & 59,1 & 59,4 & 15,1 & 51,6 & 68,8 & 63 & 3,7 & \\
\hline & Nem ruim, nem boa & 56,1 & 60,7 & 24,2 & 42,2 & 67,2 & 11 & 14,3 & \\
\hline & Ruim & 56,3 & 53,1 & 10,8 & 51,6 & 57,8 & 4 & 10,6 & \\
\hline \multirow{4}{*}{ QV Global } & Muito Boa & 77,4 & 75,0 & 14,6 & 75,0 & 87,5 & 36 & 4,8 & \multirow{4}{*}{0,008} \\
\hline & Boa & 67,5 & 75,0 & 19,1 & 62,5 & 75,0 & 62 & 4,8 & \\
\hline & Nem ruim, nem boa & 62,5 & 75,0 & 26,2 & 50,0 & 75,0 & 11 & 15,5 & \\
\hline & Ruim & 46,9 & 43,8 & 21,3 & 34,4 & 56,3 & 4 & 20,9 & \\
\hline
\end{tabular}

DP: desvio padrão; Q1 e Q3: primeiro e terceiro quartil; N: número total da amostra; IC: intervalo de confiança.

Na Tabela 25 são apresentados os valores de p obtidos das comparações entre os pares de respostas, nos domínios físico, psicológico, social e QV Global, com objetivo de verificar quais as opções de respostas influenciaram no resultado destes domínios. Verificou-se que as opções de resposta "boa" e "muito boa" influenciaram significativamente nos resultados 
destes domínios na comparação com as demais opções.

Tabela 26: Teste de Mann-Whitney: valores de $\mathrm{p}$.

\begin{tabular}{ccccc}
\hline & & Boa & Muito Boa & Nem ruim, nem boa \\
\hline \multirow{2}{*}{ Físico } & Muito Boa & $\mathbf{0 , 0 1 8}$ & & \\
& Nem ruim, nem boa & 0,849 & 0,131 & \\
\cline { 2 - 5 } Psicológico & Ruim & $\mathbf{0 , 0 4 6}$ & $\mathbf{0 , 0 3 4}$ & 0,089 \\
& Muito Boa & $\mathbf{0 , 0 1 1}$ & & \\
& Nem ruim, nem boa & 0,336 & $\mathbf{0 , 0 2 5}$ & \\
\cline { 2 - 5 } Social & Ruim & 0,293 & 0,106 & 0,470 \\
& Muito Boa & 0,076 & & \\
& Nem ruim, nem boa & 0,149 & $\mathbf{0 , 0 1 4}$ & \\
\cline { 2 - 5 } QV Global & Ruim & 0,162 & $\mathbf{0 , 0 3 7}$ & 0,692 \\
& Muito Boa & $\mathbf{0 , 0 1 2}$ & & \\
& Nem ruim, nem boa & 0,686 & 0,074 & \\
\hline & Ruim & 0,051 & $\mathbf{0 , 0 1 0}$ & 0,270 \\
\hline
\end{tabular}

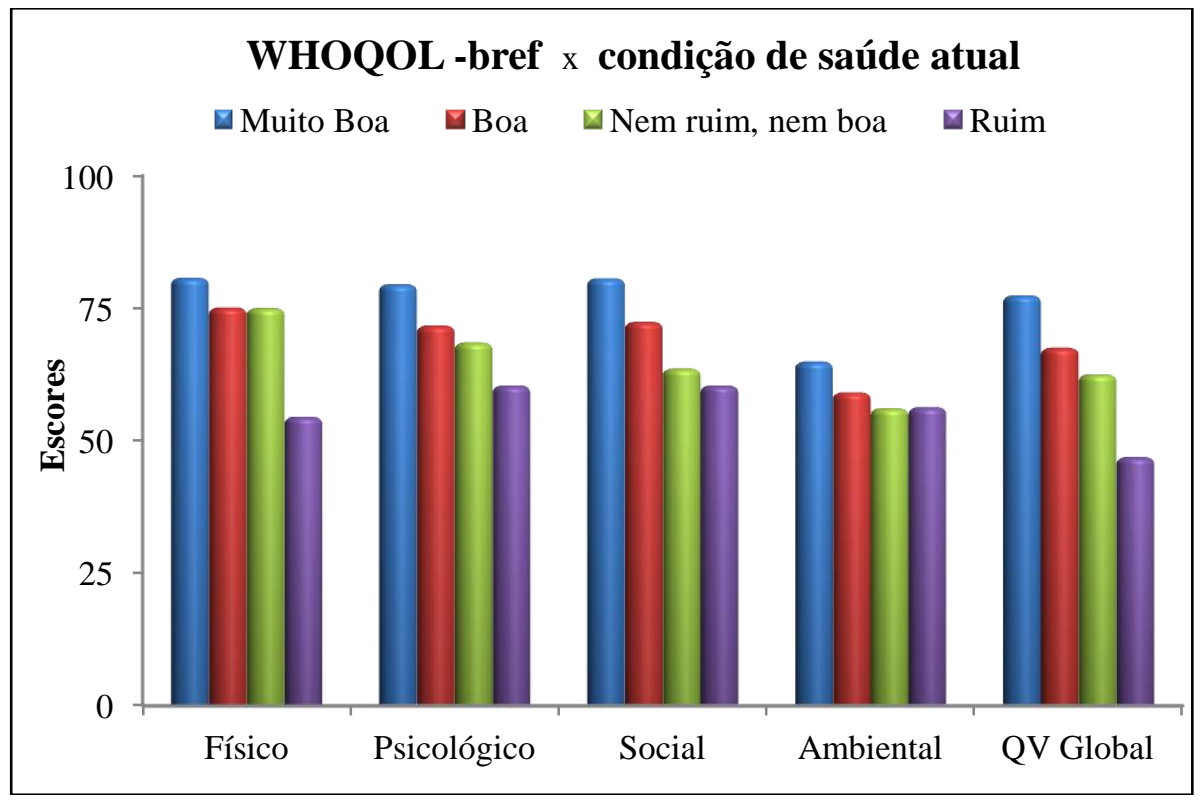

Figura 28: Comparação do WHOQOL-bref com a condição de saúde atual dos participantes. 


\section{CONCLUSÕES}

O presente estudo permitiu conhecer o perfil e a percepção de QV dos trabalhadores do serviço de radiodiagnóstico de um hospital escola na cidade de São Paulo.

O perfil traçado mostrou uma distribuição equitativa entre os gêneros. Tratou-se de um grupo de profissionais adultos, com média de idade 43,7 anos, dotados de ampla experiência profissional em procedimentos de radiodiagnóstico e, em sua maioria, em mais de uma instituição de saúde. Este fato deixa claro que estes profissionais estão expostos a dupla ou tripla jornada de trabalho com radiação ionizante. De acordo com a pesquisa, os profissionais estão, em sua maioria, satisfeitos com o trabalho em presença da radiação ionizante.

A percepção da QV dos trabalhadores do serviço de radiodiagnóstico analisado demonstrou que o domínio ambiental refletiu o pior escore de avaliação; e os escores relacionados aos domínios físico, psicológico, social e no domínio QV global foram satisfatórios.

$>\mathrm{O}$ estudo permitiu detectar, nestes trabalhadores, as facetas do domínio ambiental que apresentaram maior fragilidade no que se refere à QV, que são: oportunidade de recreação e lazer, ambiente físico (poluição/ruído/transito/clima), recursos financeiros, transporte, cuidados de saúde e oportunidade de adquirir novas informações e habilidades

$>$ Evidentemente, a instituição ou local de trabalho não pode ser responsabilizada globalmente por estes resultados, visto que a $\mathrm{QV}$ envolve outros aspectos da vida, além do trabalho. Entretanto, o conhecimento dos aspectos que estão comprometidos pode ser interessante para os gestores de recursos humanos, para que possam implementar programas voltados ao atendimento de seu pessoal, direcionados para a dimensão mais prejudicada. 
A análise de consistência interna do WHOQOL-bref pelo Alfa de Cronbach teve como valor total 0,884 , atestando alta confiabilidade do instrumento para avaliar a QV da amostra estudada.

$>$ Todos os domínios apresentaram Coeficiente de Correlação significante entre si; e na análise de Regressão Linear o domínio psicológico e o ambiental apresentaram significância estatística em relação ao domínio de QV global.

$>$ O instrumento WHOQOL-Bref mostrou-se eficaz para avaliar a QV dos trabalhadores do serviço de radiodiagnóstico, sendo confiável para esta medida.

$>$ Uma das dificuldades do estudo foi não poder comparar os resultados obtidos com a literatura referente à população estudada, por não haver um instrumento específico e validado para trabalhadores com risco potencial às radiações ionizantes.

$>$ Com base nas respostas obtidas no questionário, não foram evidenciados problemas de saúde que possam estar relacionados com o trabalho exercido em presença da radiação ionizante, sendo necessários, talvez, outros estudos utilizando questionários mais específicos para avaliar o estado de saúde do indivíduo. 


\title{
ANEXO I - TERMO DE CONSENTIMENTO LIVRE E ESCLARECIDO
}

\author{
Título do projeto: Avaliação da Qualidade de Vida dos trabalhadores de Serviços de \\ Radiodiagnóstico
}

Este estudo se refere a um projeto de Mestrado do programa de pós-graduação do Instituto de Pesquisas Energéticas e Nucleares - IPEN-CNEN/SP em parceria com a (nome da instituição).

Você está sendo convidado (a) a participar como voluntário (a) dessa pesquisa que tem como objetivos: avaliar a Qualidade de Vida (QV) em uma amostra de trabalhadores com risco potencial às radiações ionizantes. O estudo objetiva também identificar os fatores sociodemográficos relacionados ao trabalho e sua influência na QV e conhecer o perfil profissional dos trabalhadores que atuam na área de Serviços de Radiodiagnóstico.

A sua participação na pesquisa consistirá na resposta a um questionário autoaplicável, com duração de aproximadamente 10 minutos, composto de duas partes (1 e 2). A parte 1 contém perguntas como idade, sexo, estado civil, ocupação/instrução, hábito de fumar, prática de exercícios entre outras. A parte 2 se refere às 26 questões do questionário WHOQOL-bref abordando diferentes aspectos de sua vida: sua saúde física, sua vida emocional, sua relação com amigos e familiares e seu meio ambiente.

Não existe nenhum risco decorrente da sua participação nessa pesquisa.

A sua participação trará benefícios no sentido de obter informações precisas sobre o perfil dos trabalhadores que trabalham direta ou indiretamente com as radiações ionizantes, a fim de estabelecer uma interface entre saúde, trabalho, formação profissional e QV.

Em qualquer etapa do estudo, você terá acesso aos profissionais responsáveis pela pesquisa para esclarecimento de eventuais dúvidas. A principal investigadora é a $\mathrm{Sr}^{\mathrm{a}}$ Ivani Martins Fernandes que pode ser encontrada no endereço Av. Professor Lineu Prestes, 2242, Cidade Universitária. Telefone(s) 3133-9641/9640. Se você tiver alguma consideração ou dúvida sobre a ética da pesquisa, entre em contato com o Comitê de Ética em Pesquisa (CEP) - (dados da instituição)

As informações obtidas por meio desta pesquisa serão confidenciais, e asseguramos o sigilo sobre a sua participação. As informações obtidas serão analisadas em conjunto com as de outros voluntários, não sendo divulgada a identificação de nenhum voluntário. A privacidade estará garantida mediante codificação de cada participante, sem revelar nomes das pessoas ou instituições.

No caso de aceitar fazer parte do estudo, assine ao final deste documento, que está em duas vias. Uma delas é sua e a outra é do pesquisador responsável com o nome completo e o telefone, para obter quaisquer outros esclarecimentos sobre a pesquisa que desejar.

Acredito ter sido suficientemente informado a respeito das informações que li ou que foram lidas para mim, descrevendo o estudo "Avaliação da Qualidade de Vida dos Trabalhadores de Serviços de Radiodiagnóstico". Eu discuti com a responsável pelo estudo, $\mathrm{Sr}^{\mathrm{a}}$ Ivani Martins Fernandes sobre a minha decisão em participar nesse estudo. Ficaram claros para mim quais são os propósitos do estudo, os procedimentos a serem realizados, as garantias de confidencialidade e de esclarecimentos permanentes. Ficou claro também que minha participação é isenta de despesas, portanto não haverá qualquer ressarcimento ou indenização.

Concordo voluntariamente em participar deste estudo e poderei retirar o meu consentimento a qualquer momento, antes ou durante o mesmo, sem penalidades ou prejuízo ou perda de qualquer benefício que eu possa ter adquirido neste Serviço.

\begin{tabular}{|ll|l|}
\hline Nome: & Assinatura do participante & Data $\frac{/}{/}$ \\
\hline Nome: & Assinatura do Pesquisador/entrevistador & Data $/ / /$ \\
\hline
\end{tabular}




\section{ANEXO II - CARTA DE AUTORIZAÇÃO}

Ilmo Sr.

\section{Assunto: Autorização para acesso e entrevista com os profissionais de saúde do Setor (nome da instituição)}

São Paulo, de de

Prezado Senhor,

Solicito autorização para a realização do estudo intitulado: “Avaliação da Qualidade de Vida dos Trabalhadores de Serviços de Radiodiagnóstico" que se refere a um projeto de Mestrado, do programa de pós-graduação do Instituto de Pesquisas Energéticas e Nucleares - IPEN-CNEN/SP em parceria com a (nome da instituição).

De acordo com a metodologia descrita no projeto (resumo anexo), realizar-se á na unidade:

- Contato com os profissionais da saúde (médicos, tecnólogos/técnicos de radiologia, enfermeiros e técnicos e auxiliares de enfermagem) para que respondam, mediante assinatura do Termo de Consentimento Livre e Esclarecido, a um questionário autoaplicável, com duração de aproximadamente 10 minutos, dividido em duas partes (1 e 2).

- A parte 1 - Ficha de informação do participante - contém questões sobre o perfil sóciodemográfico e informações sobre a rotina de trabalho. A parte 2 do questionário se refere ao instrumento específico de avaliação de QV, o WHOQOL-Bref, da Organização Mundial da Saúde, composto por 26 questões, divididas em quatro domínios: Físico, Psicológico, Social e Ambiental, além de duas questões que formam o domínio global.

A confidencialidade dos dados, o anonimato do participante e da instituição será respeitado de acordo com os preceitos éticos de pesquisa.

Disponibilizo, em anexo, o resumo do Projeto de Pesquisa e o Termo de Consentimento Livre e Esclarecido, para que a Vossa Senhoria possa ter conhecimento dos objetivos do estudo, sua metodologia e as contribuições para a saúde dos trabalhadores e para o desenvolvimento sustentável da Instituição.

Atenciosamente, 


\section{ANEXO III - FICHA DE INFORMAÇÃO DO PARTICIPANTE}

NOME COMPLETO:

Sexo: ( ) Masculino ( ) Feminino

Idade: (em anos completos) Data de nascimento

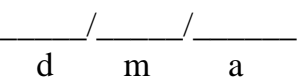

Nível de escolaridade:

( ) Ensino Fundamental

( ) Ensino médio

( ) Graduação

( ) completo

( ) incompleto

\section{Estado Civil:}

( ) Solteiro (a)

( ) Casado (a) União estável

( ) Separado (a), Divorciado (a)

( ) Viúvo (a)

Possui mais de 01 emprego? （ ) Sim （ ） Não

Se respondeu que Sim

Qual o tipo de trabalho? (setor) Quanto tempo? (anos)

Tempo de trabalho na (nome da instituição): anos

Setor de trabalho:

\section{Categoria Profissional:}

( ) Médico (a)

( ) Enfermeiro (a)

( ) Técnico / Tecnólogo em Radiologia

( ) Outro

Quando iniciou o trabalho com radiação ionizante (mês/ano):

( ) Menos que 1 ano

( ) 1-5 anos

( ) 6-15 anos

( ) 16-25 anos

( ) Mais que 25 anos

Você trabalha em plantões? ( ) Sim （ ) Não

Em que horário? ( ) manhã ( ) tarde ( ) noite

Você recebe algum tipo de treinamento? （ ） Sim （ ） Não

Qual?

Frequencia

Quais são os Equipamentos de Proteção Individual (EPI's) que você utiliza durante a realização do procedimento?

( ) Avental Plumbíferos

( ) Protetor de tireóide

( ) Óculos Plumbíferos

( ) Luvas Plumbíferas

( ) Outro - especificar 
Você utiliza alguma técnica de monitoramento individual para exposição às Radiações ionizantes?

( ) $\operatorname{Sim} \quad$ ( ) Não

Se sua resposta for SIM: Qual o tipo de controle?

Dosímetro pessoal (radiação externa)
( ) Dosímetro TL (tórax)
( ) Dosímetro TL (extremidades)

Quão satisfeito (a) você está com o trabalho em presença de radiação ionizante?

( ) Muito insatisfeito

( ) Insatisfeito

( ) Nem satisfeito nem insatisfeito

( ) Satisfeito

( ) Muito satisfeito

\section{HÁBITOS}
Você fuma? ( ) Sim
( ) Não
( ) Nunca fumou
( ) Ex-fumante
( ) Fumante ocasional
( ) Fumante

Há quanto tempo começou a fumar regularmente?
( ) Menos de um ano
( ) Entre um e cinco anos
( ) Entre cinco e dez anos
( ) Entre dez e vinte anos
( ) Mais de 20 anos

Qual a média de cigarros que fuma por dia?

( ) Entre um e dez cigarros

( ) Entre onze e vinte cigarros

( ) Entre vinte e um e trinta cigarros

( ) Mais de trinta cigarros

Você fuma no local de trabalho? ( ) Sim （ ） Não

Toma algum tipo de bebida alcoólica? ( ) Sim （ ) Não

Que tipo? ( ) Cerveja ( ) Vinho ( ) Whisky ( ) Cachaça ( ) Outros Quantas doses/dia ou semana?

Faz atividade física regular (3 vezes por semana)? ( ) Sim （ ) Não Que tipo?

\section{Como está sua saúde?}
( ) Muito ruim
( ) Ruim
( ) Nem ruim nem boa
( ) Boa
( ) Muito boa 
Você realiza exames periódicos de saúde na Instituição que você trabalha?（ ） Sim

( ) Não

Quais exames foram solicitados durante o último exame periódico?

( ) Audiometria

( ) Coloscopia, Copocitologia (somente mulheres)

( ) Eletrocardiograma

( ) Eletroencefalograma

( ) Exame de sangue: Colesterol (Total + Frações), Hemograma Completo, Hormônios da Tireóide (T3, T4, TSH), Trigliceres

( ) Exame Oftalmológico

( ) Mamografia (somente mulheres)

( ) Raio X do tórax.

Você tem algum problema de saúde no momento? CONDIÇÃO PRESENTE (marcar somente uma, que é a mais relevante para a presente busca de um serviço de saúde).

\begin{tabular}{|l|c|c|c|}
\hline 00 & Nenhum problema & 10 & Problema nervoso crônico ou emocional \\
\hline 01 & Problema de coração - doenças cardíacas & 11 & Doença de pele \\
\hline 02 & Pressão alta - hipertensão arterial & 12 & Doença de Parkinson \\
\hline 03 & Artrite ou reumatismo & 13 & Queimaduras \\
\hline 04 & Doenças respiratórias (enfisema, bronquite, asma) & 14 & Anemia \\
\hline 05 & Diabetes & 15 & Depressão \\
\hline 06 & Catarata & 16 & Problema de álcool ou drogas \\
\hline 07 & Obesidade & 17 & Câncer \\
\hline 08 & Alto teor de colesterol & 18 & Doenças renais \\
\hline 09 & Gastrite & 19 & Outro. (especificar) \\
\hline
\end{tabular}




\title{
ANEXO IV - QUESTIONÁRIO WHOQOL-BREF
}

\author{
WHOQOL - ABREVIADO
}

Versão em Português

\section{PROGRAMA DE SAÚDE MENTAL ORGANIZAÇÃO MUNDIAL DA SAÚDE - GENEBRA}

\author{
Coordenação do GRUPO WHOQOL no Brasil \\ Dr. Marcelo Pio de Almeida Fleck \\ Professor Adjunto \\ Departamento de Psiquiatria e Medicina Legal \\ Universidade Federal do Rio Grande do Sul \\ Porto Alegre - RS - Brasil
}

Instruções

Este questionário é sobre como você se sente a respeito de sua qualidade de vida, saúde e outras áreas de sua vida. Por favor, responda todas as questões. Se você não tem certeza sobre que resposta dar em uma questão, por favor, escolha entre as alternativas a que lhe parece mais apropriada. Esta, muitas vezes, poderá ser sua primeira escolha.

Por favor, tenham em mente seus valores, aspirações, prazeres e preocupações. Estamos perguntando o que você acha da sua vida, tomando como referência as duas ultimas semanas. Por exemplo, pensando nas últimas duas semanas, uma questão poderia ser:

\begin{tabular}{|l|c|c|c|c|c|}
\hline & Nada & $\begin{array}{c}\text { Muito } \\
\text { pouco }\end{array}$ & Médio & Muito & Completamente \\
\hline $\begin{array}{l}\text { Você recebe dos outros o apoio de que } \\
\text { necessita? }\end{array}$ & 1 & 2 & 3 & 4 & 5 \\
\hline
\end{tabular}

Você deve circular o número que melhor corresponde ao quanto você recebe dos outros o apoio de que necessita nestas últimas duas semanas. Portanto, você deve circular o número 4 se você recebeu "muito" apoio como abaixo.

\begin{tabular}{|l|c|c|c|c|c|}
\hline & Nada & $\begin{array}{c}\text { Muito } \\
\text { pouco }\end{array}$ & Médio & Muito & Completamente \\
\hline $\begin{array}{l}\text { Você recebe dos outros o apoio de que } \\
\text { necessita? }\end{array}$ & 1 & 2 & 3 & 4 & 5 \\
\hline
\end{tabular}

Você deve circular o número 1 se você não recebeu "nada" de apoio. 
Por favor, leia cada questão, veja o que você acha e circule no número que lhe parece a melhor resposta.

\begin{tabular}{|c|l|c|c|c|c|c|}
\hline & & Muito ruim & Ruim & $\begin{array}{c}\text { Nem ruim } \\
\text { nem boa }\end{array}$ & Boa & Muito boa \\
\hline 1 & $\begin{array}{l}\text { Como você avalia sua } \\
\text { qualidade de vida? }\end{array}$ & 1 & 2 & 3 & 4 & 5 \\
\hline
\end{tabular}

\begin{tabular}{|c|c|c|c|c|c|c|}
\hline & $\begin{array}{c}\text { Muito } \\
\text { insatisfeito }\end{array}$ & Insatisfeito & $\begin{array}{c}\text { Nem satisfeito } \\
\text { Nem insatisfeito }\end{array}$ & Satisfeito & $\begin{array}{c}\text { Muito } \\
\text { satisfeito }\end{array}$ \\
\hline 2 & $\begin{array}{l}\text { Quão satisfeito (a) você } \\
\text { está com a sua saúde? }\end{array}$ & 1 & 2 & 3 & 4 & 5 \\
\hline
\end{tabular}

As questões seguintes são sobre o quanto você tem sentido algumas coisas nas últimas duas semanas.

\begin{tabular}{|l|l|c|c|c|c|c|}
\hline & & Nada & $\begin{array}{c}\text { Muito } \\
\text { pouco }\end{array}$ & $\begin{array}{c}\text { Mais } \\
\text { ou } \\
\text { menos }\end{array}$ & Bastante & Extremamente \\
\hline 3 & $\begin{array}{l}\text { Em que medida você acha que sua dor (física) } \\
\text { impede você de fazer o que você precisa? }\end{array}$ & 1 & 2 & 3 & 4 & 5 \\
\hline 4 & $\begin{array}{l}\text { O quanto você precisa de algum tratamento } \\
\text { médico para levar sua vida diária? }\end{array}$ & 1 & 2 & 3 & 4 & 5 \\
\hline 5 & O quanto você aproveita a vida? & 1 & 2 & 3 & 4 & 5 \\
\hline 6 & $\begin{array}{l}\text { Em que medida você acha que a sua vida tem } \\
\text { sentido? }\end{array}$ & 1 & 2 & 3 & 4 & 5 \\
\hline 7 & O quanto você consegue se concentrar? & 1 & 2 & 3 & 4 & 5 \\
\hline 8 & Quão seguro (a) você se sente em sua vida diária? & 1 & 2 & 3 & 4 & 5 \\
\hline 9 & $\begin{array}{l}\text { Quão saudável é o seu ambiente físico (clima, } \\
\text { barulho, poluição, atrativos)? }\end{array}$ & 1 & 2 & 3 & 4 & 5 \\
\hline
\end{tabular}

As questões seguintes perguntam sobre quão completamente você tem sentido ou é capaz de fazer certas coisas nestas últimas duas semanas.

\begin{tabular}{|c|c|c|c|c|c|c|}
\hline & & Nada & $\begin{array}{l}\text { Muito } \\
\text { pouco }\end{array}$ & Médio & Muito & Completamente \\
\hline 10 & $\begin{array}{l}\text { Você tem energia suficiente para seu } \\
\text { dia-a-dia? }\end{array}$ & 1 & 2 & 3 & 4 & 5 \\
\hline 11 & Você é capaz de aceitar sua aparência física? & 1 & 2 & 3 & 4 & 5 \\
\hline 12 & $\begin{array}{l}\text { Você tem dinheiro suficiente para satisfazer suas } \\
\text { necessidades? }\end{array}$ & 1 & 2 & 3 & 4 & 5 \\
\hline 13 & $\begin{array}{l}\text { Quão disponíveis para você estão as informações } \\
\text { que precisa no seu dia-a-dia? }\end{array}$ & 1 & 2 & 3 & 4 & 5 \\
\hline 14 & $\begin{array}{l}\text { Em que medida você tem oportunidades de } \\
\text { atividade de lazer? }\end{array}$ & 1 & 2 & 3 & 4 & 5 \\
\hline
\end{tabular}


As questões seguintes perguntam sobre quão bem ou satisfeito você se sentiu a respeito de vários aspectos de sua vida nas últimas duas semanas.

\begin{tabular}{|l|l|c|c|c|c|c|}
\hline & Muito ruim & Ruim & $\begin{array}{c}\text { Nem ruim } \\
\text { nem bom }\end{array}$ & Bom & $\begin{array}{c}\text { Muito } \\
\text { bom }\end{array}$ \\
\hline 15 & $\begin{array}{l}\text { Quão bem você é capaz de se } \\
\text { locomover? }\end{array}$ & 1 & 2 & 3 & 4 & 5 \\
\hline
\end{tabular}

\begin{tabular}{|c|c|c|c|c|c|c|}
\hline & & $\begin{array}{l}\text { Muito } \\
\text { insatisfeito }\end{array}$ & Insatisfeito & $\begin{array}{l}\text { Nem satisfeito } \\
\text { nem insatisfeito }\end{array}$ & Satisfeito & $\begin{array}{l}\text { Muito } \\
\text { satisfeito }\end{array}$ \\
\hline 16 & $\begin{array}{l}\text { Quão satisfeito (a) você está com o } \\
\text { seu sono? }\end{array}$ & 1 & 2 & 3 & 4 & 5 \\
\hline 17 & $\begin{array}{l}\text { Quão satisfeito (a) você está com } \\
\text { sua capacidade de desempenhar as } \\
\text { atividades do seu dia-a-dia? }\end{array}$ & 1 & 2 & 3 & 4 & 5 \\
\hline 18 & $\begin{array}{l}\text { Quão satisfeito (a) você está com } \\
\text { sua capacidade para o trabalho? }\end{array}$ & 1 & 2 & 3 & 4 & 5 \\
\hline 19 & $\begin{array}{l}\text { Quão satisfeito (a) você está } \\
\text { consigo mesmo? }\end{array}$ & 1 & 2 & 3 & 4 & 5 \\
\hline 20 & $\begin{array}{l}\text { Quão satisfeito (a) você está com } \\
\text { suas relações pessoais (amigos, } \\
\text { parentes, conhecidos, colegas)? }\end{array}$ & 1 & 2 & 3 & 4 & 5 \\
\hline 21 & $\begin{array}{l}\text { Quão satisfeito (a) você está com } \\
\text { sua vida sexual? }\end{array}$ & 1 & 2 & 3 & 4 & 5 \\
\hline 22 & $\begin{array}{l}\text { Quão satisfeito (a) você está com o } \\
\text { apoio que você recebe de seus } \\
\text { amigos? }\end{array}$ & 1 & 2 & 3 & 4 & 5 \\
\hline 23 & $\begin{array}{l}\text { Quão satisfeito (a) você está com } \\
\text { as condições do local onde mora? }\end{array}$ & 1 & 2 & 3 & 4 & 5 \\
\hline 24 & $\begin{array}{l}\text { Quão satisfeito (a) você está com o } \\
\text { seu acesso aos serviços de saúde? }\end{array}$ & 1 & 2 & 3 & 4 & 5 \\
\hline 25 & $\begin{array}{l}\text { Quão satisfeito (a) você está como } \\
\text { seu meio de transporte? }\end{array}$ & 1 & 2 & 3 & 4 & 5 \\
\hline
\end{tabular}

A questão seguinte refere-se à com que frequencia você sentiu ou experimentou certas coisas nas últimas duas semanas.

\begin{tabular}{|c|l|c|c|c|c|c|}
\hline 26 & Nunca & $\begin{array}{c}\text { Algumas } \\
\text { vezes }\end{array}$ & Frequentemente & $\begin{array}{c}\text { Muito } \\
\text { frequentemente }\end{array}$ & Sempre \\
\hline $\begin{array}{l}\text { Com que freqüência você tem } \\
\text { sentimentos negativos tais como } \\
\text { mau humor, desespero, } \\
\text { ansiedade, depressão? }\end{array}$ & 1 & 2 & 3 & 4 & 5 \\
\hline
\end{tabular}

Alguém lhe ajudou a preencher este questionário?

Quanto tempo você levou para preencher este questionário?

\section{Você tem algum comentário sobre o questionário? OBRIGADO PELA SUA COLABORAÇÃO}




\section{GLOSSÁRIO}

Dose efetiva - E - é a soma das doses equivalentes ponderadas nos diversos órgãos e tecidos

$\mathrm{E}=\sum_{T} \mathrm{w}_{\mathrm{T}} \cdot \mathrm{H}_{\mathrm{T}}$, onde $\mathrm{H}_{\mathrm{T}}$ é a dose equivalente no tecido ou órgão e $\mathrm{w}_{\mathrm{T}}$ é o fator de ponderação do órgão ou tecido. A unidade de dose efetiva é o joule por quilograma $(\mathrm{J} / \mathrm{kg})$, denominada sievert (Sv).

Dosímetro individual - dispositivo usado junto a partes do corpo de um indivíduo, de acordo com regras específicas, com o objetivo de avaliar a dose efetiva ou a dose equivalente acumulada em um dado período. Também chamado de monitor individual.

Exames especiais - são todos os exames convencionais normalmente com apoio fluoroscópico que envolvem meios de contraste, manobras técnicas diferenciadas ou exigem preparações especiais. Estes exames normalmente são exames de diagnóstico e servem para esclarecimento de dúvidas clínicas pré ou pós operatórias.

Exposição médica - exposição a que são submetidos: pacientes, como parte de seu diagnóstico ou tratamento médico ou dentário; indivíduos expostos, fora do contexto ocupacional, que voluntária e eventualmente assistem pacientes durante o procedimento radiológico de terapia ou diagnóstico; indivíduos voluntários em programas de pesquisa biomédica, envolvendo sua exposição.

Exposição normal - exposição esperada em decorrência de uma prática autorizada, em condições normais de operação de uma fonte ou de uma instalação, incluindo os casos de pequenos possíveis contratempos que podem ser mantidos sob controle.

Exposição do público - exposição recebida pelos indivíduos do público devido a fontes de radiação ionizante, excluindo qualquer exposição ocupacional ou médica e a exposição natural normal à radiação ambiental do local.

Exposição ocupacional - exposição normal ou potencial de um indivíduo em decorrência de seu trabalho ou treinamento em práticas autorizadas ou intervenções, excluindo-se a radiação 
natural do local.

Exposição potencial - exposição cuja ocorrência não pode ser prevista com certeza, mas que pode resultar de um acidente envolvendo diretamente uma fonte de radiação ou em consequiência de um evento ou de uma série de eventos de natureza probabilística, incluindo falhas de equipamentos e erros de operação.

Fluoroscopia - é uma técnica de imagem comumente utilizada por médicos para obter imagens em tempo real em movimento das estruturas internas de um paciente através do uso de um fluoroscópio. Na sua forma mais simples, um fluoroscópio consiste de uma fonte de raios-X e de uma tela fluorescente entre a qual o paciente é posicionado.

Indivíduo do público - Qualquer membro da população não submetido à exposição ocupacional ou exposição médica.

Limites de dose individual - São valores estabelecidos para exposição ocupacional e exposição do público, de modo que uma exposição continuada pouco acima do limite de dose resultaria em um risco adicional que poderia ser considerado inaceitável em circunstâncias normais. Os limites constituem parte integrante dos princípios básicos de proteção radiológica para práticas autorizadas.

Monitoração - medição de dose para fins de controle da exposição à radiação, e a interpretação dos resultados. Pode ser classificada em monitoração individual e monitoração de área.

Monitoração individual (externa) - monitoração por meio de dosímetros individuais colocados sobre o corpo do indivíduo para fins de controle das exposições ocupacionais. A monitoração individual tem a função primária de avaliar a dose no indivíduo monitorado. É também, um mecanismo efetivo para detectar flutuações das condições de trabalho e para fornecer dados úteis para o programa de otimização.

Prática - qualquer atividade humana que implique ou possa potencialmente implicar em exposições de pessoas à radiação ionizante. 
Proteção radiológica - conjunto de medidas que visa proteger o homem, seus descendentes e seu meio ambiente contra possíveis efeitos indevidos causados por radiação ionizante proveniente de fontes produzidas pelo homem e de fontes naturais modificadas tecnologicamente.

Radiodiagnóstico - todas as intervenções médicas que utilizam a radiação $\mathrm{X}$ para obter um diagnóstico.

Radiação ionizante, ou simplesmente radiação - para fins de proteção radiológica, qualquer partícula ou radiação eletromagnética que, ao interagir com a matéria biológica, ioniza seus átomos ou moléculas.

Risco potencial - condição de risco potencial inerente às atividades com radiações ionizantes, existente como faculdade ou possibilidade mediante a sua previa avaliação.

Segurança radiológica - conjunto de medidas técnico-administrativas aplicáveis conforme apropriadas, ao projeto, à construção, à manutenção, à operação e descomissionamento de uma instalação, visando evitar a ocorrência de acidentes de natureza radiológica e minimizar suas conseqüências.

Serviço de radiodiagnóstico - estabelecimento ou um setor definido do estabelecimento ou instituição, onde se realizam procedimentos radiológicos médicos ou odontológicos. Nesta definição estão incluídos os consultórios odontológicos com equipamento de raios-X diagnósticos.

Situação de exposição planejada: são situações que envolvem a introdução e operação planejada das fontes. Este tipo de situação de exposição inclui situações que foram anteriormente categorizadas como práticas. 


\section{REFERÊNCIA BIBLIOGRÁFICA}

1. THE WHOQOL GROUP. The World Health Organization quality of life assessment (WHOQOL): position paper from the World Health Organization. Soc. Sci. Méd.; 41(10): p.1403-1409, 1995.

2. WORLD HEALTH ORGANIZATION. The first ten years of the World Health Organization. Geneva, 1958.

3. NISCHIMURA, L.Y.; POTENZA, M. M.; CESARETTI I. U. R. Enfermagem nas Unidades de diagnóstico por Imagem: aspectos fundamentais. São Paulo: Atheneu; 1999.

4. CALEGARO, K. M. S. Exposição à radiação ionizante dos profissionais de saúde em hemodinâmica: o enfoque da enfermagem. Dissertação (Mestrado em Enfermagem). Universidade do Estado do Rio de Janeiro, Rio de Janeiro, 2007.

5. UNITED NATIONS SCIENTIFIC COMMITTEE ON THE EFFECTS OF ATOMIC RADIATION (UNSCEAR, 2000). Sources and Effects of Ionizing Radiation. Report to the General Assembly, with scientific annexes. Volume I: Sources, Annex E. United Nations, New York, 2000.

6. INTERNATIONAL COMMISSION ON RADIOLOGICAL PROTECTION 1990 Recommendations of the International Commission on Radiological Protection. ICRP Publication 60, Pergamon Press, Oxford (1991).

7. INTERNATIONAL COMMISSION ON RADIOLOGICAL PROTECTION 1996 Radiological protection and safety in medicine. ICRP Publication 73, Pergamon Press, Oxford, 1996.

8. INTERNATIONAL COMMISSION ON RADIOLOGICAL PROTECTION. The 2007 Recommendations of the International Commission on Radiological Protection. ICRP Publication 103, Oxford (2007) 
9. INTERNATIONAL COMMISSION ON RADIOLOGICAL PROTECTION 2007 Radiological Protection in Medicine. ICRP Publication 105, Oxford (2007).

10. COMISSÃO NACIONAL DE ENERGIA NUCLEAR - Diretrizes Básicas de Proteção Radiológica. CNEN-NN-3.01. CNEN, 2011.

11. MINISTÉRIO DA SAÚDE. SECRETARIA DE VIGILÂNCIA SANITÁRIA. Diretrizes de Proteção Radiológica em Radiodiagnóstico Médico e Odontológico. Portaria $\mathrm{n}^{\mathrm{o}}$ 453, 1998. Publicado no DOU de 2 de junho de 1998.

12. UNSCEAR - United Nations Scientific Committee on the Effects of Atomic Radiation (UNSCEAR, 2008). Sources and Effects of Ionizing Radiation. Report to the General Assembly, with scientific annexes. Annex B, 2008.

13. Oliveira, L. S. R. Princípios Básicos de Proteção Radiológica. [texto na internet]. Disponível em: 〈http://www.tecnologiaradiologica.com/materia_princ_prot_radiol.htm〉. Acesso em 10 jul. 2011.

14. BOWLING, A. Health-related quality of life: a discussion of the concept, its use and measurement. In: BOWLING, A, editor. Measuring disease. Buckingham: Open University Press; 1995. p. 1-19.

15. BIREME. Centro Latino-Americano de Informações em Ciências da Saúde. Biblioteca Virtual em Saúde - BVS. Disponível em: <http://pesquisa.bvsalud.org/regional/index.php>. Acesso em: 27 jul. 2011.

16. FLECK, M. P. A.; LOUZADA, S.; XAVIER, M.; CHACHAMOVICH, E.; VIEIRA , G.; SANTOS, L.; PINZON, V. Desenvolvimento da versão em português do instrumento de avaliação de qualidade de vida da OMS (WHOQOL-100). Rev Bras Psiquiatr 1999; 21(1): 19-28.

17. MAGRI, C.; KLUTHCOVSKY, A. C. G. C. Qualidade de vida no trabalho: uma revisão da produção científica. Rev Salus-Guarapuava-PR. Jan./jun. 2007; 1(1):87-94.

18. MINAYO, M. C. S.; HARTZ, Z. M. A.; BUSS, P. M. Qualidade de vida e saúde: um debate necessário. Ciência \& Saúde Coletiva, Rio de Janeiro, v.5, n.1, p.7-18, 2000. 
19. GONZALES, R. M. B. Expressão de indicadores de (in)satisfação no trabalho por enfermeiras coordenadoras de área de um hospital universitário. Cogitare Enferm, Curitiba, v. 3, n. 1, p. 105-109, jan./jun. 1998.

20. BELASCO, A. G. S.; SESSO, R. C. C. Qualidade de vida: princípios, focos de estudo e intervenções. In: DINIZ, D. P.; SCHOR, N. Qualidade de vida. São Paulo: Manole, 2006. p. 1-10.

21. LIPP, M.; ROCHA, J. C. Stress, hipertensão e qualidade de vida. Campinas: Papirus, 1996.

22. MARTIM, A. J.; STOCKLER, M. Quality of life assessment health come research and practice. Evolution and Health Professions, v. 21, p. 141-156, 1998.

23. ROCHA, A. D. et al. Qualidade de vida, ponto de partida ou resultado final? Ciência e Saúde Coletiva, v. 5, n. 1, p. 63-81, 2000.

24. NAHAS, M. V. Atividade física, saúde e qualidade de vida: conceitos e sugestões para um estilo de vida ativo. 4 ed. Londrina: Midiograf, 2006.

25. FLECK, M. P. A. \& cols. Problemas conceituais em qualidade de vida. In: FLECK, M. P. A. et al. A avaliação de qualidade de vida: guia para profissionais da saúde. Porto Alegre: Artmed, 2008. p. 19-27.

26. COSTA NETO, S. B. Qualidade de vida dos portadores de câncer de cabeça e pescoço. Tese (Doutorado). Brasília: Instituto de Psicologia da Universidade de Brasília; 2002.

27. DUARTE, P. S.; CICONELLI, R. M. Instrumentos para a avaliação da qualidade de vida: genéricos e específicos. In: DINIZ, D. P.; SCHOR, N. Qualidade de vida. São Paulo: Manole, 2006. p.11-18.

28. BLAY, S. L.; MERLIN, M. S. Desenho e metodologia de pesquisa em qualidade de vida. In: DINIZ, D. P.; SCHOR, N. Qualidade de vida. Manole; 2006. p.19-30.

29. PEDROSO, B.; PILATTI, L. A. Avaliação de indicadores da área da saúde: a qualidade de vida e suas variantes. Revista Eletrônica FAFIT-FACIC. Itararé - SP - Brasil v. 01, n. 01, jan./jun. 2010, p. 01-09. 
30. ZANEI, S. S. V. Análise dos Instrumentos de Avaliação de Qualidade de Vida WHOQOL-Bref e SF-36: confiabilidade, validade e concordância entre pacientes de Unidades de Terapia Intensiva e seus familiares. São Paulo; 2006. Tese (Doutorado) Escola de Enfermagem da Unidade de São Paulo.

31. FLECK, M. P. A.; LOUZADA, S.; XAVIER, M.; CHACHAMOVICH, E.; VIEIRA, G.; SANTOS, L.; PINZON, V. Aplicação da versão em português do instrumento de avaliação de qualidade de vida da organização mundial da saúde (WHOQOL-100). Rev Saude Publica, 1999;33(2):198-205.

32. FLECK, M. P. A.; LOUZADA, S.; XAVIER, M.; CHACHAMOVICH, E.; VIEIRA , G.; SANTOS, L.; PINZON, V. Aplicação da versão em português do instrumento WHOQOL-bref. Rev Saude Publica, 2000;34(2):178-83.

33. PILATTI, L. A.; PEDROSO, B.; GUTIERREZ, L. G.; Propriedades psicométricas de instrumentos de avaliação: um debate necessário. R. B. E. C. T., vol. 3, nº 1, jan./abr. 2010 .

34. PASQUALI, L. Medida Psicométrica. IN; PASQUALI, L. Teoria e Métodos de medida em Ciências do Comportamento. Brasília: Laboratório de Pesquisa em Avaliação e Medida. Instituto de Psicologia. UNB: INEP, 1996, 73-112.

35. GÜNTER, H. Desenvolvimento de Instrumentos para levantamento de dados. IN: PASQUALI, L. Teoria e métodos de Medida em ciências do comportamento. Brasília: Laboratório de pesquisa em avaliação e medida. Instituto de Psicologia. UNB: INEP, 1996, 387-402.

36. ALVES, E. F. Qualidade de vida no trabalho: indicadores e instrumentos de medidas. Diálogos \& Saberes, Mandaguari, v. 6, n. 1, p.77-87, 2010.

37. CRONBACH, L. J. Coefficient alpha and the internal structure of tests. V. 16, n. 3, p. 297-334, Psychometrika, Set. 1951.

38. CRONBACH, L. J. Fundamentos da testagem psicológica. Tradutores Carlos Alberto Silveira Neto e Maria Adriana Veríssimo Veronese. 5.ed. Porto Alegre: Artes Médicas, 1996. 575p. 
39. HAIR, J.; ANDERSON, R. E.; TATHAM, R. L.; BLACK, W. C. Análise multivariada de dados. 5.ed. Porto Alegre: Bookman, 2005.

40. SIEGEL, S. Estatística não-paramétrica para ciências do comportamento. Porto Alegre: Artmed, 1981.

41. DANCEY, C. P.; REIDY, J. Estatística sem matemática para psicologia: Usando SPSS para Windows. Porto Alegre: Artmed, 2006.

42. WAGNER, M. B.; MOTTA, V. T.; DORNELLES, C. SPSS passo a passo: Statistical Package for the Social Sciences. Caxias do Sul, RS: EDUCS, 2004.

43. COSTA NETO, P. L. O. Estatística. São Paulo: Edgard Blücher, 1977.

44. MOTULSKY, H. J. Analyzing Data with GraphPad Prism: A companion to GraphPad Prism version 3, 1999. Disponível em: http://www.graphpad.com/articles/AnalyzingData.pdf. Acesso em: 02 de novembro de 2011.

45. MINISTÉRIO DA SAÚDE. Diretrizes e normas regulamentadoras de pesquisas envolvendo seres humanos: Resolução no 196/96. 1996.

46. LIMA, A. F. B. S. Qualidade de vida em pacientes do sexo masculino dependentes de álcool. Dissertação (Mestrado em Clínica Médica) - Universidade Federal do Rio Grande do Sul, Porto Alegre, 2002.

47. SOUZA, F. F. Avaliação da qualidade de vida do idoso em hemodiálise: comparação entre dois instrumentos genéricos. Dissertação (Mestrado em Enfermagem) Universidade Estadual de Campinas, Campinas, 2004.

48. AGUILAR, P. I. S. G. Qualidade de vida em pessoas com Diabetes Mellitus Tipo 2. Tese (Doutorado em Enfermagem) - Universidade de São Paulo, Ribeirão Preto, 2004.

49. The WHOQOL Group. The World Health Organization quality of life assessment (WHOQOL): development and general psychometric properties. Soc Sci Med. 1998; 46:1569-85. 
50. The WHOQOL-HIV Group. WHOQOL-HIV Instrument Users Manual. Geneva: 2002.

51. ZIMPEL, R.; FLECK, M. P. A. WHOQOL-HIV: Desenvolvimento, aplicação e validação. In: FLECK, M. P. A. et al. A avaliação de qualidade de vida: guia para profissionais da saúde. Porto Alegre: Artmed, 2008. p.83-92.

52. FLECK, M. P. A.; SKEVINGTON, S. Explicando o significado do WHOQOL-SRPB. Revista de Psiquiatria Clínica. v. 34, Suplemento 1, p. 146-149, 2007.

53. ROCHA \& cols. Desenvolvimento do módulo para avaliar espiritualidade, religiosidade e crenças pessoais do WHOQOL (WHOQOL-SRPB). In: FLECK, M. P. A. et al. A avaliação de qualidade de vida: guia para profissionais da saúde. Porto Alegre: Artmed, 2008. p.93-101.

54. POWER, M. et al. Development of the WHOQOL-Old module. Quality of Life Research. v. 14, n. 10, p. 2197-2214, 2005.

55. CHACHAMOVICH \& cols. Desenvolvimento do instrumento WHOQOL-OLD. In: FLECK, M. P. A. et al. A avaliação de qualidade de vida: guia para profissionais da saúde. Porto Alegre: Artmed, 2008. p.102-111.

56. BAMPI, L. N. S., GUILHEM, D., LIMA, D. D. Qualidade de Vida em Pessoas com Lesão Medular Traumática: um estudo com o WHOQOL-Bref. Rev. Bras. Epidemiol. 2008; 11(1): 67-77.

57. ARAGAKI, I. M. M. A avaliação e percepção de nutrizes a cerca de sua qualidade de vida. São Paulo; 2008. Tese (Doutorado) - Escola de Enfermagem da Unidade de São Paulo.

58. THE WHOQOL GROUP. Development of the World Health Organization WHOQOLBREF Quality of Life Assessment. Psychological Medicine, Cambridge, UK, v. 28, n. 3, p. 551-558, may 1998.

59. PEDROSO, B.; PILATTI, L. A.; GUTIERREZ, L. G.; PICININ, T. C.; Cálculo dos escores e estatística descritiva do WHOQOL-Bref através do Microsoft Excel. Revista Brasileira de Qualidade de Vida, Ponta Grossa, Vol. 2, nº 1, jan./jun. 2010, p. 31-36. 
60. GRUPO WHOQOL. Versão em português dos instrumentos de avaliação da qualidade de vida (WHOQOL). Faculdade de Medicina da UFRGS, 1998. Departamento de Psiquiatria. Disponível em: <http://www.ufrgs.br/psiq/whoqol1.html. Acesso em: 22/09/2011.

61. The WHOQOL Group. WHOQOL-Bref: introduction, administration, scoring and generic version of the assessment. Geneva: WHO; 1996. Disponível em:

<http://www.who.int/mental_health/media/en/76.pdf>. Acesso em: 26/05/2011.

62. STEPS FOR CHECKING AND CLEANING DATA AND COMPUTING DOMAIN SCORES FOR THE WHOQOL-BREF. Disponível em: <http://www.ufrgs.br/psiq/Sintaxe.pdf>. Acesso em: 26/05/ 2011.

63. SPSS FOR WINDOWS VERSION 16.0: A Basic Tutorial. Disponível em: http://www.ssric.org/spss_manualv16/spss_v16.pdf. Acesso em: 30 mar. 2011.

64. MINITAB 16 STATISTICAL SOFTWARE. Conheça o Minitab 16. Disponível em: http://www.minitab.com/uploadedFiles/Shared_Resources/Documents/MeetMinitab/PT16 _MeetMinitab.pdf. Acesso em: 30 mar. 2011.

65. SILVA, F. A. F. Perfil de trabalhadores técnicos em radiologia expostos à radiação ionizante no Município de João Pessoa/PB. Dissertação (Mestrado em Ciências da Saúde). Universidade Cruzeiro do Sul, São Paulo, 2010.

66. ASSUMPÇÃO, L. O. T.; MORAIS, P. P.; FONTOURA, H. Relação entre Atividade Física, Saúde e Qualidade de vida. Notas Introdutórias. Universidade Católica de Brasília. Revista Digital, Buenos Aires, ano 8, n. 52, 2002.

67. MARTINS, M. M. Qualidade de vida e capacidade para o trabalho dos profissionais em enfermagem no trabalho em turnos. Dissertação (Mestrado em Engenharia de Produção). UFSC. Florianópolis, 2002. 